\title{
Long-Term Monitoring of Desert Land and Natural Resources and Application of Remote Sensing Technologies: Final Report
}

Environmental Science Division

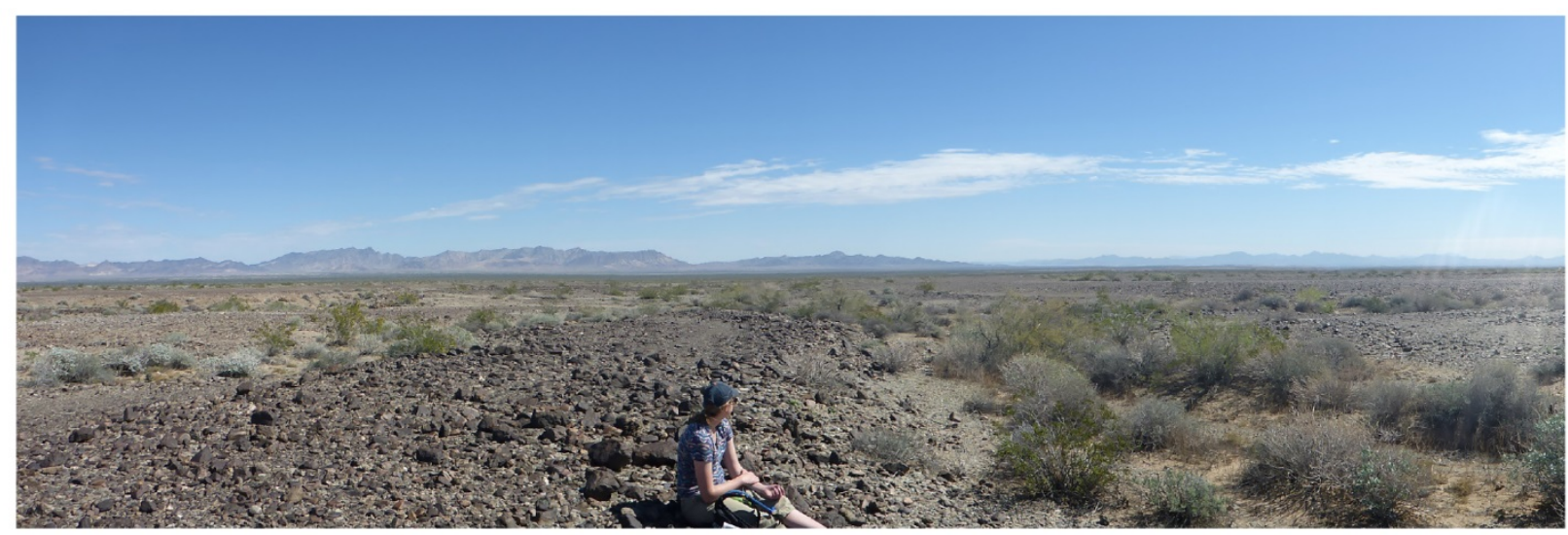




\begin{abstract}
About Argonne National Laboratory
Argonne is a U.S. Department of Energy laboratory managed by UChicago Argonne, LLC under contract DE-AC02-06CH11357. The Laboratory's main facility is outside Chicago, at 9700 South Cass Avenue, Argonne, Illinois 60439. For information about Argonne and its pioneering science and technology programs, see www.anl.gov.
\end{abstract}

\title{
DOCUMENT AVAILABILITY
}

Online Access: U.S. Department of Energy (DOE) reports produced after 1991 and a growing number of pre-1991 documents are available free via DOE's SciTech Connect (http://www.osti.gov/scitech/).

Reports not in digital format may be purchased by the public from the National Technical Information Service (NTIS):

U.S. Department of Commerce

National Technical Information Service

5301 Shawnee Road

Alexandria, VA 22312

www.ntis.gov

Phone: (800) 553-NTIS (6847) or (703) 605-6000

Fax: (703) 605-6900

Email: orders@ntis.gov

Reports not in digital format are available to DOE and DOE contractors from the Office of Scientific and Technical Information (OSTI):

U.S. Department of Energy

Office of Scientific and Technical Information

P.O. Box 62

Oak Ridge, TN 37831-0062

www.osti.gov

Phone: (865) 576-8401

Fax: (865) 576-5728

Email: reports@osti.gov

\section{Disclaimer}

This report was prepared as an account of work sponsored by an agency of the United States Government. Neither the United States Government nor any agency thereof, nor UChicago Argonne, LLC, nor any of their employees or officers, makes any warranty, express or implied, or assumes any legal liability or responsibility for the accuracy, completeness, or usefulness of any information, apparatus, product, or process disclosed, or represents that its use would not infringe privately owned rights. Reference herein to any specific commercial product, process, or service by trade name, trademark, manufacturer, or otherwise, does not necessarily constitute or imply its endorsement, recommendation, or favoring by the United States Government or any agency thereof. The views and opinions of document authors expressed herein do not necessarily state or reflect those of the United States Government or any agency thereof. 


\section{Long-Term Monitoring of Desert Land and Natural Resources and Application of Remote Sensing Technologies: Final Report}

by

Yuki Hamada and Katherine E. Rollins

Environmental Science Division, Argonne National Laboratory

November 2016 



\section{CONTENTS}

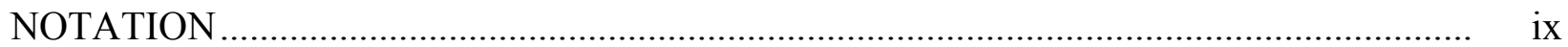

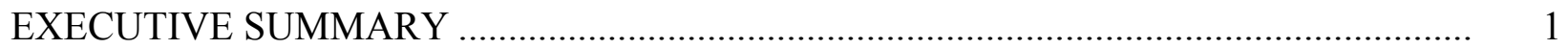

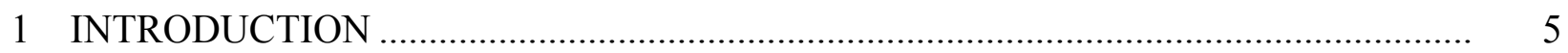

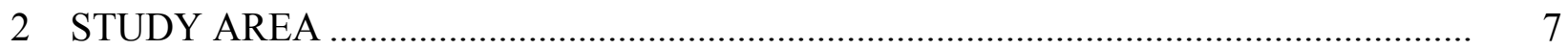

3 PREVIOUSLY GENERATED REMOTE SENSING PRODUCTS ............................ 9

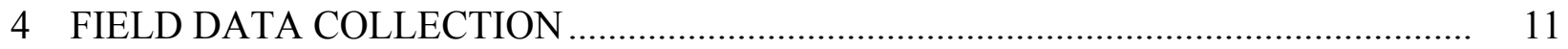

4.1 Vegetation and Surface Data Collection............................................................ 12

4.2 Hydrology and Spatial Referenced Data Collection ......................................... 13

4.3 Database Development and Management........................................................... 14

5 VALIDATION AND ANALYSIS OF REMOTE SENSING PRODUCTS ................... 15

5.1 Accuracy Measures .......................................................................................... 15

5.2 Validation of Vegetation and Vegetated Surface............................................... 15

5.2.1 Validating Vegetation Distribution....................................................... 15

5.2.2 Validating Canopy Height Estimate ...................................................... 19

5.2.3 Validating Fractional Cover of Surface Types ...................................... 20

5.3 Validation of Desert Pavement ................................................................................. 23

5.4 Validation of Biological Soil Crust....................................................................... 25

5.5 Validation of Ephemeral Stream Channels.......................................................... 26

5.5.1 Validating Ephemeral Channel Distribution......................................... 26

5.5.2 Validating Ephemeral Channel Width .................................................... 30

5.6 Analysis of Surface Stability .......................................................................... 31

5.7 Summary of Validation and Analysis of Previously Generated Remote Sensing Products ...................................................................................... 34

6 REFINEMENT OF REMOTE SENSING METHODOLOGY ................................... 37

6.1 Vegetation Distribution............................................................................ 37

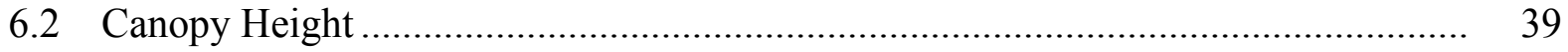

7 ANALYSIS OF VEGETATION ALLIANCES .......................................................

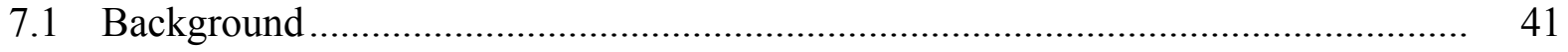

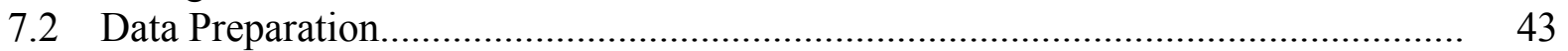




\section{CONTENTS (Cont.)}

7.3 Qualitative Observation of Vegetation Alliances .....................................................

7.4 Fractional Cover of Land Cover Type within Vegetation Alliances ........................ 44

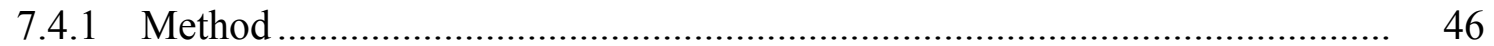

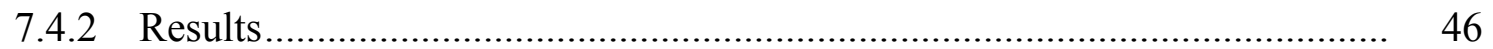

7.5 Spatial Structure of Vegetation Alliances .............................................................. 47

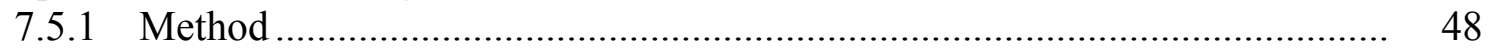

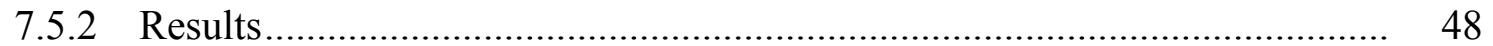

7.5.3 Application for Monitoring Vegetation Alliances ....................................... 54

7.6 Image Resolution and Vegetation Patterns ........................................................... 56

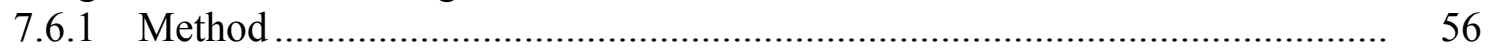

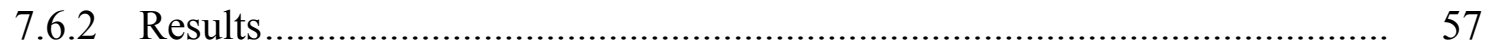

7.6.3 Application for Monitoring Vegetation Alliances ....................................... 64

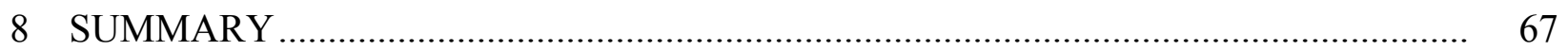

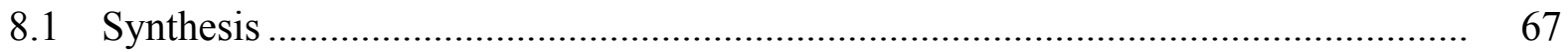

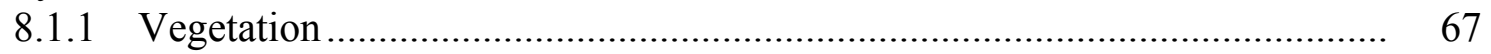

8.1.2 Fractional Cover of Surface Type ............................................................. 69

8.1.3 Desert Pavement, Biological Soil Crust, Surface Stability, and Ephemeral Channels ............................................................................ $\quad 70$

8.1.4 Vegetation Alliance Analysis ………………............................................ 71

8.2 Recommendations....................................................................................... 72

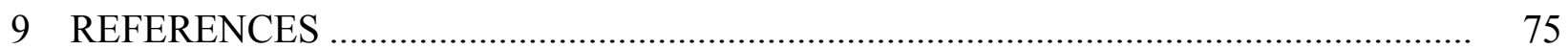

\section{FIGURES}

$1 \quad$ Study Area

2 Study Area Landscape and Vegetation ……………............................................... 8

3 Survey Locations for March 2015 Field Work …………......................................... 12

4 Accuracy of Vegetation Distribution Maps Validated Using 2015 Field Data............... 18

5 Correlation between Canopy Height Measured during 2015 Field Survey and Canopy Height Estimated Using Remote Sensing

6 Correlation between Reference Cover Obtained from 2015 Field Data and Cover Estimated Using Remote Sensing 


\section{FIGURES (Cont.)}

7 Ternary Plot of Tree, Shrub, and Bare Ground Cover Fractions

8 Correlation between Biological Soil Crust Cover Estimated Using 2015 Field

Data and Spectral Indices

9 Examples of Biological Soil Crusts in the Study Area

10 Accuracy of Ephemeral Channel Detection Using Very High Resolution Images

11 Ephemeral Stream Channels Generated by the National Hydrography Dataset and Argonne's Algorithm

12 Correlation between Reference Channel Width and Channel Width Estimated Using Remote Sensing

13 Refined Vegetation Distribution Map Generated Using Visible Atmospherically Resistant Index before and after Filtering Based on Erosion Resistance Index

14 Vegetation Distribution Maps before and after Refinement of Methodology

15 Correlation between Reference Canopy Height and Canopy Height Estimated Using Remote Sensing

16 Example of Variogram.

17 Plots Used for Characterizing Spatial Patterns of Vegetation Alliance .......................... 44

18 Subsets of Visible Atmospherically Resistant Index Used for Analysis ....................... 45

19 Semivariograms of the Parkinsonia florida-Olneya tesota Alliance with Lag Sizes of $15 \mathrm{~cm}, 30 \mathrm{~cm}, 50 \mathrm{~cm}, 1 \mathrm{~m}, 1.5 \mathrm{~m}, 5 \mathrm{~m}, 10 \mathrm{~m}$, and $15 \mathrm{~m}$

20 Semivariograms of the Larrea tridentata-Encelia farinosa Alliance with Lag Sizes of $15 \mathrm{~cm}, 30 \mathrm{~cm}, 50 \mathrm{~cm}, 1 \mathrm{~m}, 1.5 \mathrm{~m}, 5 \mathrm{~m}, 10 \mathrm{~m}$, and $15 \mathrm{~m}$

21 Semivariograms of the Larrea tridentata-Ambrosia Dumosa Alliance with Lag Sizes of $15 \mathrm{~cm}, 30 \mathrm{~cm}, 50 \mathrm{~cm}, 1 \mathrm{~m}, 1.5 \mathrm{~m}, 5 \mathrm{~m}, 10 \mathrm{~m}$, and $15 \mathrm{~m}$...

22 Semivariograms of the Chorizanthe rigida-Geraea canescens Alliance with Lag Sizes of $15 \mathrm{~cm}, 30 \mathrm{~cm}, 50 \mathrm{~cm}, 1 \mathrm{~m}, 1.5 \mathrm{~m}, 5 \mathrm{~m}, 10 \mathrm{~m}$, and $15 \mathrm{~m}$ 


\section{FIGURES (Cont.)}

23 Subsets of Visible Atmospherically Resistant Index for the Parkinsonia floridaOlneya tesota Alliance with 15-cm, 30-cm, 50-cm, 1-m, and 1.5-m Spatial Resolutions

24 Subsets of Visible Atmospherically Resistant Index for the Larrea tridentataAmbrosia Dumosa Alliance with 15-cm, 30-cm, 50-cm, 1-m, and 1.5-m Spatial Resolutions

25 Subsets of Visible Atmospherically Resistant Index for the Larrea tridentataEncelia farinosa Alliance with 15-cm, 30-cm, 50-cm, 1-m, and 1.5-m Spatial Resolutions.....

26 Subsets of Visible Atmospherically Resistant Index for the Chorizanthe rigidaGeraea canescens Alliance with 15-cm, 30-cm, 50-cm, 1-m, and 1.5-m Spatial Resolutions

27 Semivariograms of the Parkinsonia florida-Olneya tesota and Larrea tridentataEncelia farinosa Alliances with 30-cm, 50-cm, 1-m, and 1.5-m Resolutions

28 Semivariograms of the Larrea tridentata-Ambrosia Dumosa and Chorizanthe rigida-Geraea canescens Alliances with 30-cm, 50-cm, 1-m, and 1.5-m Resolutions

29 Schematic Representation of Relationship between Spatial Resolution of Image and Vegetation Canopies

\section{TABLES}

1 Remote Sensing Products and Output Generated Prior to 2015

2 Variables and Parameters for Validation and Analysis Collected during

Field Work

3 Accuracy Measures for Remote Sensing Products

4 Spectral Vegetation Indices Validated.....

5 Accuracy of Vegetation Distribution Maps Validated Using 2015 Field Data

6 Classification Scheme for Land Cover Type 


\section{TABLES (Cont.)}

$7 \quad$ Accuracy of Land Cover Type Fractions Validated Using 2015 Field Data .................. 24

$8 \quad$ Accuracy of Desert Pavement Map from January 2014 Image .................................... 26

$9 \quad$ Spectral Index for Predicting Soil Crust Distribution ..................................................... 26

10 Surface Materials Analyzed for Correlation with Erosion Resistance Index................... 32

11 Correlation between Erosion Resistance Index Value and Fractional Cover of Surface Material ............................................................................................. 33

12 Accuracy of Vegetation Distribution Maps before and after Refinement of Methodology ..................................................................................................... 39

13 Accuracy of Canopy Height Maps before and after Refinement of Methodology ......... 40

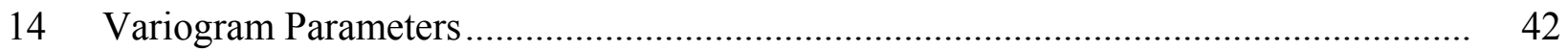

15 Summary Statistics of Surface Cover Fractions of Four Vegetation Alliances ............. 46

16 Lag Sizes Tested and Remotely Sensed Image Types Having Corresponding Spatial Resolutions ................................................................................................... 47

17 Summary of Semivariograms, Observations, and Field Measurements of Four Vegetation Alliances ................................................................................................. 53

18 Variogram Parameters for Four Vegetation Alliances across Resolutions .................... 64 
This page intentionally left blank. 


\section{NOTATION}

The following is a list of acronyms, abbreviations, and units of measure used in this document. Some acronyms used only in tables may be defined only in those tables.

\section{GENERAL ACRONYMS AND ABBREVIATIONS}

\begin{tabular}{|c|c|}
\hline AIM & Assessment, Inventory, and Monitoring \\
\hline BLM & Bureau of Land Management \\
\hline BSCI & Biological Soil Crust Index \\
\hline CHRI-GECA & Chorizanthe rigida-Geraea canescens \\
\hline CI & Crust Index \\
\hline DSM & digital surface model \\
\hline DTM & digital terrain model \\
\hline ERI & Erosion Resistance Index \\
\hline GPS & global positioning system \\
\hline LATR-AMDU & Larrea tridentata-Ambrosia dumosa \\
\hline LATR-ENFA & Larrea tridentate-Encelia farinose \\
\hline LiDAR & Light Detection and Ranging \\
\hline MAE & mean absolute error \\
\hline ME & mean error \\
\hline MODIS & Moderate Resolution Imaging Spectroradiometer \\
\hline MSAVI & Modified Soil-Adjusted Vegetation Index \\
\hline NAIP & National Agriculture Imagery Program \\
\hline NDVI & Normalized Difference Vegetation Index \\
\hline NHD & National Hydrography Dataset \\
\hline NIR & near-infrared \\
\hline NPV & non-photosynthetic vegetation \\
\hline PAFL-OLTE & Parkinsonia florida-Olneya tesota \\
\hline RMSE & ean squared el \\
\hline
\end{tabular}




$\begin{array}{ll}\text { SAVI } & \text { Soil-Adjusted Vegetation Index } \\ \text { SDE } & \begin{array}{l}\text { Spatial Database Engine } \\ \text { solar energy zone }\end{array} \\ \text { SEZ } & \text { spectral vegetation index } \\ \text { SVI } & \text { shortwave infrared } \\ \text { SWIR } & \text { U.S. Geological Survey } \\ \text { USGS } & \text { Visible Atmospherically Resistant Index } \\ \text { VARI } & \text { very high spatial resolution }\end{array}$

\section{UNITS OF MEASURE}

$\begin{array}{ll}\mathrm{cm} & \text { centimeter(s) } \\ \mathrm{km} & \text { kilometer(s) } \\ \mathrm{km}^{2} & \text { square kilometer(s) } \\ \mathrm{m} & \text { meter(s) } \\ \mathrm{m}^{2} & \text { square meter(s) }\end{array}$




\title{
LONG-TERM MONITORING OF DESERT LAND AND NATURAL RESOURCES AND APPLICATION OF REMOTE SENSING TECHNOLOGIES
}

\section{FINAL REPORT}

by

\author{
Yuki Hamada and Katherine E. Rollins
}

\section{EXECUTIVE SUMMARY}

Monitoring environmental impacts over large, remote desert regions for long periods of time can be very costly. Remote sensing technologies present a promising monitoring tool because they entail the collection of spatially contiguous data, automated processing, and streamlined data analysis. This report provides a summary of remote sensing products and refinement of remote sensing data interpretation methodologies that were generated as part of the U.S. Department of the Interior Bureau of Land Management Solar Energy Program.

In March 2015, a team of researchers from Argonne National Laboratory (Argonne) collected field data of vegetation and surface types from more than 5,000 survey points within the eastern part of the Riverside East Solar Energy Zone (SEZ). Using the field data, remote sensing products that were generated in 2014 using very high spatial resolution (VHSR; $15 \mathrm{~cm}$ ) multispectral aerial images were validated in order to evaluate potential refinements to the previous methodologies to improve the information extraction accuracy.

The validation results indicated the following:

1. The overall vegetation detection accuracy was $77 \%$. Detection accuracy may be improved by adjusting a threshold value of the Visible Atmospherically Resistant Index (VARI) for classifying vegetation;

2. The canopy height estimate obtained using remote sensing was strongly correlated with the reference height obtained from the field data $\left(R^{2}=0.72\right)$, although absolute height was consistently underestimated (root mean squared error $[\mathrm{RMSE}]=2.86 \mathrm{~m})$. Height estimate may be improved by predicting elevation under vegetation canopies using the digital surface model (DSM), rather than using the digital terrain model (DTM) provided by the vendor;

3. If the accuracy of the vegetation detection and canopy height estimate is considerably improved, then estimates of surface cover type fractions (RMSE $=4.2 \%-7.8 \%$ ) would improve;

4. Desert pavement detection was $89 \%$ overall and does not require improvement in the previous algorithm; 
5. The effectiveness of the Biological Soil Crust Index and Crust Index could not be properly tested due to extremely limited biological soil crust in the study area; and

6. Ephemeral channel extraction accuracy would be improved by a consensus approach integrating the U.S. Geological Survey's (USGS's) National Hydrography Dataset (NHD) (2008) and the Argonne algorithm capability.

Using the 2015 field data, we also examined the association between surface material composition and the Erosion Resistance Index (ERI), which would indicate surface stability. The results suggested that surface material composition was one of many factors influencing ERI (other factors include mineral composition, moisture, and surface roughness). Despite the complex relationship between surface characteristics and ERI, surface stability appeared to have consistent spectral characteristics corresponding to surface conditions (e.g., exposed soil, undisturbed desert pavement); thus, ERI would be a useful indicator for quantifying surface stability.

Based on the findings from the field validation, we refined the image processing routines for (1) vegetation detection, by lowering the VARI threshold values to classify vegetation more inclusively than was done in the previous routine, and for (2) canopy height estimation, by modeling under-canopy elevation via spatial-interpolation of DSM values for all vegetation locations. The results indicated that neither refinement was effective. Although it correctly detected shaded trees and small shrubs, lowering the VARI threshold actually decreased overall vegetation detection accuracy by $1 \%$ (overall accuracy $=76 \%$ ) from the previous methodology. The refined canopy height estimation methodology underestimated height by a factor of 20 from the previous methodology despite the theoretically sound technique. This suggests a need for a highly customized image collection strategy to accurately estimate canopy height, which would require very different specifications from those for other monitoring indicators.

In addition to vegetation detection and canopy height estimation, the past and present studies conducted at Argonne using the 15-cm multispectral aerial image provided the following insights into the use of VHSR aerial images for monitoring desert environments:

- Fractional cover of tree, shrub, and bare ground was estimated with an error in absolute cover of $<7.2 \%$, which suggested that a change of $10 \%$ in absolute cover in any of the three cover types could be accurately monitored and mapped using remotely sensed aerial imagery in desert environments over time when applying the method for future monitoring. A ternary plot would be a useful tool for visualizing fractional cover structure of the desert landscape to inform land management decisions.

- Desert pavement was accurately monitored using remotely sensed aerial imagery ( $89 \%$ accuracy). A comparable accuracy could be achieved even using an image with $>15-\mathrm{cm}$ resolution (e.g., $1 \mathrm{~m}$ ). 
- Extremely sparse distribution of small biological soil crusts could not be mapped even at $15-\mathrm{cm}$ resolution.

- Surface stability of desert lands was quantitatively monitored using ERI, which consistently corresponds to surface conditions having characteristic erosion risks.

- A successful extraction of ephemeral streams would require integration of a coarse-scale approach (e.g., the use of NHD) and a fine-scale approach (e.g., Argonne's algorithm). Estimation of ephemeral channel width would require a strategy different from the current approach.

Our exploration of the use of geostatistics (i.e., variogram) using the VARI provided the following useful information for monitoring vegetation alliances in desert regions:

- Increased and decreased range of the variogram would be indicative of expansion and contraction of plant canopy and patch size, respectively.

- Shift of the variogram from spherical to exponential forms and exponential to spherical forms would be indicative of improvement and decline of vegetation diversity, respectively.

- Increased and decreased sill in variograms would be indicative of an increase in and a reduction of vegetation density, respectively.

- A tree-dominant alliance could be monitored using 1-m resolution images, while shrub- and herb-dominant alliances would require $50-\mathrm{cm}$ and $30-\mathrm{cm}$ resolution images to monitor overall vegetation cover and spatial structure of vegetation, respectively.

- Images at 1- to $1.5-\mathrm{m}$ resolution may provide similar results when they are captured at the end of the growing season (or wet season) because of the larger, denser, and greener vegetation canopies.

- The use of commercial high-resolution images could be a viable option for cost-effective long-term land resource monitoring given the detail of and the availability of imagery from a large number of image collection dates.

Our recommendations to further facilitate remote sensing applications for long-term monitoring for desert environments include (1) determining the accuracy of tree-shrub differentiation using high-resolution, multi-temporal satellite images to compensate for the lack of height information; (2) testing methodologies using high-resolution satellite images that have more spectral bands than aerial images have, in order to explore the integration of standardized, high-quality, widely available high-resolution images into a reliable and seamless remote sensing monitoring strategy; (3) investigating the utility of coarse-scale, high-temporal-frequency satellite images for early detection of potential land surface changes in desert environments to 
complement a high-resolution, low-frequency strategy; (4) developing a standardized, spatially comprehensive long-term monitoring strategy for using multi-scale remote sensing; and (5) determining a priority for ephemeral channel monitoring and improving remote sensing methodology accordingly. 


\section{INTRODUCTION}

The U.S. Department of the Interior Bureau of Land Management (BLM) has established a Solar Energy Program to facilitate utility-scale solar development on public lands in the southwestern United States. Utility-scale solar development is a relatively new use of public lands, and the desert environment in which it is occurring is fragile. It can take decades or even centuries to reverse environmental impacts, which makes early detection and assessment of such impacts critical. One element of the BLM Solar Energy Program entails the implementation of comprehensive long-term monitoring programs for solar energy zones (SEZs). However, monitoring environmental impacts over large, remote desert regions for long periods of time could be very costly.

Remote sensing technologies present a promising monitoring tool because they entail the collection of spatially contiguous data, automated processing, and streamlined data analysis. If these technologies can be used successfully to characterize key environmental conditions over the desert landscape and monitor changes in those conditions, they can substantially reduce the costs associated with long-term monitoring. Traditional field data collection activities provide very accurate detailed information about the environment. However, the data lack spatial continuity, coverage, and data volume, which are important to gain an understanding of changes across the landscape. Thus, information generated using remote sensing complements knowledge gained from field measurements and observation. This report provides a summary of the project work conducted during 2015, which corresponds to the following tasks: (1) field data collection (Subtask 1.1), (2) evaluation of remote sensing products (Subtask 1.2), (3) refinement of remote sensing data interpretation methodologies (Subtask 1.3), and (4) analysis of vegetation alliances (Task 2). 
This page intentionally left blank. 


\section{STUDY AREA}

Since 2012, Argonne National Laboratory (Argonne) has been developing a remote sensing methodology for long-term environmental monitoring of the Palo Verde Mesa in eastern Riverside County, California (Figure 1). The study area is a part of the Riverside East SEZ, the largest of the SEZs identified by the BLM in the Record of Decision that established the BLM Solar Energy Program (BLM 2012). The total area designated for utility-scale solar energy projects within the SEZ is $598.6 \mathrm{~km}^{2}$. As of April 2015, four solar projects had been authorized and three applications were pending within the SEZ; these proposed projects cover an area of about $118 \mathrm{~km}^{2}$, which equates to approximately $20 \%$ of the SEZ.

The study area included approximately $170 \mathrm{~km}^{2}$ for the 2012 data collection and $90 \mathrm{~km}^{2}$ for the 2014 data collection, both of which include portions of at least one proposed solar facility project area (construction has not yet began in these areas). The area is primarily covered by bare

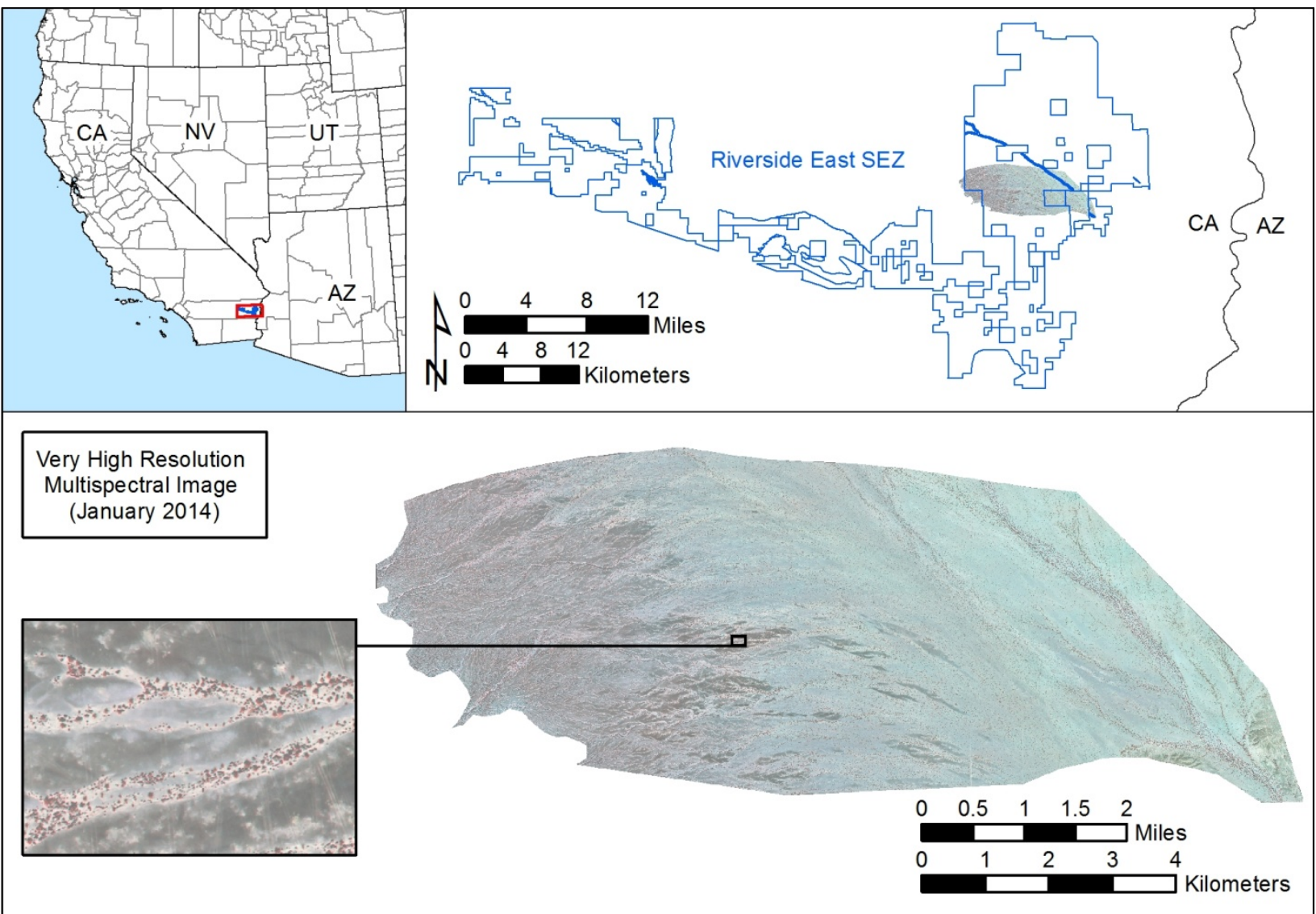

FIGURE 1 Study Area (The image shown is a $15 \mathrm{~cm}$ resolution multispectral image). The image was collected on January 15-16, 2014. The image consists of blue (B), green (G), red (R), and near infrared (NIR) spectral bands, and it is displayed as RGB =NIR, R, and G. Bare ground appears as a light blue to grey color, and desert pavement appears in a dark grey tone. Tree and shrub canopies and patches are resolved in the image). 
ground with sparsely distributed vegetation that consists of desert scrub species (e.g., creosotebush [Larrea tridentata] and white bursage [Ambrosia dumosa]), microphyll trees (e.g., blue palo verde [Parkinsonia florida] and ironwood [Olneya tesota]), perennial grass such as galleta grass (Pleuraphis rigida or Hilaria rigida), and annual herbs such as desert sunflower (Geraea canescens) (Figure 2). The study area exhibits typical desert stream networks made up of single-thread and braided channels mixed with discontinuous forms. The ground surface primarily consists of erodible soils formed by silt and sand, desert pavement, and sparsely distributed biological soil crust. Approximately a quarter of the area to the west exhibits rugged topography, it has about $130 \mathrm{~m}$ of elevation gain from 185 to $315 \mathrm{~m}$ above mean sea level; the rest of the study area has a subtle topographic gradient toward the foothills.

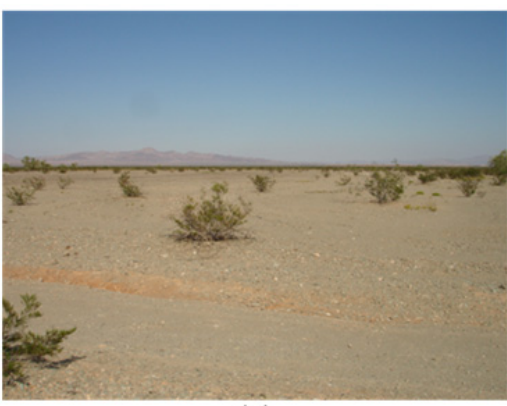

(a)

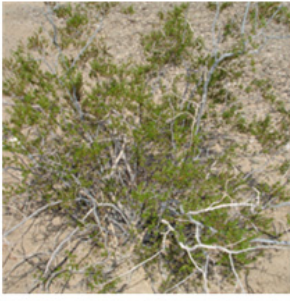

(d)

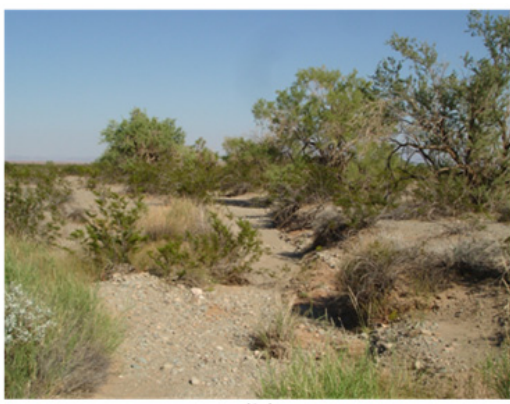

(b)

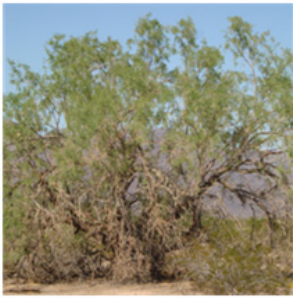

(f)

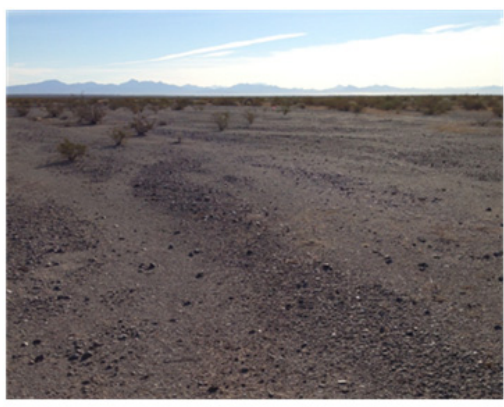

(c)

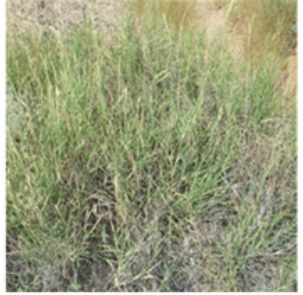

(g)

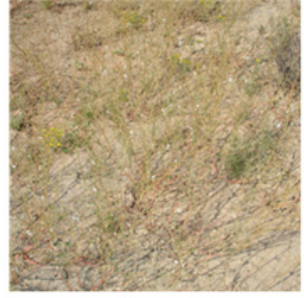

(h)

FIGURE 2 Study Area Landscape and Vegetation (The area is dominated by (a) scrubland with riparian habitat having some areas of (b) dense vegetation. Large patches of (c) desert pavement are present in the western half of the study area. Common plant species include (d) creosotebush (Larrea tridentata), (e) white bursage (Ambrosia dumosa), (f) ironwood (Olneya tesota), (g) galleta grass (Hilaria rigida or formerly Pleuraphis rigida), and (h) annual herbaceous plants.) 


\section{PREVIOUSLY GENERATED REMOTE SENSING PRODUCTS}

A total of six maps and two information types representing a range of surface properties were generated using the very high spatial resolution (VHSR) multispectral images that were collected November 12-13, 2012, and January 15-16, 2014 (Hamada et al. 2014) (Table 1). These 2014 products were subject to validation for accuracy using the ground-truth data collected during the 2015 field work. Brief descriptions of the methodologies for the products are provided in Section 5 under corresponding subsections.

TABLE 1 Remote Sensing Products and Output Generated Prior to 2015a

\begin{tabular}{cl}
\hline Type & \multicolumn{1}{c}{ Variable } \\
\hline Vegetation & - Vegetation distribution \\
& - Vegetation type fractional cover \\
& - Canopy height $^{\mathrm{b}}$ \\
\hline Surface & - Bare ground fractional cover $\mathrm{b}$ \\
& - Desert pavement distribution \\
& - Biological soil crust potential \\
& - Surface stability \\
\hline Hydrology & - Ephemeral stream channel distribution \\
& - Ephemeral stream channel width \\
\hline
\end{tabular}

a Products and output subject to validation are indicated in italics. $\mathrm{b}$ Only the 2014 product was validated due to uncertainty in land surface condition change between 2012 and 2015. 
This page intentionally left blank. 


\section{FIELD DATA COLLECTION}

Field data collection was conducted March 9 through 13, 2015, in the same study area where previous field surveys had been conducted. Variables and parameters recorded during the 2015 field work are summarized in Table 2. Field data were collected from more than 5,000 survey points from a total of 37 plots to perform validation of the remote sensing products that were generated during the 2014 effort. The number and locations of survey plots were selected based on the accessibility, allowable time for the field work, and variability of land cover. Therefore, the plots were not evenly distributed across the study area (Figure 3).

The field data collected during the field work were exclusively focused on validating the remote sensing products generated in previous work: vegetation distribution, canopy height, fractional cover of plant life-form types (i.e., tree, shrub, and herbs) and bare ground, desert pavement distribution, biological soil crust potential, and ephemeral stream channel distribution and width (Table 1). Due to time, resource, and budget constraints, the size of sand grains and pebbles in streambeds and disturbance severity in desert pavement were not measured during the field work.

TABLE 2 Variables and Parameters for Validation and Analysis Collected during Field Work

\begin{tabular}{|c|c|}
\hline Preliminary Variable Proposed in SOW & Reference Data Collection Method \\
\hline \multicolumn{2}{|l|}{ Vegetation } \\
\hline $\begin{array}{l}\text { - Occurrence of individuals } \\
\text { - Identification of plant life-form type }{ }^{\mathrm{a}} \text { or species } \\
\text { - Canopy height } \\
\text { - Canopy diameter } \\
\text { - Fractional cover of life-form type or species }\end{array}$ & $\begin{array}{l}\text { - Line-point intercept } \mathrm{t}^{\mathrm{b}} \\
\text { - Line-point intercept } \mathrm{t}^{\mathrm{b}} \\
\text { - Line-point intercept } \mathrm{t}^{\mathrm{b}} \text { (only where vegetation } \\
\text { intercepted) } \\
\text { - Line-point intercept }{ }^{\mathrm{b}} \text { (only where vegetation } \\
\text { intercepted) } \\
\text { - Calculated from line-point intercept data }\end{array}$ \\
\hline \multicolumn{2}{|l|}{ Surface } \\
\hline $\begin{array}{l}\text { - Presence of bare ground } \\
\text { - Identification of surface type (e.g., desert pavement, } \\
\text { sandy soil, and plant litter) } \\
\text { - Surface properties across surface disturbances } \\
\text { - Distribution of biological soil crusts } \\
\text { - Fractional cover of surface type }\end{array}$ & $\begin{array}{l}\text { - Line-point intercept } \mathrm{t}^{\mathrm{b}} \\
\text { - } 40 \text {-cm } \times 40 \text {-cm plot (integrated into the line-point } \\
\text { intercept method) } \\
\text { - Not collected } \\
\text { - Line-point intercept } \mathrm{t}^{\mathrm{b}} \\
\text { - Calculated from line-point intercept data }\end{array}$ \\
\hline \multicolumn{2}{|l|}{ Hydrology } \\
\hline $\begin{array}{l}\text { - Ephemeral channel location } \\
\text { - Channel width } \\
\text { - Streambed composition }\end{array}$ & $\begin{array}{l}\text { - Field observation and image interpretation } \\
\text { - Calculated from survey GPS cross section data } \\
\text { - Not collected }\end{array}$ \\
\hline \multicolumn{2}{|l|}{ Spatial Reference } \\
\hline $\begin{array}{l}\text { - Horizontal coordinate } \\
\text { - Elevation }\end{array}$ & $\begin{array}{l}\text { - Survey GPS at selected section corners } \\
\text { - Survey GPS at selected section corners }\end{array}$ \\
\hline
\end{tabular}

Abbreviations: GPS = global positioning system; SOW = statement of work.

a Plant life-form types consist of tree, shrub, and herbs.

b Scheme adopted from Herrick et al. (2015). 


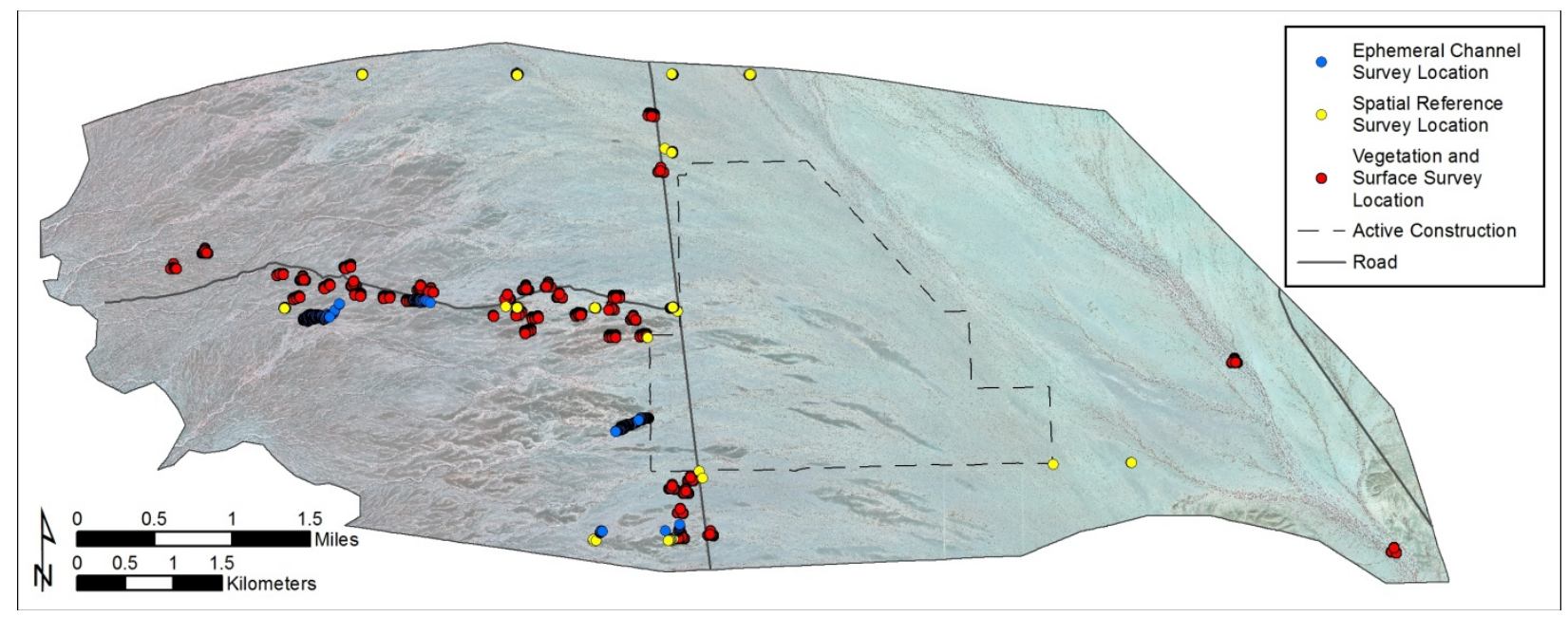

FIGURE 3 Survey Locations for March 2015 Field Work

The field data collection was performed by six team members. Four team members (two ecologists, a remote sensing specialist, and a geospatial technologist) with knowledge and experience in field data collection conducted the vegetation and surface survey. Two team members with a background in hydrology and familiarity with survey equipment collected data for surface hydrology and spatial references. Field data were collected over the course of five consecutive days. Total man-hours for this field data collection were approximately 440 hours. Despite the substantial effort, the area covered was a small fraction of the study area (Figure 3). This illustrates the anticipated challenges for repeated field-based data collection to monitor remote desert regions with limited physical access over time.

\subsection{VEGETATION AND SURFACE DATA COLLECTION}

Figure 3 shows vegetation and surface survey locations. Eight vegetation and surface variables and parameters were recorded using three transects representing a plot suggested by Herrick et al. (2005a,b) (Table 2). We adopted a 30-m transect instead of a 50-m transect, as recommended by Herrick et al. (2005a,b), in order to survey a sufficient number of plots under the time and budget constraints. To compensate for the limited transect length, each survey plot was selected from areas with a relatively consistent surface composition greater than $4,000 \mathrm{~m}^{2}$ or a 35-m-radius area, to avoid boundaries of habitat or land surface types.

For areas with no clear physical transition in landscape, we used a plot with a spoke design containing three transects (circular plot); for areas containing ephemeral channels or riparian corridors, we adopted a design consisting of three transects perpendicular to the channel or corridor (riparian plot). To minimize the edge effect of sampling, a 15-m buffer was applied for the upstream and downstream transects (but not the middle transect) when defining a riparian plot. A total of 76 survey plots were selected prior to the field work based on accessibility (e.g., access roads/trails and topography). Distribution of surface cover type was also considered in plot selection. Particularly, we ensured that a range of fractional cover of trees and shrubs was 
represented in the selected plots in order to support rigorous validation of vegetation cover type. Survey plots that were selected, but never surveyed, during previous field work were also included in these new survey plots. Because of ongoing construction and access restrictions, which we discovered upon arrival at the site, 23 survey plots out of the 76 pre-selected plots were inaccessible. However, the remaining plots were sufficient to support validation, and thus no new arbitrary survey plots were added during the field work.

Along each transect, occurrence of vegetation and surface types (e.g., rock, soil, and biological crust) and plant life-form types (or species) were recorded every $1 \mathrm{~m}$. Canopy height and diameter were also recorded along transects, only where survey points intersected with vegetation. Canopy height was measured using a 2-m folding ruler or clinometer, and canopy diameter was measured using a measuring tape or ruler depending on the size of the canopy.

Surface composition was observed using a $40-\mathrm{cm} \times 40-\mathrm{cm}$ plot $\left(0.16 \mathrm{~m}^{2}\right)$ placed every $3 \mathrm{~m}$ along the transect. This sampling method was designed to collect field data for examining the Erosion Resistant Index (ERI) map. Because of considerable heterogeneity in surface composition (e.g., loose soil, crusts, vegetation, and rocks) within a 35-m-radius area (approximately $3,850 \mathrm{~m}^{2}$ ) suggested by Herrick et al. (2005a,b), an alternative survey method was needed to examine how well ERI corresponds to surface materials having distinct surface stability. Although it is not standard methodology, by integrating into the line-point intercept method, this fine-scale sampling method successfully accommodated collection of necessary data at an appropriate spatial scale with a sufficient sample size in an efficient manner.

\subsection{HYDROLOGY AND SPATIAL REFERENCED DATA COLLECTION}

Topographic surveying was conducted to characterize ephemeral stream channels and to collect spatial reference data for recalibrating the VHSR image mosaics, DSM, and digital terrain model (DTM) for change analysis for future study. Survey-grade, global positioning system (GPS) equipment (Epoch-50, Spectra Precision, Westminster Colorado) was used and operated in real-time kinetic (RTK) mode to collect topographic data with a horizontal accuracy of $\pm 0.010 \mathrm{~m}$ and a vertical accuracy of $\pm 0.020 \mathrm{~m}$. Control points for the topographic survey were based on monuments designating township-range boundaries established by cadastral surveys performed by the BLM.

Channel bathymetry consisted of measurements from five locations in the study area (Figure 3, blue points). Two locations were situated approximately 2.5 to $4 \mathrm{~km}$ west from the north-south road adjacent to the access road that extends west from the north-south road. The other three locations were approximately $800 \mathrm{~m}$ west of the north-south road. In the first two locations, the ephemeral channel segments had an average width of $30.2 \mathrm{~m}$ (standard deviation $13.1 \mathrm{~m}$ ). In the other three locations, the channel segments had an average channel width of $5.4 \mathrm{~m}$ (standard deviation $2.4 \mathrm{~m}$ ). These survey reaches were selected during the field survey in coordination with spatial reference data collection and based on accessibility, time allowed, and variability of channel forms. 
Spatial reference data or ground control point data were collected from 13 locations in the study area (Figure 3, yellow dots). To select those locations, a grid resembling township-range boundaries was overlain with the VHSR images based on the survey dataset at section corners that the BLM provided prior to field work. All intersections of the boundaries were identified as potential survey locations. The potential survey locations were examined based on existing cadastral survey locations provided by the BLM, proximity to access roads, and topography; the final survey locations were determined to yield ground control points that were relatively well distributed across the study area. To supplement the standard ground control points, additional survey data were collected from landscape features such as large rock fragments and vegetation patches near the 13 locations. These survey data represent boundaries of the identified features in the image and are expected to considerably improve positional accuracy of the VHSR images and the derived products.

\subsection{DATABASE DEVELOPMENT AND MANAGEMENT}

To facilitate validation and analysis for the remote sensing products generated during our previous work, the field data collected during the 2015 field work were organized in an Arc Spatial Database Engine (SDE) database. An ArcSDE database manages all the collected geospatial data in a relational database management system and enables the database to be accessed and edited by multiple ArcGIS clients. To comply with BLM's Assessment, Inventory, and Monitoring (AIM) protocols, we created a database schema that maintains the integrity of data throughout the data collection process. The schema was designed with the survey data sheet in mind by containing properly coded value domains and range values for each column. The data were then entered using these specific coded domain values, and comparable abbreviations were assigned for additional data collected during the field survey. Each field photo was digitally linked to a corresponding record for easy access in order to enhance understanding of the data and to support decisions during data analysis and interpretation.

Because of collection in a rural environment, the data had to be stored locally on the mobile device until a well-functioning Internet connection could be established. Once connected, the ArcGIS client was able to upload and synchronize newly collected data with the ArcSDE database on the remote servers. At the end of the data collection process, a total of 3,072 records of vegetation and surface observations and measurements were entered into the database, which equated to $2.5 \mathrm{~GB}$ of geospatial data. This geospatially referenced database allowed us to query data for review, generate reference data for validation, and investigate explanations of analysis results. Using this database that is compliant with the AIM protocols, validation data were systematically derived from the 2015 field data in order to evaluate previously generated remote sensing products. Detailed methodologies for reference data generation are described in detail in Section 5 under corresponding subsections. 


\section{VALIDATION AND ANALYSIS OF REMOTE SENSING PRODUCTS}

\subsection{ACCURACY MEASURES}

Table 3 shows the measures used to validate the accuracy of products using the 2015 field data. Two distinct sets of accuracy measures were used to evaluate discrete features and continuous properties. These measures are commonly utilized in remote sensing applications for land cover mapping.

\subsection{VALIDATION OF VEGETATION AND VEGETATED SURFACE}

\subsubsection{Validating Vegetation Distribution}

Vegetation distribution was extracted as a part of Argonne's fractional cover estimation routine (Hamada et al. 2014; Hamada and Grippo 2015a). Upon developing the routine, 10 spectral vegetation indices (SVIs) were examined prior to the development of the land cover classification algorithm. Based on our analysis, the Visible Atmospherically Resistant Index (VARI) was identified as the optimal SVI and applied to the algorithm to identify desert vegetation. In the current study, 4 out of the 10 vegetation distribution maps generated in previous work were validated. Those vegetation distribution maps were generated using the Normalized Difference Vegetation Index (NDVI; Tucker 1979), VARI (Gitelson et al. 2002), Soil-Adjusted Vegetation Index (SAVI; Huete 1988), and Modified Soil-Adjusted Vegetation Index (MSAVI; Qi et al. 1994) (Table 4). These SVIs were selected for validation because they exhibited the highest accuracy in our previous study or are frequently used for mapping desert vegetation.

For validating the vegetation distribution maps, the field data collected using the linepoint intercept method were stratified into two groups: vegetation and non-vegetation. The vegetation group consists of woody life-form types such as trees and shrubs, and the nonvegetation group consists of bare ground such as soil, rock fragments, and soil crusts. Herbaceous vegetation was excluded from the validation, except for galleta grass, because this life-form type was likely senesced when the VHSR images were collected in 2012 and 2014, based on the precipitation record prior to image collection. Galleta grass, a perennial grass characterized by clumps of shrubby narrow leaves and that is approximately 1-m tall, may have maintained some green foliage at the time of image collection, unlike typical herbaceous plants in the study area. Thus, galleta grass was included in the validation.

To generate a reference dataset, pixel values of the vegetation distribution maps (vegetation $=1$, non-vegetation $=0$ ) generated from NDVI, VARI, SAVI, and MSAVI were extracted to 100 randomly selected points for each vegetation or non-vegetation group. In order to mitigate uncertainty in positional accuracy between the survey locations and the maps, a 0.5-m-radius area around vegetation points was considered. That is, when the circular area around observed vegetation intersected with a pixel value of 1 in the vegetation distribution map, 
TABLE 3 Accuracy Measures for Remote Sensing Products

\begin{tabular}{|c|c|c|c|c|c|c|c|c|}
\hline Measure & Indication & 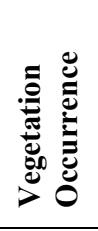 & 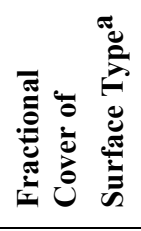 & 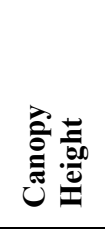 & 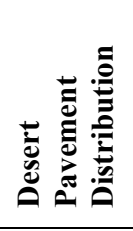 & 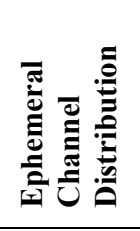 & 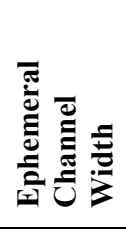 & 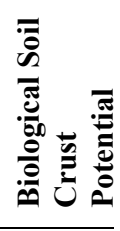 \\
\hline $\begin{array}{c}\text { Overall } \\
\text { accuracy }\end{array}$ & $\begin{array}{l}\text { Level of overall accuracy } \\
\text { regardless of over- or under- } \\
\text { estimations. }\end{array}$ & $X$ & & & $X$ & $X$ & & \\
\hline $\begin{array}{l}\text { Producer's } \\
\text { accuracy }\end{array}$ & $\begin{array}{l}\text { Proportion of targets in the } \\
\text { reference data that were } \\
\text { correctly detected. A lower } \\
\text { value suggests a greater } \\
\text { false negative rate or } \\
\text { underestimation of targets. }\end{array}$ & $X$ & & & $X$ & $X$ & & \\
\hline $\begin{array}{c}\text { User's } \\
\text { accuracy }\end{array}$ & $\begin{array}{l}\text { Proportion of targets in the } \\
\text { product that were actually } \\
\text { present in the reference. A } \\
\text { lower value suggests a } \\
\text { greater false positive rate or } \\
\text { overestimation of targets. }\end{array}$ & $X$ & & & $X$ & $X$ & & \\
\hline $\begin{array}{c}\text { Kappa } \\
\text { coefficient of } \\
\text { accuracy }(K)\end{array}$ & $\begin{array}{l}\text { Accuracy that accounts for } \\
\text { random chance. A value } \\
>0.5 \text { indicates a better than } \\
\text { random classification } \\
(K=0.5) \text {. }\end{array}$ & $X$ & & & $X$ & $X$ & & \\
\hline $\begin{array}{l}\text { Mean error } \\
\text { (ME) }\end{array}$ & $\begin{array}{l}\text { Average difference between } \\
\text { observed and predicted } \\
\text { values. It provides the trend } \\
\text { in error, such as over- or } \\
\text { under-prediction since the } \\
\text { direction of errors is } \\
\text { maintained in calculation. }\end{array}$ & & $X$ & $X$ & & & $X$ & $X$ \\
\hline $\begin{array}{l}\text { Mean absolute } \\
\text { error (MAE) }\end{array}$ & $\begin{array}{l}\text { Average absolute difference } \\
\text { between observed and } \\
\text { predicted values. Outliers do } \\
\text { not impose significant } \\
\text { impact since individual } \\
\text { differences are weighted } \\
\text { equally. }\end{array}$ & & $X$ & $X$ & & & $X$ & $X$ \\
\hline $\begin{array}{l}\text { Root mean } \\
\text { squared error } \\
\text { (RMSE) }\end{array}$ & $\begin{array}{l}\text { A diagnostic measure of the } \\
\text { difference between observed } \\
\text { and predicted values. It has } \\
\text { a relatively high weight to } \\
\text { large errors because the } \\
\text { errors are squared before } \\
\text { being averaged. }\end{array}$ & & X & $X$ & & & $X$ & $X$ \\
\hline $\begin{array}{l}\text { Correlation of } \\
\text { determination } \\
\qquad\left(R^{2}\right)\end{array}$ & $\begin{array}{l}\text { Correlation between } \\
\text { predicted and observed } \\
\text { values. }\end{array}$ & & $X$ & $X$ & & & $X$ & $X$ \\
\hline
\end{tabular}

a Surface type includes vegetation types defined by plant life-form type and bare ground. 
TABLE 4 Spectral Vegetation Indices Validated

\begin{tabular}{|c|c|c|}
\hline Remote Sensing Metric & Definition & Reference \\
\hline $\begin{array}{c}\text { Normalized Difference Vegetation } \\
\text { Index (NDVI) }\end{array}$ & $\frac{\rho_{\text {NIR }}-\rho_{\text {red }}}{\rho_{\text {NIR }}+\rho_{\text {red }}}$ & Tucker 1979 \\
\hline $\begin{array}{l}\text { Visible Atmospherically Resistant } \\
\text { Index (VARI) }\end{array}$ & $\frac{\rho_{\text {NIR }}-\rho_{\text {green }}}{\rho_{\text {NIR }}+\rho_{\text {green }}+\rho_{\text {red }}}$ & $\begin{array}{l}\text { Gitelson et al. } \\
2002\end{array}$ \\
\hline Soil-Adjusted Vegetation Index (SAVI) & $\begin{array}{c}\frac{\left(\rho_{N I R}-\rho_{\text {red }}\right) *(1+L)}{\rho_{N I R}+\rho_{\text {red }}+L} \\
L=0.5\end{array}$ & Huete 1988 \\
\hline $\begin{array}{c}\text { Modified Soil-Adjusted Vegetation } \\
\text { Index (MSAVI) }\end{array}$ & $\frac{2 \rho_{N I R}+1-\sqrt{\left(2 \rho_{N I R}+1\right)^{2}-8\left(\rho_{N I R}-\rho_{\text {red }}\right)}}{2}$ & Qi et al. 1994 \\
\hline
\end{tabular}

it was considered a correct detection of vegetation, even if the point of observed vegetation did not exactly overlap with a vegetation pixel in the map.

Table 5 and Figure 4 show the accuracy of four vegetation distribution maps derived from NDVI, VARI, SAVI, and MSAVI that were validated using the 2015 field data. The vegetation detection accuracy of all four indices was relatively comparable. Overall accuracy ranged from 75\% to 78\% for November 2012 and from 74\% to 77\% for January 2014 . Producer's accuracy is typically slightly higher for January 2014 (i.e., $73 \%-88 \%$ ) than for November 2012 (64\%-72\%), and user's accuracy shows the opposite pattern (i.e., $80 \%-82 \%$ for 2012 and $69 \%-79 \%$ for 2014). This indicates that vegetation was slightly underestimated for 2012 and overestimated for 2014. This varying trend between years (or images) would make it challenging to select a single threshold value that achieves high detection accuracy for multiple years. The Kappa coefficient of accuracy $(K)$ ranged from 0.48 to 0.55 and indicates that the accuracy is around $50 \%$ when disregarding correct detection by chance.

NDVI shows the highest vegetation detection accuracy in 2012 of all indices examined, while it shows the lowest accuracy in 2014. This suggests potential instability of the index in detecting vegetation in images collected at different times and/or images with different vegetation conditions. For both 2012 and 2014, NDVI shows the highest producer's accuracy and (one of) the lowest user's accuracy, which suggests its tendency to overestimate vegetation.

At a glance, determining a single threshold index value that achieves high vegetation detection accuracy for multiple years appears challenging. However, when closely looking at the accuracy measures, VARI shows potential for being a robust index for monitoring desert vegetation. NDVI, SAVI, and MSAVI show lower rates in false positive detection than false negative detection in 2012, while showing an opposite pattern in 2014 (Figure 4). In contrast, its lower rates of false positive detection than false negative detection for both years suggest that VARI consistently underestimated vegetation regardless of year. This consistent negative bias of VARI indicates that lowering the threshold value would increase the number of vegetation pixels 
TABLE 5 Accuracy of Vegetation Distribution Maps Validated Using 2015 Field Data

\begin{tabular}{|c|c|c|c|c|c|c|}
\hline & $\begin{array}{c}\text { Kappa } \\
(K)\end{array}$ & $\begin{array}{c}\text { Overall } \\
\text { Accuracy } \\
(\%)\end{array}$ & $\begin{array}{c}\text { Producer's } \\
\text { Accuracy } \\
(\%)\end{array}$ & $\begin{array}{c}\text { User's } \\
\text { Accuracy } \\
(\%)\end{array}$ & $\begin{array}{c}\text { False } \\
\text { Positive } \\
\text { Rate } \\
(\%) \\
\end{array}$ & $\begin{array}{c}\text { False } \\
\text { Negative } \\
\text { Rate } \\
(\%) \\
\end{array}$ \\
\hline \multicolumn{7}{|c|}{ November 2012} \\
\hline NDVI & 0.550 & 77.5 & 72.0 & 80.9 & 19.1 & 28.0 \\
\hline VARI & 0.520 & 76.0 & 67.0 & 81.7 & 18.3 & 33.0 \\
\hline SAVI & 0.510 & 75.5 & 68.0 & 80.0 & 20.0 & 32.0 \\
\hline MSAVI & 0.500 & 75.0 & 64.0 & 82.1 & 17.9 & 36.0 \\
\hline \multicolumn{7}{|c|}{ January 2014} \\
\hline NDVI & 0.480 & 74.0 & 88.0 & 69.0 & 31.0 & 12.0 \\
\hline VARI & 0.530 & 77.0 & 73.0 & 79.0 & 22.0 & 27.0 \\
\hline SAVI & 0.490 & 75.0 & 78.0 & 73.0 & 27.0 & 22.0 \\
\hline MSAVI & 0.540 & 77.0 & 78.0 & 77.0 & 24.0 & 22.0 \\
\hline
\end{tabular}

Abbreviations: NDVI $=$ Normalized Difference Vegetation Index; VARI $=$ Visible

Atmospherically Resistant Index; SAVI = Soil-Adjusted Vegetation Index; MSAVI = Modified SAVI.
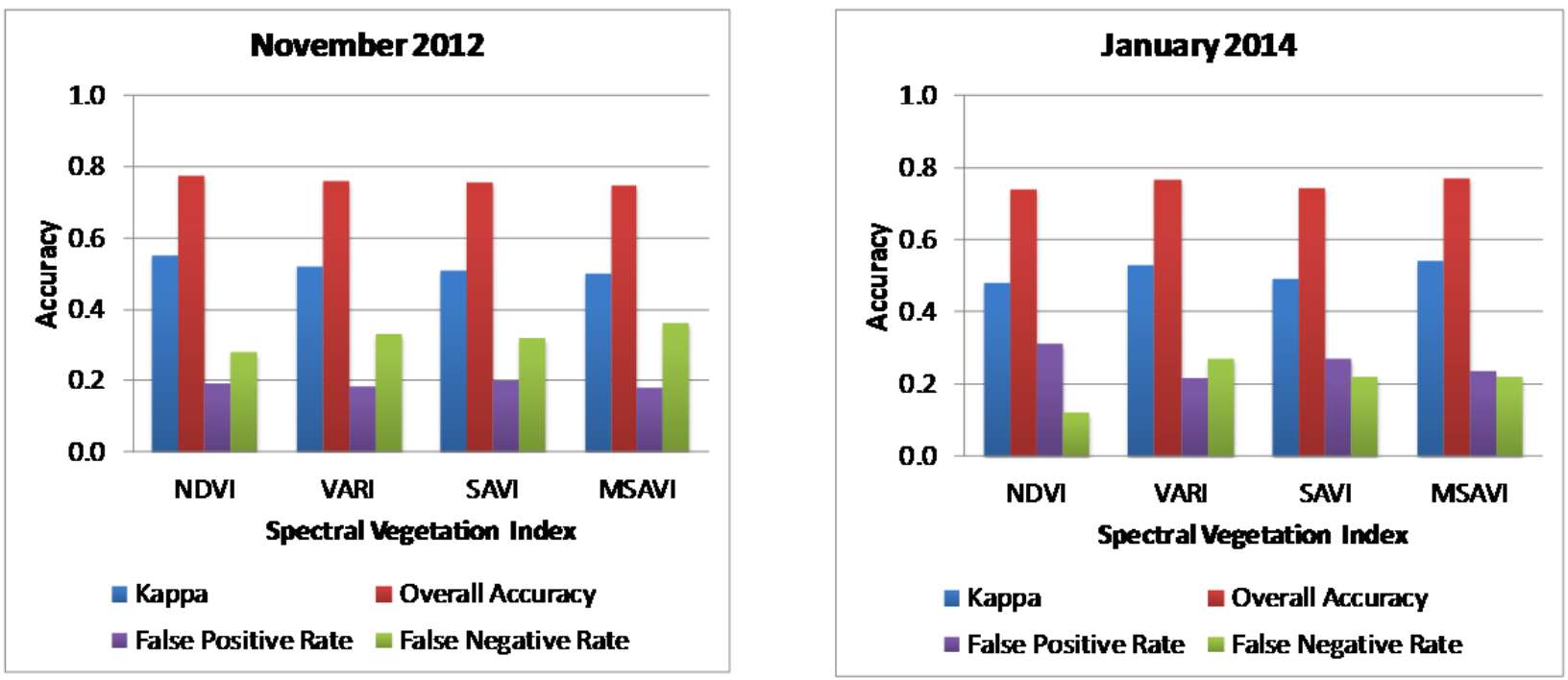

FIGURE 4 Accuracy of Vegetation Distribution Maps Validated Using 2015 Field Data

by including those with slightly lower index values, and thus vegetation detection accuracy would improve for both images. This suggests the potential effectiveness of VARI for monitoring changes in desert vegetation over time. A refined vegetation detection methodology with lowering VARI threshold value is evaluated in Section 6.1. It should also be noted that time lag between image collection and field data collection for training and validation would have contributed to error in fractional cover estimate. 


\subsubsection{Validating Canopy Height Estimate}

Canopy height was previously estimated via simple subtraction of DTM from DSM, both of which were generated using an aerial triangulation technique applied for the 2014 VHSR image frames having at least $80 \%$ forward overlap and at least $75 \%$ side overlaps (Hamada et al. 2014). Using the 2015 field data, the canopy height estimates derived from the remotely sensed imagery were validated using the canopy height of 30 individual trees or shrubs measured in the field.

The results showed that the canopy height obtained using remote sensing was strongly correlated with the reference height $\left(R^{2}=0.72\right)$, although absolute height was consistently underestimated (Figure 5). Mean error (ME) $(-2.83 \mathrm{~m})$ also suggests a height underestimation when using remote sensing. Mean absolute error (MAE) and root mean squared error (RMSE) of canopy height estimates were $2.83 \mathrm{~m}$ and $2.86 \mathrm{~m}$, respectively, and the small difference between ME and RMSE $(0.03 \mathrm{~m})$ suggests an absence of outliers. Although the DSM, DTM, and image collection parameters should be re-evaluated, it would be worthwhile testing an alternative methodology for estimating canopy height only using the DSM in conjunction with a vegetation mask and a spatial interpolation technique (Gillan et al. 2014). This alternative methodology is evaluated in Section 6.2.

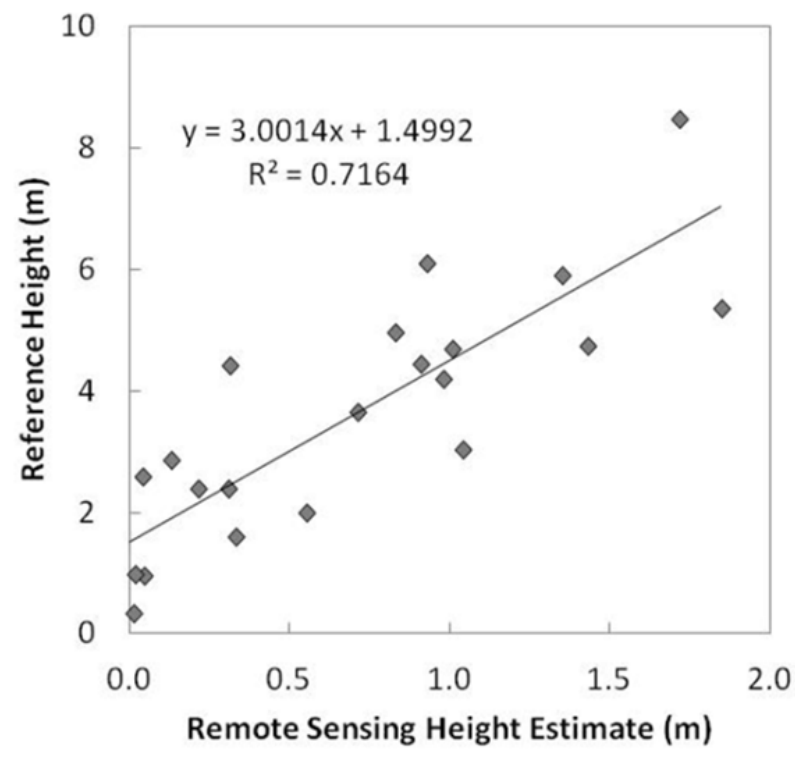

FIGURE 5 Correlation between Canopy Height Measured during 2015 Field Survey and Canopy Height Estimated Using Remote Sensing 


\subsubsection{Validating Fractional Cover of Surface Types}

Fractional cover maps of surface types (i.e., tree, shrub, non-photosynthetic vegetation [NPV], and bare ground) were previously generated based on multiple steps - preliminary classification, tree-shrub differentiation, bare ground merge, and cover fraction calculation (Hamada et al. 2014; Hamada and Grippo 2015a). Vegetation, NPV, and bare ground were first mapped using the maximum likelihood classifier applied to a layer stack of the VHSR image and VARI. The vegetation class was differentiated into tree and shrub classes based on the canopy height estimated by subtracting DTM from DSM. Due to spectral variability within a class, the initial classification produced multiple subclasses such as desert pavement and bright-colored soil for the bare ground class. These subclasses were merged into a single bare ground class according to BLM's AIM Program criteria (Toevs et al. 2011). Fractional cover of each surface type was computed for a $30-\mathrm{m} \times 30-\mathrm{m}$ area from the surface type map consisting of tree, shrub, and bare ground.

To validate the fractional cover maps of surface types, reference cover fractions for vegetation and surface types were calculated from the 2015 field data collected using the linepoint intercept method. A total of 36 plots (21 non-riparian and 15 riparian) were selected for validation data. Cover is defined as "the proportion of the soil surface covered by a vertical projection of the cover class of interest" (Pellant et al. 2005; Toves et al. 2011). Thus, we only used the top vegetation or surface type data for each survey point, although multiple vertical strata were recorded in the field. A total of 14 classes of top vegetation and surface types were recorded in the field - tree, dead tree, shrub, dead shrub, unknown dead vegetation, annual forb, perennial forb, annual grass, perennial grass, unknown herbaceous plant, duff (or plant litter), soil, rock, and biological crust. For each plot, fractions of these 14 cover types were calculated by dividing the sum of the cover type observation by total survey points within a plot.

We validated the land cover type fractions using six stratification schemes (Table 6): (1) stratification currently used for fractional cover maps (Current); (2) dead individuals with identifiable life-form types incorporated into corresponding classes (e.g., trees and shrubs) (DeadInc); (3) galleta grass that was recorded as perennial grass incorporated into the shrub class because nearly $80 \%$ of the species we surveyed were intermixed with shrub canopies or directly adjacent to large shrubs in the field (GalletaSH); (4) plant litter or duff incorporated into the bare ground class (LitterBG); (5) surface components other than tree, dead tree, shrub, dead shrub, and galleta grass were merged into a single class because these components are small, extremely sparse, spectrally similar, intermixed, and/or functionally less significant than trees and shrubs (Other); and (6) land surface stratified into three classes - tree, shrub, and bare ground - for analysis focusing on important life-form types (i.e., trees and shrubs) in desert ecosystems (3-class). 
TABLE 6 Classification Scheme for Land Cover Type

\begin{tabular}{|c|c|c|c|c|c|c|}
\hline & Current & DeadInc & GalletaSH & LitterBG & Other & 3-Class \\
\hline \multirow[t]{2}{*}{ Tree } & TR & TR & TR & TR & TR & TR \\
\hline & & TRD & & & TRD & TRD \\
\hline \multirow[t]{3}{*}{ Shrub } & $\mathrm{SH}$ & $\mathrm{SH}$ & $\mathrm{SH}$ & $\mathrm{SH}$ & $\mathrm{SH}$ & $\mathrm{SH}$ \\
\hline & & SHD & & & & SHD \\
\hline & & & PG & & PG & PG \\
\hline \multirow[t]{9}{*}{ NPV } & $\mathrm{AF}$ & $\mathrm{AF}$ & $\mathrm{AF}$ & $\mathrm{AF}$ & $\mathrm{AF}$ & \\
\hline & $\mathrm{PF}$ & $\mathrm{PF}$ & $\mathrm{PF}$ & $\mathrm{PF}$ & $\mathrm{PF}$ & \\
\hline & $\mathrm{AG}$ & $\mathrm{AG}$ & $\mathrm{AG}$ & $\mathrm{AG}$ & $\mathrm{AG}$ & \\
\hline & PG & PG & & PG & & \\
\hline & $\mathrm{H}$ & $\mathrm{H}$ & $\mathrm{H}$ & $\mathrm{H}$ & $\mathrm{H}$ & \\
\hline & TRD & & TRD & TRD & & \\
\hline & SHD & & SHD & SHD & SHD & \\
\hline & VD & VD & VD & VD & VD & \\
\hline & $\mathrm{D}$ & D & $\mathrm{D}$ & & $\mathrm{D}$ & \\
\hline \multirow[t]{8}{*}{ Bare Ground } & $\mathrm{S}$ & $S$ & $\mathrm{~S}$ & $S$ & $S$ & $S$ \\
\hline & $\mathrm{R}$ & $\mathrm{R}$ & $\mathrm{R}$ & $\mathrm{R}$ & $\mathrm{R}$ & $\mathrm{R}$ \\
\hline & $\mathrm{LC}$ & $\mathrm{LC}$ & $\mathrm{LC}$ & $\mathrm{LC}$ & $\mathrm{LC}$ & $\mathrm{LC}$ \\
\hline & & & & $\mathrm{D}$ & & D \\
\hline & & & & & & $\mathrm{AF}$ \\
\hline & & & & & & $\mathrm{PF}$ \\
\hline & & & & & & $\mathrm{AG}$ \\
\hline & & & & & & $\begin{array}{c}\mathrm{H} \\
\mathrm{VD}\end{array}$ \\
\hline
\end{tabular}

\footnotetext{
Abbreviations: DeadInc $=$ dead trees and shrubs observations included in the tree and shrub classes; GalletaSH $=$ galleta grass (recorded as PG [perennial grass]) included in the shrub class; LitterBG = litter (recorded as D [duff]) included in the bare ground class; Other = cover types other than tree, dead tree, shrub, dead shrub, and galleta grass aggregated in the "other" class; TR = tree; TRD = dead tree; $\mathrm{SH}=$ shrub; $\mathrm{SHD}=$ dead shrub; $\mathrm{AF}=$ annual forb; $\mathrm{PF}=$ perennial forb; $\mathrm{AG}=$ annual grass; $\mathrm{H}=$ herb; $\mathrm{VD}=$ dead unknown vegetation; $\mathrm{D}=$ duff; $\mathrm{S}=$ soil; $\mathrm{R}=$ rock; LC $=$ biological crust.
}

Figure 6 summarizes the correlation between the reference cover fractions and those estimated using remote sensing by classification scheme. Correlation of fractional cover between remote sensing estimates and the reference data varied across the cover type. Bare ground cover showed the highest correlation regardless of classification scheme $\left(R^{2}=0.78-0.82\right)$. Tree cover consistently showed moderate to high correlation (around $R^{2}=0.60$ ), and shrub cover was moderately correlated with the reference data $\left(R^{2}=0.44-0.63\right)$. Correlation of NPV was consistently low $\left(R^{2}=0.01-0.04\right)$, which suggests that NPV does not have a unique spectral signature in the image. While the classification schemes that consist of four classes showed uneven correlations across the classes, the 3-class classification scheme, with NPV aggregated into bare ground, showed relatively even correlation across tree, shrub, and bare ground ( $R^{2}=0.60,0.61$, and 0.78 , respectively). 

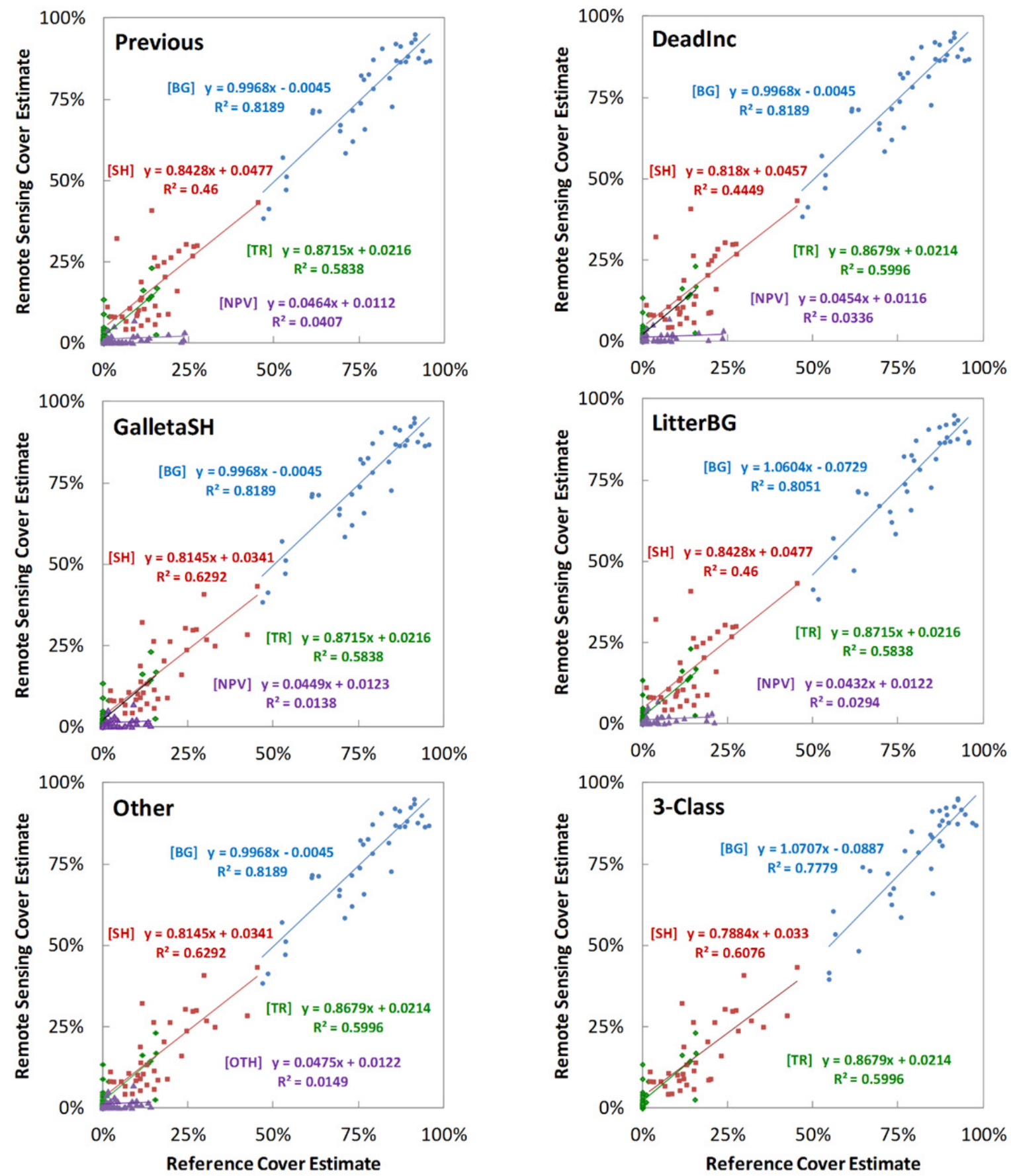

FIGURE 6 Correlation between Reference Cover Obtained from 2015 Field Data and Cover Estimated Using Remote Sensing (TR = tree; $\mathrm{SH}=$ shrub; NPV = non-photosynthetic vegetation; $\mathrm{OTH}=$ other; $\mathrm{BG}=$ bare ground; DeadInc $=$ dead trees and shrubs observations included in the tree and shrub classes; GalletaSH = galleta grass (recorded as PG [perennial grass]) included in the shrub class; LitterBG = litter (recorded as D [duff]) included in the bare ground class; Other = cover types other than tree, dead tree, shrub, dead shrub, and galleta grass aggregated in the "other" class; 3-Class = all surface types classified into one of tree, shrub, and bare ground classes.) 
While estimation of tree cover was relatively stable regardless of the classification scheme (i.e., inclusion or exclusion of dead parts), estimation of shrub cover noticeably varied depending on the classification of shrub (Table 6, Figure 6). The major factor influencing the estimation of shrub cover was how galleta grass was treated in the analysis. Out of six classification schemes tested, the Galleta SH, Other, and 3-class schemes considered galleta grass as shrub. In the field, a large proportion of galleta grass was intermixed with or directly adjacent to shrubs or trees. It is likely that when the pin hit galleta grass in shrub canopy gaps, we recorded the species as a top canopy plant. Ultra-fine-scale observation or differentiation of species is not possible using $15-\mathrm{cm}$ resolution images. Thus, classifying galleta grass as shrub would be considered acceptable for validation of a remote sensing product.

In general, the magnitude of error in the fractional cover estimate was small $(<8.5 \%$ absolute cover). ME, which indicates overall bias in the cover estimate, suggests that fractional cover of tree and shrub was consistently overestimated across the classification schemes, except for the 3-class classification $(\mathrm{ME}=1.8 \%-1.9 \%$ absolute tree cover, $\mathrm{ME}=-0.3 \%-2.6 \%$ absolute shrub cover), while NPV cover was consistently underestimated (ME $=-5.3 \%-3.2 \%$ absolute cover) (Table 7). Estimates of bare ground cover had the least bias of the cover types for the 4-class-classification schemes ( $\mathrm{ME}=-1.1 \%-0.7 \%$ absolute cover), but that is not the case for the 3-class classification ( $\mathrm{ME}=-3.2 \%$ absolute cover). The difference between RMSE and MAE (Diff.) ranged from $0.3 \%$ to $2.6 \%$ absolute cover across the land cover types and stratification schemes. This indicates low likelihood of outliers or extreme values in the validation samples.

Fractional cover of the three surface types (i.e., tree, shrub, and bare ground) obtained from the 36 plots was plotted in a ternary plot to examine characteristics of fractional cover composition across habitat types such as riparian and scrubland habitats in the study area (Figure 7). The plot shows noticeable separation across the habitat types, as well as their relative locations in the landscape. Non-riparian plots mostly consisting of creosotebush scrublands are tightly clustered at the corner of the triangle with no tree cover and $82 \%$ to $100 \%$ bare ground cover. Less-defined or obscured riparian habitats are characterized by nearly no tree cover with sparse to moderate shrub cover in the plot, which agrees with the patterns we observed in the field. The riparian habitat plots along well-defined ephemeral streams are characterized by $>10 \%$ tree cover with shrub cover approximately $2 \%$ to $40 \%$, which is mostly consistent with our general observation in the field. The cover composition plot indicates that approximately $18 \%$ shrub cover is the threshold separating the riparian habitat type from non-riparian habitat types. This shrub cover threshold could provide useful information about loss and degradation of riparian habitats in desert environments.

\subsection{VALIDATION OF DESERT PAVEMENT}

The distribution of desert pavement was previously extracted during the land cover classification routine as a part of the fractional cover estimation as described in Section 5.2.3 (Hamada et al. 2014). In the land cover classification algorithm, desert pavement may be classified into more than one subclass depending on the spectral characteristics associated with color, type, and density of rock fragments. 
TABLE 7 Accuracy of Land Cover Type Fractions Validated Using 2015 Field Data

\begin{tabular}{|c|c|c|c|c|c|c|}
\hline & $\begin{array}{c}\text { Current } \\
(\%)\end{array}$ & $\begin{array}{c}\text { DeadInc } \\
(\%)\end{array}$ & $\begin{array}{c}\text { GalletaSH } \\
(\%)\end{array}$ & $\begin{array}{c}\text { LitterBG } \\
(\%)\end{array}$ & $\begin{array}{c}\begin{array}{c}\text { Other } \\
(\%)\end{array} \\
\end{array}$ & $\begin{array}{c}\text { 3-Class } \\
(\%)\end{array}$ \\
\hline \multicolumn{7}{|l|}{ Tree } \\
\hline ME & 1.8 & 1.9 & 1.8 & 1.8 & 1.8 & 1.8 \\
\hline MAE & 2.6 & 5.8 & 2.6 & 2.6 & 2.5 & 2.5 \\
\hline RMSE & 4.3 & 8.4 & 4.3 & 4.3 & 4.2 & 4.2 \\
\hline Diff. & 1.7 & 2.6 & 1.7 & 1.7 & 1.7 & 1.7 \\
\hline \multicolumn{7}{|l|}{ Shrub } \\
\hline ME & 2.6 & 1.9 & 0.4 & 2.6 & 0.4 & -0.3 \\
\hline MAE & 5.9 & 5.8 & 5.3 & 5.9 & 5.3 & 5.6 \\
\hline RMSE & 8.4 & 8.4 & 6.9 & 8.4 & 6.9 & 7.1 \\
\hline Diff. & 2.6 & 2.6 & 1.5 & 2.6 & 1.5 & 1.5 \\
\hline \multicolumn{7}{|l|}{ NPV } \\
\hline ME & -5.3 & -4.6 & -3.2 & -3.5 & NA & NA \\
\hline MAE & 5.8 & 5.2 & 3.7 & 4.3 & NA & NA \\
\hline RMSE & 8.4 & 7.6 & 5.2 & 6.9 & NA & NA \\
\hline Diff. & 2.6 & 2.4 & 1.4 & 2.6 & NA & NA \\
\hline \multicolumn{7}{|l|}{ Other } \\
\hline ME & NA & NA & NA & NA & -3.1 & NA \\
\hline MAE & NA & NA & NA & NA & 3.7 & NA \\
\hline RMSE & NA & NA & NA & NA & 5.1 & NA \\
\hline Diff. & NA & NA & NA & NA & 1.4 & NA \\
\hline \multicolumn{7}{|c|}{ Bare Ground } \\
\hline ME & -0.7 & -0.7 & 0.7 & -1.1 & -0.7 & -3.2 \\
\hline MAE & 5.5 & 5.5 & 5.8 & 5.8 & 5.5 & 6.0 \\
\hline RMSE & 6.5 & 6.5 & 6.9 & 7.1 & 6.5 & 7.8 \\
\hline Diff. & 0.3 & 4.3 & 2.1 & 4.0 & 2.2 & 2.2 \\
\hline
\end{tabular}

Abbreviations: DeadInc $=$ dead trees and shrubs observations included in the tree and shrub classes; GalletaSH $=$ galleta grass (recorded as PG [perennial grass]) included in the shrub class; LitterBG = litter (recorded as D [duff]) included in the bare ground class; Other = cover types other than tree, dead tree, shrub, dead shrub, and galleta grass aggregated in the "other" class; NPV = non-photosynthetic vegetation; ME = mean error; MAE = mean absolute error; RMSE = root mean squared error; Diff. $=$ difference between MAE and RMSE; NA = not applicable.

Reference data for validating desert pavement were manually delineated in the 2014 VHSR image based on observations during the 2015 field work and image interpretation. Field observation from previous field work was also used to delineate desert pavement. A total of 74 desert pavement polygons that equate to $593,768 \mathrm{~m}^{2}$ were delineated for validation. Because the reference data were generated primarily based on field observations and assisted by image interpretation, the reference data were distributed near the access roads. 


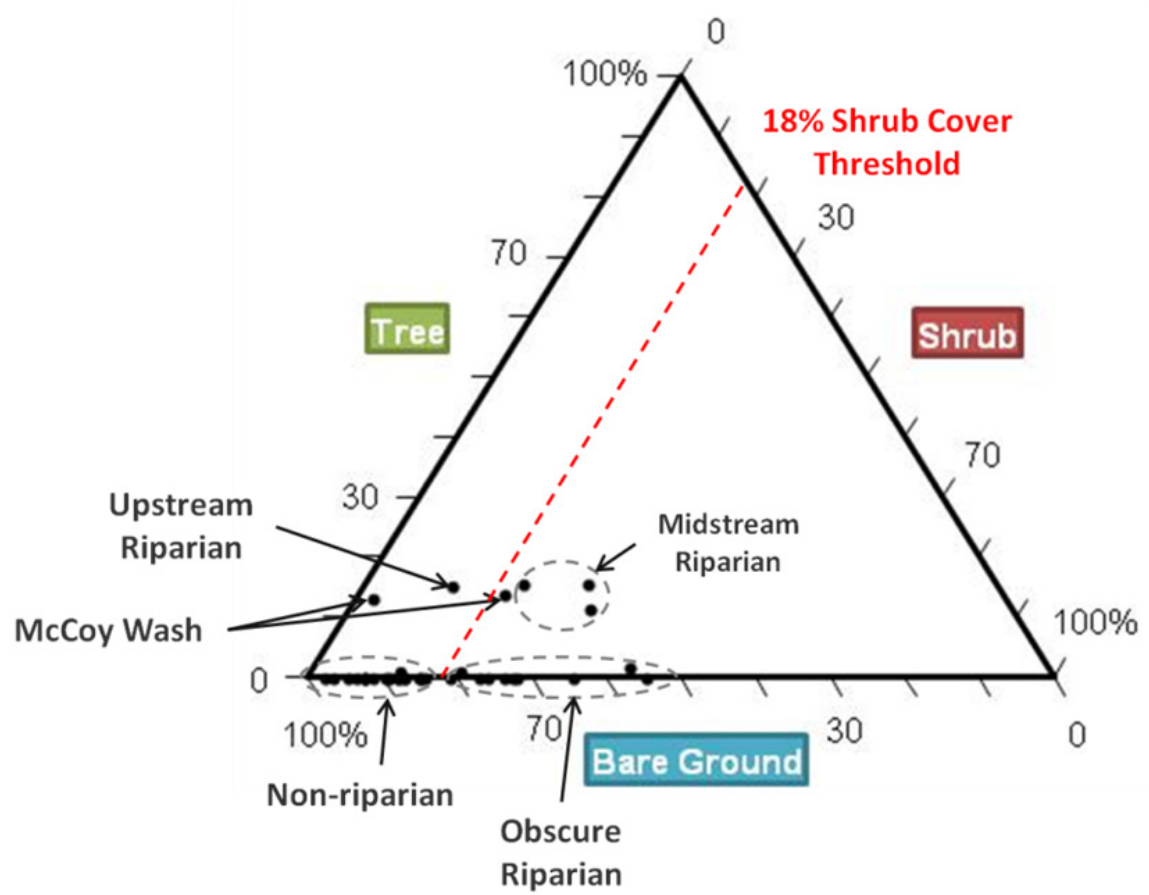

FIGURE 7 Ternary Plot of Tree, Shrub, and Bare Ground Cover Fractions (The plot was generated from the 3-class fractional cover estimates.)

The results show the strong utility of remote sensing for mapping desert pavement (Table 8). Overall accuracy of desert pavement detection was $89 \%$ with $K=0.79$. High producer's accuracy $(90 \%)$ and user's accuracy $(89 \%)$ suggest that there is no over- or underdetection of desert pavement. The current land cover classification algorithm, which is a part of the fractional cover estimate routine, is effective for mapping desert pavement distribution without refinement.

\subsection{VALIDATION OF BIOLOGICAL SOIL CRUST}

Biological Soil Crust Index (BSCI; Chen et al. 2005) and Crust Index (CI; Karnieli et al. 1999) were previously computed using the 2014 VHSR image (Table 9). To validate biological soil crust potential predicted from the VHSR image, the fractional cover of biological soil crust estimated in the field using a $40-\mathrm{cm} \times 40-\mathrm{cm}$ plot was compared with the BSCI and CI values.

The results show inconsistent correlations between cover fractions of biological soil crust and both BSCI and CI for both 2012 and 2014 (Figure 8). The primary reason for this inconsistency, as well as very weak correlations, is primarily due to the extremely sparse distribution of biological soil crusts in the study area (Figure 9). Clusters of crusts are too small for the spatial resolution of the image $(15 \mathrm{~cm})$ to resolve. A very low density of such small 
TABLE 8 Accuracy of Desert Pavement Map from January 2014 Image

\begin{tabular}{ccccccc}
\hline & Kappa & $\begin{array}{c}\text { Overall } \\
\text { Accuracy }\end{array}$ & $\begin{array}{c}\text { Producer's } \\
\text { Accuracy } \\
\text { (Sensitivity) } \\
(\boldsymbol{K})\end{array}$ & $\begin{array}{c}\text { User's } \\
\text { Accuracy } \\
(\text { Precision) } \\
(\mathbf{\%})\end{array}$ & $\begin{array}{c}\text { False } \\
\text { Positive } \\
\text { Rate } \\
(\%)\end{array}$ & $\begin{array}{c}\text { False } \\
\text { Negative } \\
\text { Rate } \\
(\%)\end{array}$ \\
\hline Desert pavement & 0.79 & 89.3 & 89.7 & 89.1 & 10.9 & 10.3 \\
\hline
\end{tabular}

TABLE 9 Spectral Index for Predicting Soil Crust Distribution

\begin{tabular}{ccc}
\hline Remote Sensing Metric & Definition & Reference \\
\hline Biological Soil Crust Index (BSCI) & $\frac{1-L \times\left|\rho_{\text {red }}-\rho_{\text {green }}\right|}{\left(\rho_{\text {green }}+\rho_{\text {red }}+\rho_{\text {NIR }}\right) / 3}$ & Chen et al. 2005 \\
Crust Index (CI) & $1-\frac{\rho_{\text {red }}-\rho_{\text {blue }}}{\rho_{\text {red }}+\rho_{\text {blue }}}$ & Karnieli et al. \\
& 1999 \\
\hline
\end{tabular}

clusters would not produce strong enough spectral signals to be detected by the camera. Therefore, we concluded that this study area is not suitable for testing true effectiveness of the BSCI and CI for mapping biological soil crust potential.

\subsection{VALIDATION OF EPHEMERAL STREAM CHANNELS}

\subsubsection{Validating Ephemeral Channel Distribution}

Argonne's previously developed ephemeral channel extraction algorithm integrates knowledge about desert landscapes, such as abundance and spatial configuration of vegetation and surface color of the ground, as a series of image transformations and statistical operations (Hamada et al. 2014; Hamada and Grippo 2015a). The algorithm produces a vector map representing centerlines of ephemeral stream channels in desert environments.

Reference data for validating ephemeral channel distribution were generated by delineating channel centerlines based on field observations and visual interpretation of the 2014 VHSR image. A total of 35 channel centerlines were delineated, 5 of which were surveyed during the 2015 field work. The reference channel length ranges from $19 \mathrm{~m}$ to $1,747 \mathrm{~m}$, and the mean and standard deviation are $383 \mathrm{~m}$ and $422 \mathrm{~m}$, respectively. Because the reference data were generated primarily based on field observations, they were distributed near access roads and small segments of the major wash, where field data were collected. The channel centerlines extracted from Argonne's algorithm were overlain with the reference channel centerlines. A fundamental criterion that we applied was that the extracted centerlines or line segments exactly overlapping with or located within $5 \mathrm{~m}$ of the reference centerlines were determined to be 
BSCI (2012)

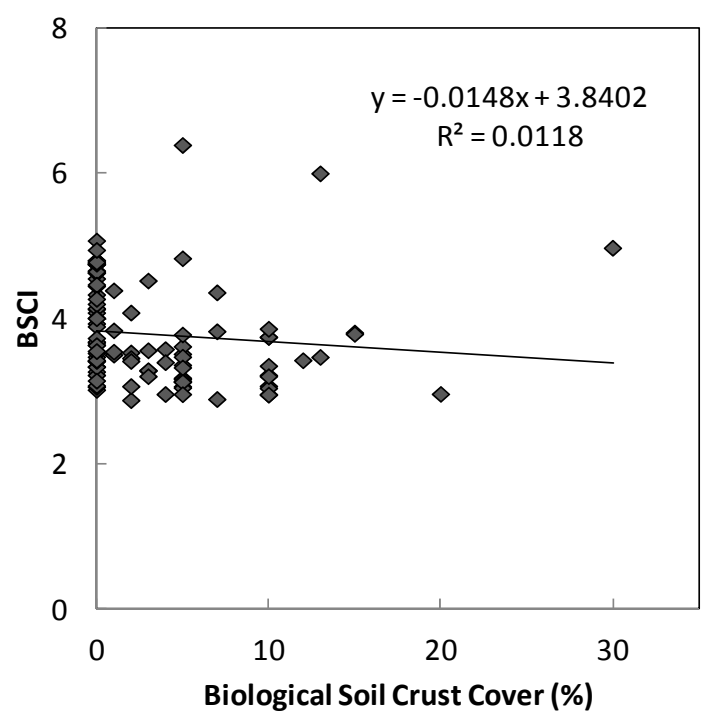

Cl (2012)

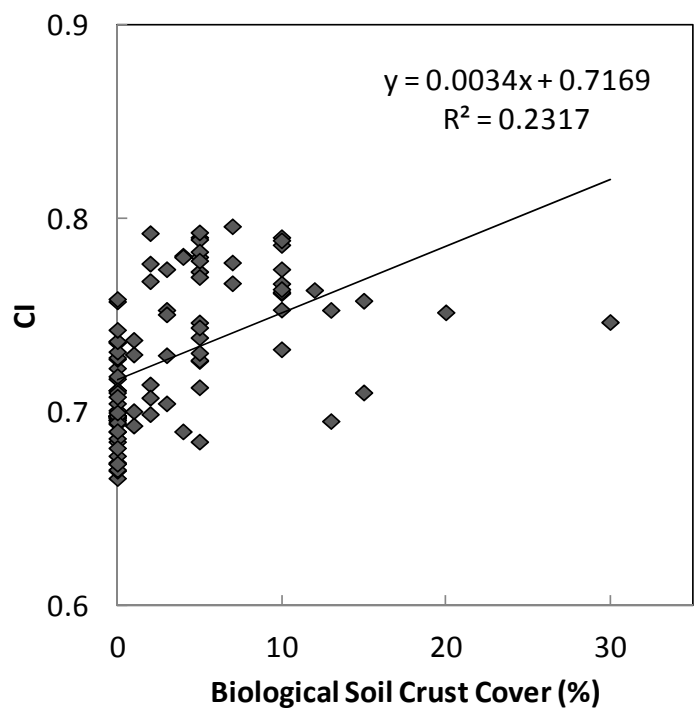

BSCI (2014)

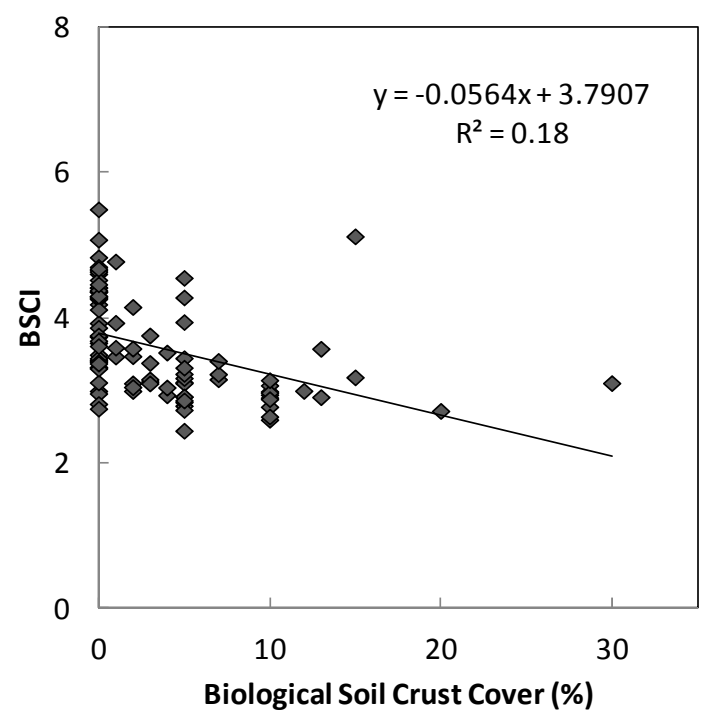

Cl (2014)

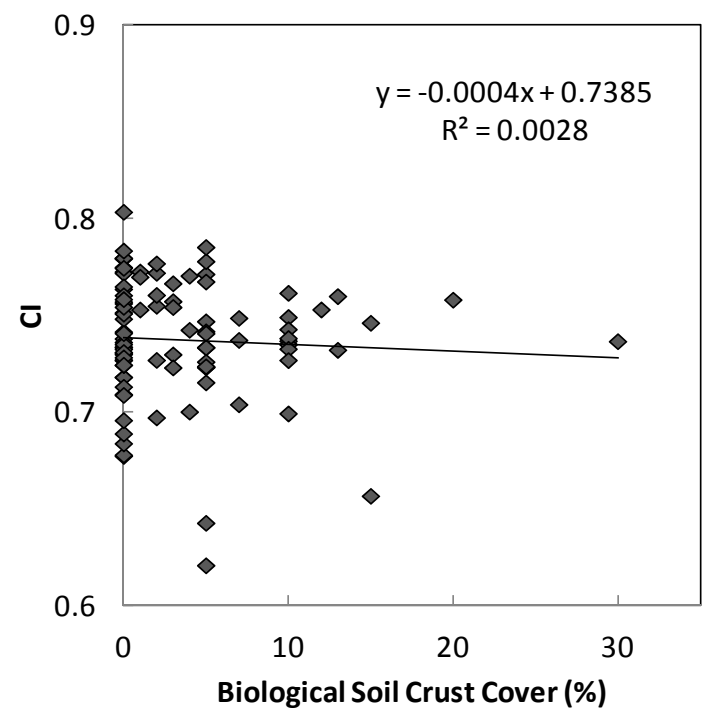

FIGURE 8 Correlation between Biological Soil Crust Cover Estimated Using 2015 Field Data and Spectral Indices (Biological Soil Crust Index [BSCI] and Crust Index [CI] derived from very high resolution multispectral image mosaics.) 


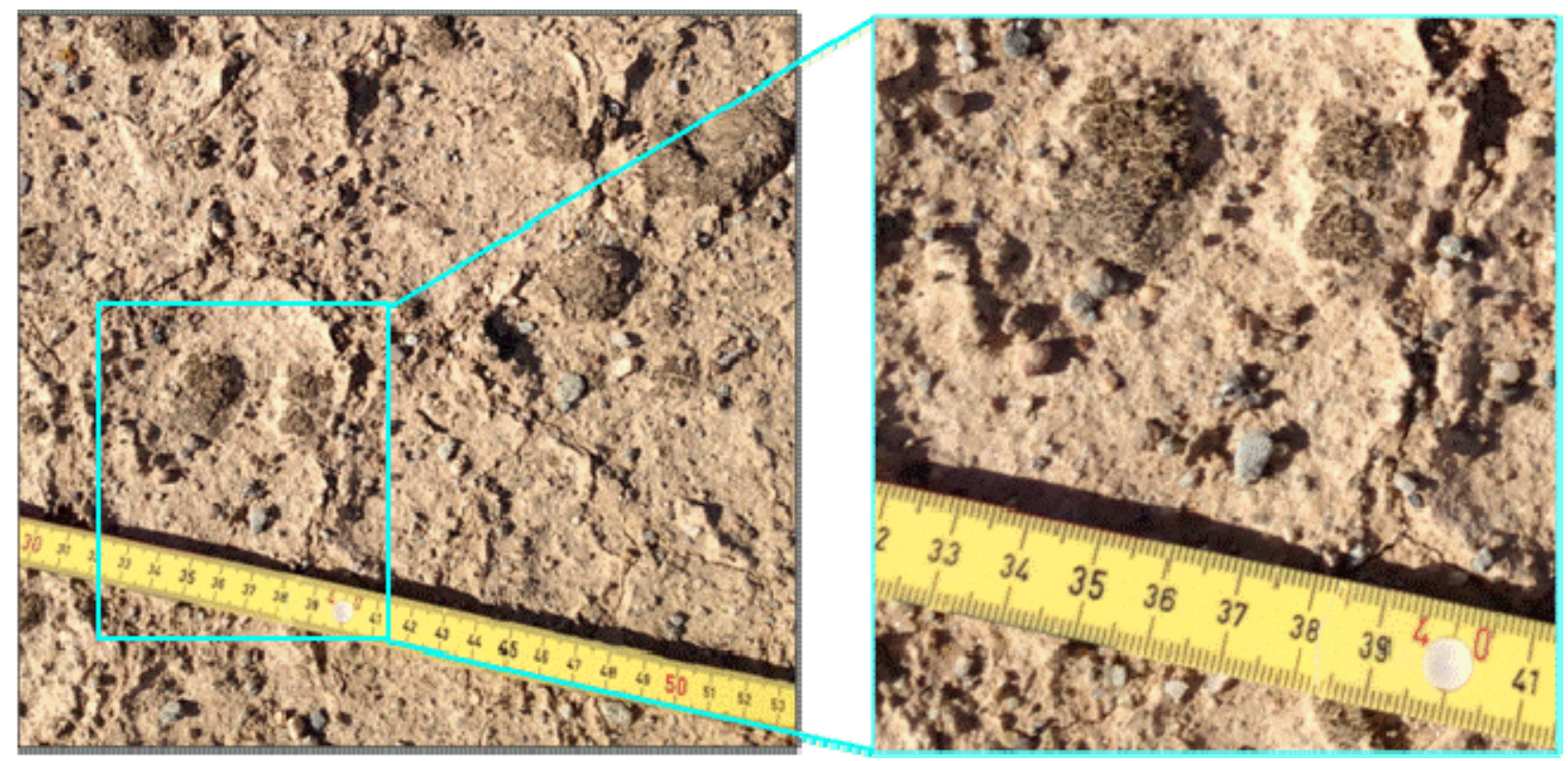

FIGURE 9 Examples of Biological Soil Crusts in the Study Area (Individual crusts are typically a few centimeters in diameter, which are not resolved in a $15-\mathrm{cm}$ resolution image. These small crusts form sparse clusters that are unevenly distributed across the landscape in the study area.)

successful channel identification. The 5-m distance freedom was applied in order to mitigate uncertainty in positional accuracy of the VHSR image and reference channel centerlines.

The results showed that detection accuracy varies widely depending on the threshold for "success.' Figure 10 shows the relationship between the threshold for "success" (i.e., \% minimum extraction length) and the channel detection accuracy (i.e., count of correctly detected channels). For example, when we applied $50 \%$ of the reference channel length as a threshold to determine success, the detection accuracy was around $80 \%$, or approximately 28 correctly detected channels. When we applied a stricter threshold, such as $70 \%$, the accuracy was $58 \%$ or approximately 20 correctly detected channels. Based on the visual comparison between extracted channels and reference channels, three independent analysts identified $87 \%$ to $89 \%$ of the reference channels as accurately detected by the algorithm.

The results also revealed strengths and weaknesses of the ephemeral stream extraction algorithm and the need for a multi-scale approach and interdisciplinary collaborative effort. Ephemeral channels extracted using Argonne's ephemeral channel extraction algorithm appeared to complement those in the U.S. Geological Survey's National Hydrography Dataset (NHD) (USGS 2008) (Figure 11). Large stream channels exhibiting varying vegetation density and a mixture of single and multiple braided channels (e.g., McCoy wash) were not correctly detected by Argonne's algorithm because typical characteristics of those streams showed extreme heterogeneity in the VHSR images. Although fine-resolution images are able to capture details, the spectral and contextual variability within ephemeral channels likely exceeds that across landscape types in a VHSR image. Thus, a coarse-scale method that generalizes the heterogeneity, such as the NHD, is more suitable for mapping large streams. In contrast, 

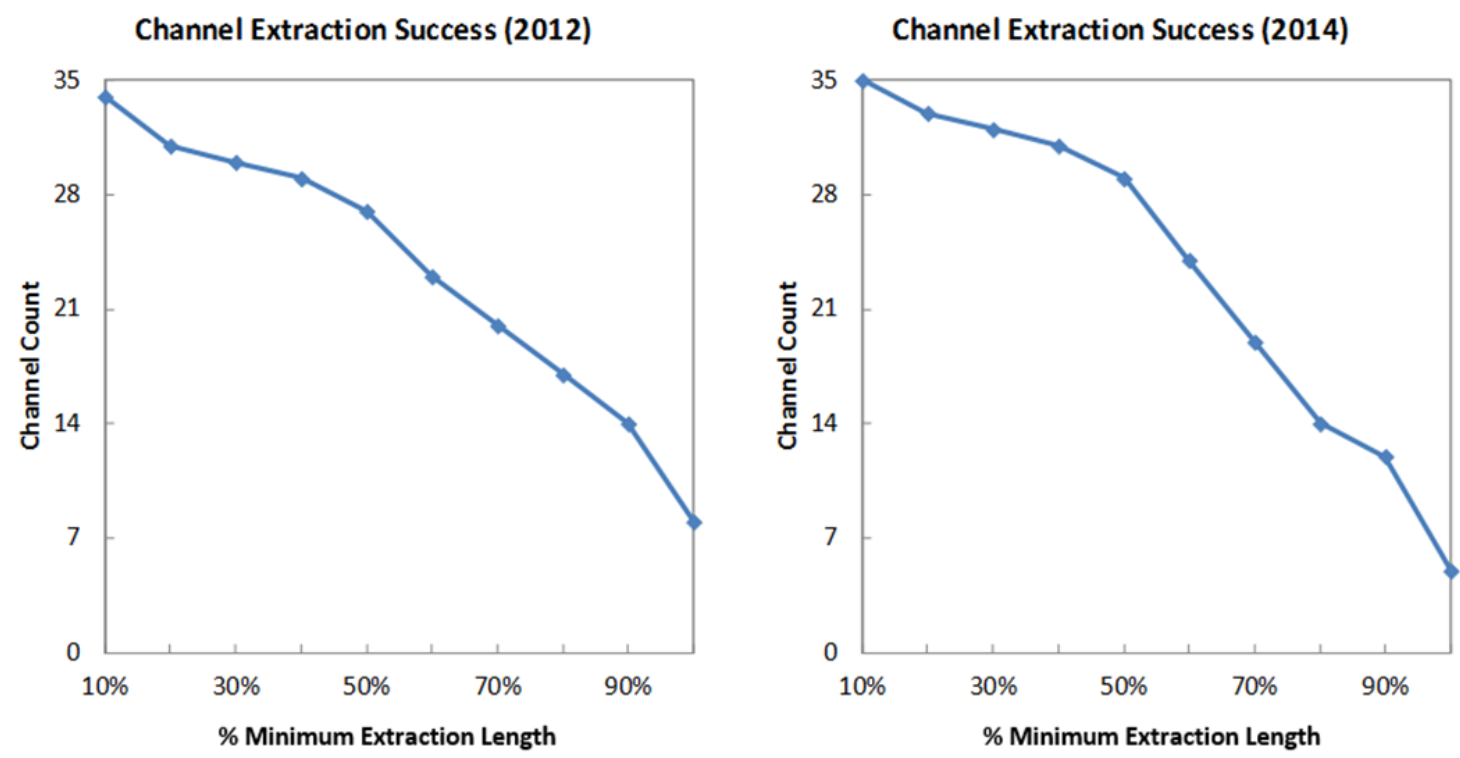

FIGURE 10 Accuracy of Ephemeral Channel Detection Using Very High Resolution Images (Variability across thresholds of correct detection is shown in $10 \%$ increments. The accuracy is determined by the number of correctly detected channels.)

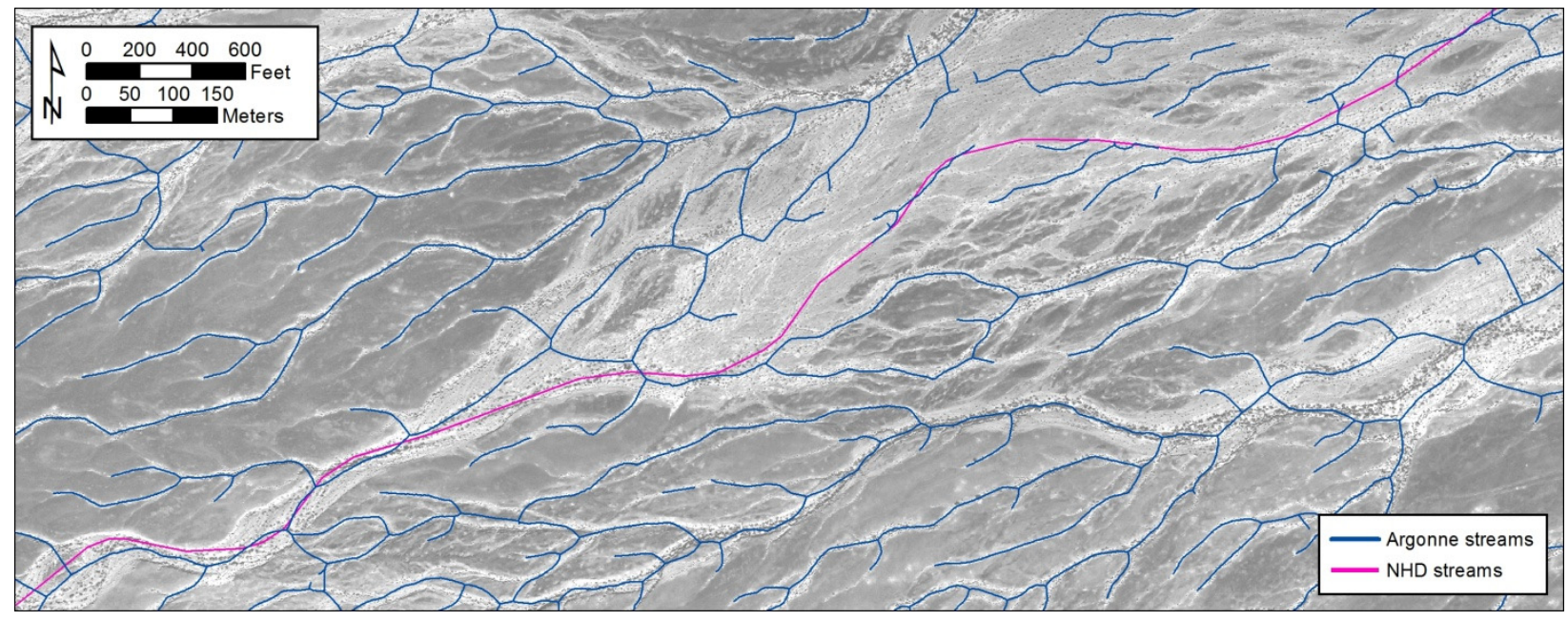

FIGURE 11 Ephemeral Stream Channels Generated by the National Hydrography Dataset (NHD) and Argonne's Algorithm

relatively well-defined streams with strong contrast from surrounding areas were accurately extracted using Argonne's algorithm. Many of these streams are not mapped in the NHD because, in coarse images, these narrow channels are dissolved in their surrounding cover types (e.g., scrubland and desert pavement). They are narrow, yet exhibit characteristics of typical riparian habitats and contain important shrub species in the region. This complementary nature of the two methods suggests that a multi-scale consensus approach that integrates a coarse-scale 
NHD and the fine-scale Argonne algorithm would create the optimal ephemeral stream maps for desert environments.

There are noticeable false positives (or over classification) of ephemeral stream channels in the map generated using Argonne's ephemeral channel extraction algorithm. Figure 11 shows some extra lines within a large wash. Developing solutions to over classification would require at least one of the following: (1) a definition of ephemeral streams in desert regions, (2) conservation priority of ephemeral streams, and (3) clear monitoring objectives for ephemeral streams. Successful solutions would likely be developed through iterative processes with an interdisciplinary team, based on which ephemeral streams are important for water and ecological resources management, what remote sensing can and cannot map, and what and how much information field survey data can provide.

\subsubsection{Validating Ephemeral Channel Width}

Argonne's ephemeral channel extraction algorithm was primarily developed to detect locations of ephemeral stream channels. The algorithm produces polygons that may represent stream areas in an intermediate product during the raster-to-vector conversion process. The width of channels may be calculated using the polygons.

Reference data for validating ephemeral channel width were created by reviewing GPS survey points collected at three to five points per cross section in a diagonal fashion during the 2015 field survey. The outer GPS points indicating the edge of the channel were used to measure channel widths. Channel width is defined as the distance of channels perpendicular to the channel centerline. A total of 45 channel cross sections within 4 channel segments, which contain a range of widths, were initially used to obtain reference channel width data. The reference channel width ranged from $2.1 \mathrm{~m}$ to $51.9 \mathrm{~m}$, and the mean and standard deviation were $10.9 \mathrm{~m}$ and $12.4 \mathrm{~m}$, respectively. Because the reference data were generated primarily based on field observations, they were distributed near access roads and small segments of the major wash, where field data were collected. The reference data were overlain with the 2014 VHSR image to examine overall agreement within the landscape. The channel widths that were estimated from Argonne's algorithm were extracted to the reference cross sections.

The results showed that the width of ephemeral stream channels obtained using VHSR remote sensing was weakly, yet positively correlated with the reference channel width $\left(R^{2}=0.28\right)$ (Figure 12). Although the relationship between the reference and estimated channel width was relatively consistent (slope $=0.84$ ), it was strongly biased (intercept $=-12.4$ ). The ME $(6.1 \mathrm{~m})$ suggested a trend of overestimation using the remote sensing method. MAE and RMSE of channel width estimates were $10.9 \mathrm{~m}$ and $15.7 \mathrm{~m}$, respectively, which indicates the potential presence of outliers.

The noticeable discrepancy in channel width estimates strongly suggests the limitation of the current approach. Channel width is estimated as the width of a channel polygon, which was derived as part of the ephemeral channel extraction algorithm. The algorithm incorporates the presence of riparian corridors, which does not necessarily linearly correlate with channel width. 


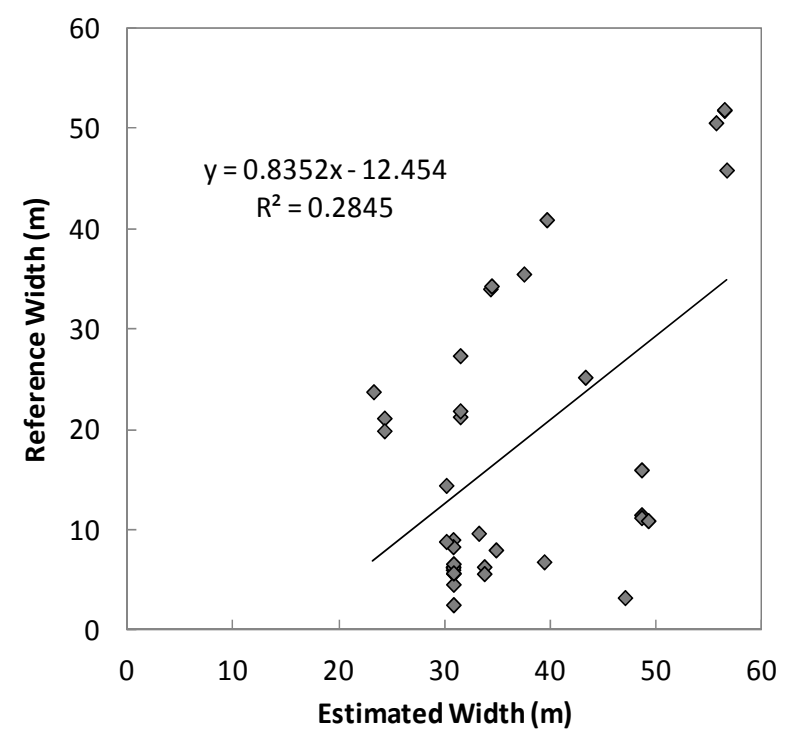

FIGURE 12 Correlation between Reference

Channel Width and Channel Width

Estimated Using Remote Sensing

To reduce false negatives (or misdetections) for extracting ephemeral streams, a 3-m buffer was incorporated into the algorithm, which likely resulted in overestimation of channel width. Thus, to reliably estimate channel width, it is recommended to develop a highly precise Light Detection and Ranging (LiDAR) technology or photogrammetric approach, although the mapping/monitoring extent may be limited to a small number of channels within a limited extent.

\subsection{ANALYSIS OF SURFACE STABILITY}

Argonne previously developed the ERI as a surface stability indicator to assess erosion risks in desert landscapes (Hamada et al. 2014; Hamada and Grippo 2015b). The index was developed by applying trigonometry to the combination of the green-red band ratio and the green-near-infrared band ratio from VHSR multispectral imagery. The resultant ERI maps showed spatially cohesive distributions of high and low index values across the study areas. High index values were observed over areas that were resistant to erosion, such as desert pavement and dense vegetation, whereas low index values overlapped with areas that were likely dominated by loose sandy soils, such as streambeds and access roads.

Unlike other landscape variables discussed above, the purpose of the analysis for surface stability was to understand how ERI values are associated with physical environments such as relative surface composition (i.e., proportional cover of materials on the ground) in desert land surface. To analyze the association with ERI, fractional covers of 10 surface materials were calculated based on the field data collected using a $40-\mathrm{cm} \times 40-\mathrm{cm}$ plot and field photo interpretation. The 10 surface materials consisted of live and dead vegetation, biological and physical crust, compact and loose soil, litter, and rock or pebble approximately $<1 \mathrm{~cm}, 1 \mathrm{~cm}$ to 
$5 \mathrm{~cm}$, and $>5 \mathrm{~cm}$, all of which are considered to have a different erosion potential (Table 10). These surface materials were also merged into three categories - vegetation, soil, and rock - to examine association with ERI. The analysis was performed using the data extracted from 48 survey locations that cover a range of material fractions. However, fractional cover of vegetation, litter, and physical and biological soil crust were very limited in our study area. Therefore, the surface materials that did not provide sufficient samples were excluded from the analysis during a multiple linear regression analysis.

The pair-wise correlation analysis of ERI and relative surface composition of the 10 surface material types (Table 10) showed that there is not a consistent relationship between ERI and any of the surface materials (Table 11). Correlation of determination $\left(R^{2}\right)$ ranged from 0.01 (live vegetation and litter) to 0.65 (rock fragment smaller than $1 \mathrm{~cm}$ ). Dead vegetation and rock with an approximately 1 - to 5 -cm diameter were the only two materials that had statistically significant correlations $(p<0.01)$. When stratifying the surface materials into three categories based on the scheme described in Table $10, R^{2}$ ranged from 0.03 (rock) to 0.54 (vegetation). Soil consisting of physical crust, compact and loose soil, and litter had $R^{2}=0.44$ with $p=0.004$, which suggests greater correlation with ERI than that of each surface material examined independently.

The multiple linear regression analysis of the 10 surface material types and the 3 merged categories indicated that vegetation, soil, and rock smaller than $1 \mathrm{~cm}$ were significant predictors for ERI $(p<0.01)$. The regression model describing ERI was as follows:

$$
E R I=0.06883 \times \text { Vegetation }-0.01156 \times \text { Soil }-0.08584 \times \text { Rock }<1 \mathrm{~cm}+0.10742
$$

The model showed an $F$-value of 17.86 with statistical significance $(p<0.001)$ and an $R^{2}$ value of 0.55 with standard error $(S E)$ of 0.03 . The composition of three surface materials-

TABLE 10 Surface Materials Analyzed for Correlation with Erosion Resistance Index

\begin{tabular}{ll}
\hline Surface Material & Aggregated Category \\
\hline $\begin{array}{l}\text { Live vegetation } \\
\text { Dead vegetation }\end{array}$ & Vegetation \\
\hline Biological soil crust & Biological soil crust \\
\hline Physical crust & Soil \\
Compact soil & \\
Loose soil & \\
Litter & \\
Rock approximately $<1 \mathrm{~cm}$ & Rock \\
Rock approximately $1-5 \mathrm{~cm}$ & \\
Rock approximately $>5 \mathrm{~cm}$ & \\
\hline
\end{tabular}


TABLE 11 Correlation between Erosion Resistance Index Value and Fractional Cover of Surface Material

\begin{tabular}{lcclcc}
\hline Surface Material & \multicolumn{5}{c}{ Merged Category } \\
\hline Live vegetation & $R^{2}$ & $p$ & & $R^{2}$ & $p$ \\
Dead vegetation & 0.01 & 0.544 & Vegetation & 0.54 & 0.063 \\
\hline Biological soil crust & 0.54 & 0.000 & & & \\
\hline Physical crust & 0.07 & 0.754 & Biological soil crust & 0.07 & 0.754 \\
Compact soil & 0.06 & 0.809 & Soil & 0.44 & 0.004 \\
Loose soil & 0.19 & 0.304 & & & \\
Litter & 0.23 & 0.573 & & & \\
\hline Rock approximately $<1 \mathrm{~cm}$ & 0.65 & 0.028 & Rock & 0.03 & 0.461 \\
Rock approximately $1-5 \mathrm{~cm}$ & 0.04 & 0.001 & & & \\
Rock approximately $>5 \mathrm{~cm}$ & 0.02 & 0.084 & & & \\
\hline
\end{tabular}

vegetation, soil, and rock - smaller than $1 \mathrm{~cm}$ can explain $55 \%$ of the variation in ERI values with an average deviation of 0.03 . The model also showed that the amount of vegetation is positively correlated with ERI, which suggests that vegetation cover provides surface stability. Exposed soil and small rocks were negatively correlated with ERI, which suggests that lands that are largely covered with these materials have a high risk of erosion.

Challenges in examining the association between ERI and physical environments, such as composition of surface materials in desert environments, included the limitation of sufficient data representing a range of composition of surface materials. For live vegetation, litter, and physical and biological soil crust, only a small range of fractional cover was represented in the samples despite our best effort to sample a range of surface materials. This constraint certainly limited our analysis.

The composition of surface materials is one of many parameters of physical environments. How land surface interacts with light (known as spectral responses) is determined primarily by organic matter content, moisture content, mineral composition, and surface roughness. Desert land surface is often covered with loose sandy soil, crusty soil, and rock fragments (i.e., desert pavement) with limited plant materials. Spectral responses of such arid land are primarily influenced by two factors: (1) mineral composition determining the color of materials, and (2) surface roughness determined by the size of rocks and pebbles and compactness of soil. In our study area, highly stable bare ground, such as desert pavement and surface dominated by large rock fragments, is often characterized by dark-colored, rough surfaces, while erodible bare ground, such as streambeds and disturbed surfaces, is characterized by a mixture of small rock fragments and sandy soil or compact soil, both of which exhibit relatively smooth surfaces. Some exceptions include sandy streambeds containing a few rocks larger than $5 \mathrm{~cm}$ and open scrublands with tightly packed, very small, dark-colored rock fragments. These plots are examples of spectral responses more strongly influenced by mineral 
composition than generalized material composition; thus, their ERI values were explained very well using material composition.

The analysis revealed that ERI cannot be explained solely by the composition of surface materials (e.g., rocks, exposed soil, and vegetation) because of the complexity of spectral responses at a fine scale. When applying coarser scale categories or landscape context, such as desert pavement, scrubland, and ephemeral stream, however, ERI corresponds to expected risk of surface erosion described in Hamada et al. (2014) and Hamada and Grippo (2015b). This coarsescale or contextual relationship between a spectral index and landscape characteristics was also observed in earlier studies using the Soil Stability Index conducted by Dube (1994), Pickup and Nelson (1984), and Washington-Allen et al. (2010). Thus, the ERI provides insights into the risk of erosion because there is a consistent relationship between spectral responses and physical environments, such as materials and their properties, which are associated with surface stability or surface conditions (e.g., intact or disturbed desert pavement, erodible surface that is made of depositions transported by water and wind).

\subsection{SUMMARY OF VALIDATION AND ANALYSIS OF PREVIOUSLY GENERATED REMOTE SENSING PRODUCTS}

As described in Sections 5.1 through 5.6, we have conducted validation using the 2015 field data for products representing six land resource properties that were derived from the 2012 and/or 2014 VHSR multispectral aerial images: (1) vegetation distribution, (2) canopy height, (3) fractional cover of surface types, (4) desert pavement distribution, (5) biological soil crust potential, and (6) ephemeral stream channel distribution and width. We also performed analysis of ERI to determine the association of the index with surface materials. Our findings from the validation and analysis of previously generated remote sensing products were as follows:

1. The accuracy of the vegetation distribution was fairly high for less vigorous vegetation of desert landscape ( $K$ and overall accuracy as high as 0.55 and $77 \%$, respectively). The accuracy might be improved by adjusting threshold values of SVIs, particularly for VARI (overall accuracy 77\%), which could further improve fractional cover estimates of surface types $\left(R^{2}=0.61-0.78\right.$, RMSE $=4.2 \%-7.8 \%$ absolute cover for the tree-shrub-bare ground classification). This method for further improving the accuracy of the vegetation distribution estimate is evaluated in Section 6.1.

2. The accuracy of the canopy height estimate $\left(R^{2}=0.72, \operatorname{RMSE}=2.86 \mathrm{~m}\right)$ might be improved by predicting surface elevation under canopies from the DSM by applying a vegetation mask and a spatial interpolation technique. This methodology for improving the canopy height estimate is evaluated in Section 6.2. 
3. The current methodology for mapping desert pavement, as a part of the land cover classification routine, is very effective without refinement $(K=0.79$, overall accuracy $=89 \%$ ).

4. The study area is not suitable for evaluating the effectiveness of the BSCI and CI for mapping biological soil crust potential because the distribution is very sparse across the landscape.

5. Argonne's algorithm alone may not be optimal for accurately mapping diverse ephemeral stream types in desert regions. Accuracy of ephemeral channel extraction would be improved by developing a consensus approach integrating NHD's ability to capture major stream channels and the Argonne algorithm's capability of detecting fine-scale stream channels. Argonne's algorithm, which was developed for extracting ephemeral stream centerlines, is not very effective for estimating channel width.

6. The composition and abundance of surface materials with varying erosion resistance (e.g., vegetation, soil, and rock) explain approximately $55 \%$ of the variability in ERI. Other factors such as mineral composition in soil and rocks and soil moisture content contribute to the index. Although surface materials are not solo determinants, surface stability or conditions appeared to have consistent spectral responses, which can be captured by ERI. 
This page intentionally left blank. 


\section{REFINEMENT OF REMOTE SENSING METHODOLOGY}

Based on the findings discussed in Section 5, we evaluated refinements to our methodologies for estimating vegetation distribution and canopy height. We did not anticipate noticeable improvement in the accuracy of surface cover type fractions, because improvement of accuracies for vegetation distribution and canopy height was marginal. Therefore, we did not re-estimate the fractional cover of surface types. Although the ephemeral channel extraction algorithm may be improved, the task requires additional information from experts as discussed in Section 5.5, and the development of a new methodology is beyond the scope of our current effort.

\subsection{VEGETATION DISTRIBUTION}

The current image processing routine for mapping vegetation distribution using VHSR imagery was refined by (1) updating the threshold index value to differentiate vegetation from non-vegetation in the image, and (2) including an additional filtering step using ERI. The refinement was made only using VARI, which was determined to be the optimal SVI for vegetation detection in our previous study. The index also showed consistent underestimation of vegetation both in the 2012 and 2014 images, which suggests lowering the minimum threshold value would compensate for the underestimation and improve the accuracy regardless of the year of image collection. Previously VARI $>0.22$ was considered vegetation in the classification routine. The value was interactively decreased to VARI $>0.18$ to compensate for underestimation of vegetation for refinement. The preliminary vegetation distribution map using the lowered threshold value showed noticeable overestimation of vegetation or false positive, particularly in some desert pavement areas (Figure 13, top). In order to mitigate confusion between shaded vegetation and desert pavement, both of which appear as dark features in the image, areas having ERI $>0.22$ were masked out from the final vegetation distribution map (Figure 13, bottom).

Figure 14 shows the final vegetation distribution maps before and after the refinement. Overall, vegetation distributions were comparable in the two maps. A few clusters of dense vegetation that do not correspond to riparian corridors can be observed in the refined map. Those clusters overlap with desert pavement near the center and some dark surface at the southeastern corner of the study area. The refined methodology detected small or less vigorous shrubs (Figure 14, top close view). The refined methodology is more inclusive of canopy edges than the previous methodology, and also detected shaded vegetation, particularly in sparse tree canopies better than the previous methodology (Figure 14, bottom close view). Lowering the index threshold compensated for underestimation of vegetation by detecting shaded and less vigorous desert vegetation; however, it also increased misclassification of dark surfaces as vegetation. The near infrared (NIR) band used in the vegetation index, which is known for its effectiveness for differentiating vegetation, has a limited effect. The trade-off did not appear beneficial according to the accuracy measures (Table 12). The change was minimal, but the accuracy of vegetation detection decreased slightly after the refinement of the methodology across the measures. 


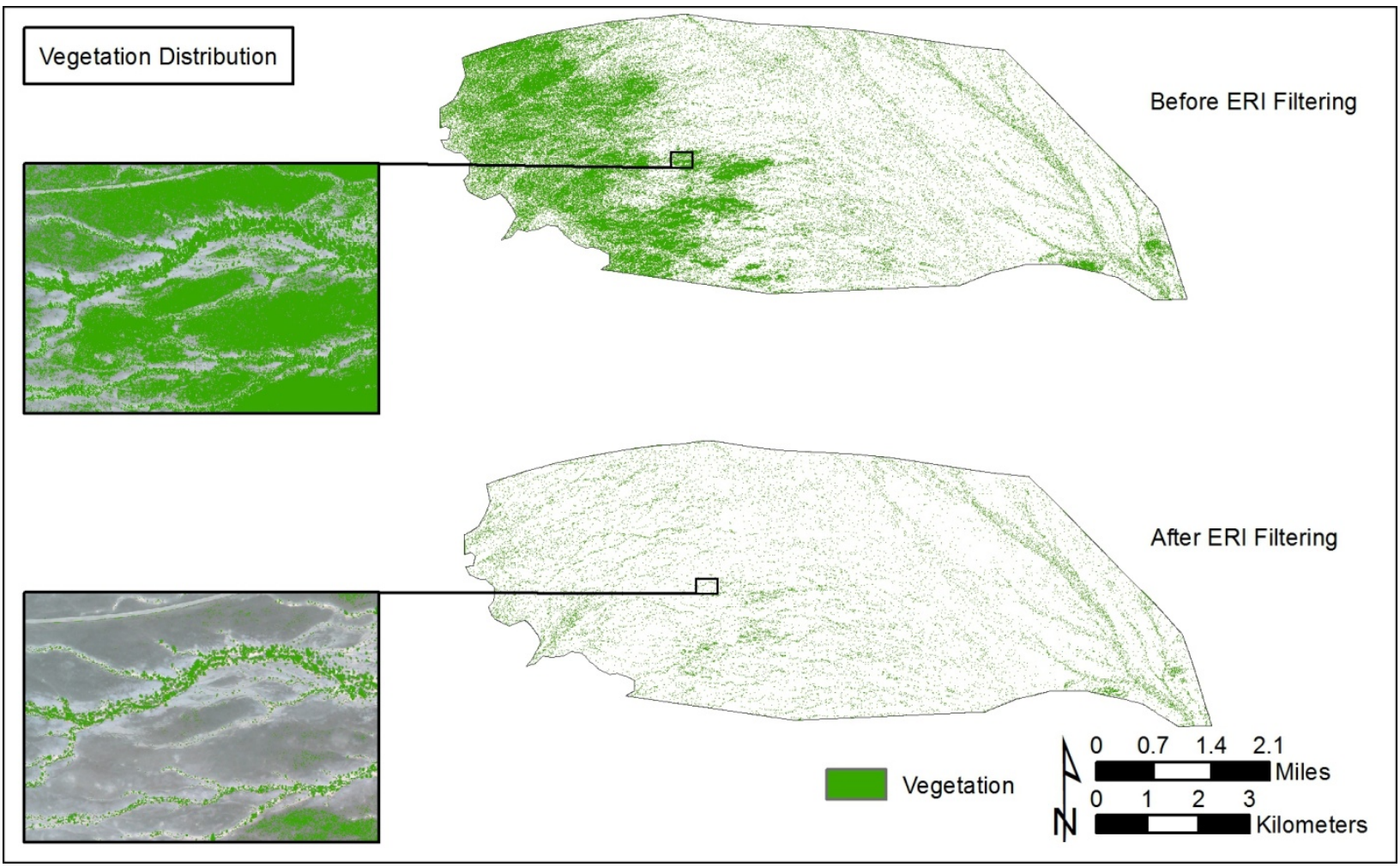

FIGURE 13 Refined Vegetation Distribution Map Generated Using Visible Atmospherically Resistant Index before and after Filtering Based on Erosion Resistance Index

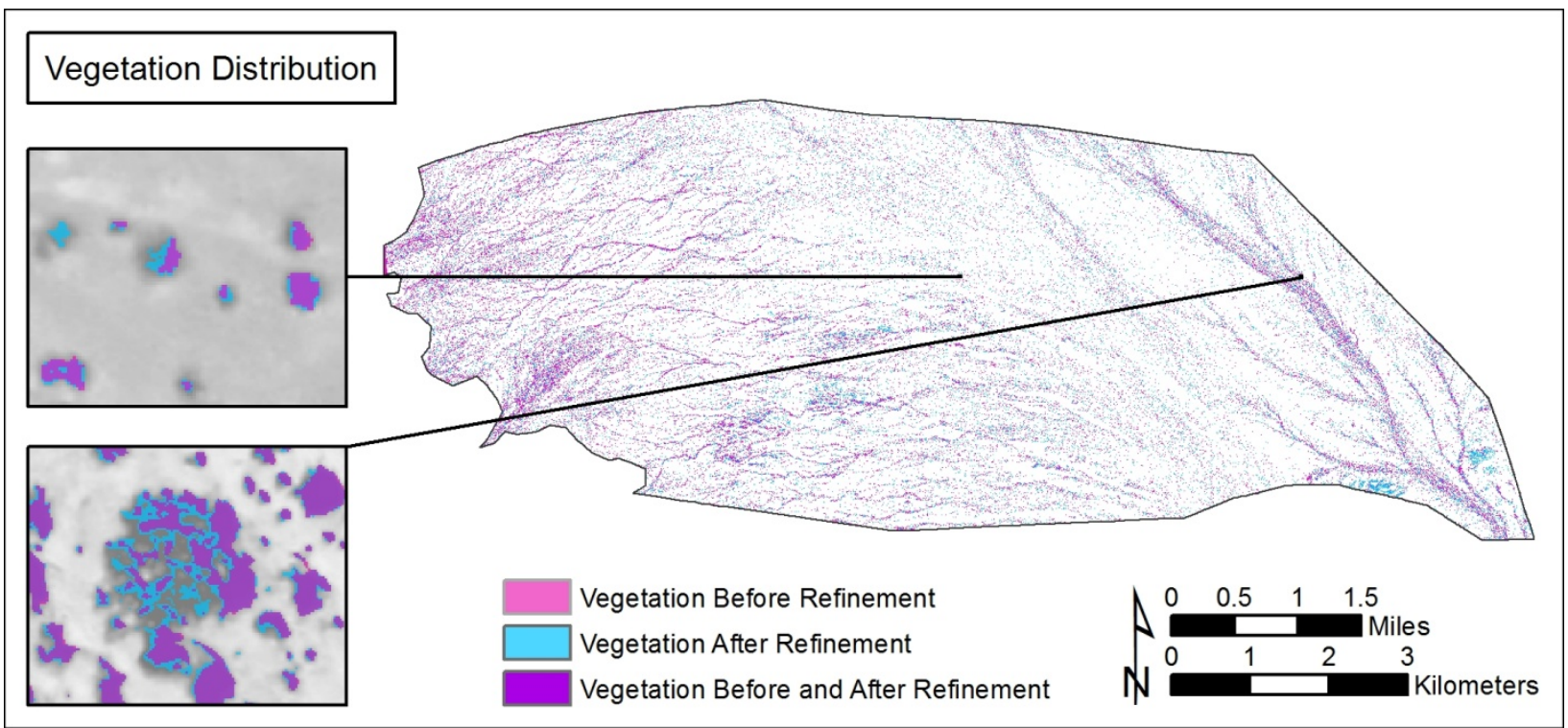

FIGURE 14 Vegetation Distribution Maps before and after Refinement of Methodology 
TABLE 12 Accuracy of Vegetation Distribution Maps before and after Refinement of Methodology

\begin{tabular}{lcccccc}
\hline January 2014 & & & & & & \\
\hline & $\begin{array}{c}\text { Kappa } \\
(\boldsymbol{K})\end{array}$ & $\begin{array}{c}\text { Overall } \\
\text { Accuracy } \\
(\boldsymbol{\%})\end{array}$ & $\begin{array}{c}\text { Producer's } \\
\text { Accuracy } \\
(\mathbf{\%})\end{array}$ & $\begin{array}{c}\text { User's } \\
\text { Accuracy } \\
(\mathbf{\%})\end{array}$ & $\begin{array}{c}\text { False } \\
\text { Positive } \\
\text { Rate } \\
(\%)\end{array}$ & $\begin{array}{c}\text { False } \\
\text { Negative } \\
\text { Rate } \\
(\%)\end{array}$ \\
\hline Previous & 0.53 & 77 & 73 & 79 & 22 & 27 \\
Refined & 0.52 & 76 & 72 & 78 & 22 & 28 \\
\hline
\end{tabular}

Therefore, we concluded that this refinement strategy for the vegetation detection methodology is not effective and unnecessary.

\subsection{CANOPY HEIGHT}

The previous image processing methodology for estimating canopy height was a simple subtraction of values of the DTM (2.5-m horizontal resolution) provided by the vendor from those of the DSM (0.73-m horizontal resolution). To refine the methodology, a DTM was generated from the DSM by adopting the technique described in Gillan et al. (2014).

The DSM was first converted into a point cloud. Vegetation canopies and patches that were identified by the vegetation detection algorithm described in Section 5.2.1 were deleted in the point cloud. The gaps in the point cloud were filled using an inverse distance weighting interpolation technique to model elevation under the vegetation canopies (Watson and Philip 1985). This resulted in a DTM representing approximate terrain elevation without vegetation. The DTM values were subtracted from the DSM values to create a layer representing height of vegetation canopies.

The results showed that the canopy height obtained using the refined methodology had slightly higher correlation with the reference height $\left(R^{2}=0.77\right.$; Figure 15) than the previous methodology $\left(R^{2}=0.72\right.$; Figure 5$)$. However, absolute height was an order of magnitude lower than the reference height, and the difference was even greater than the previous methodology (Table 13). The ME $(-2.83 \mathrm{~m})$ also suggests underestimation when using remote sensing. MAE and RMSE of canopy height estimates were $2.68 \mathrm{~m}$ and $3.45 \mathrm{~m}$, respectively, and a greater difference between ME and RMSE $(0.77 \mathrm{~m})$ than that from the previous methodology suggests the possible presence of extreme values in the validation samples. Based on the results and required processing time, the alternative methodology for estimating canopy height that we tested is not recommended for these particular image sets. However, the methodology could be effective if images were collected using specifications that were exclusively focused on height extraction. 


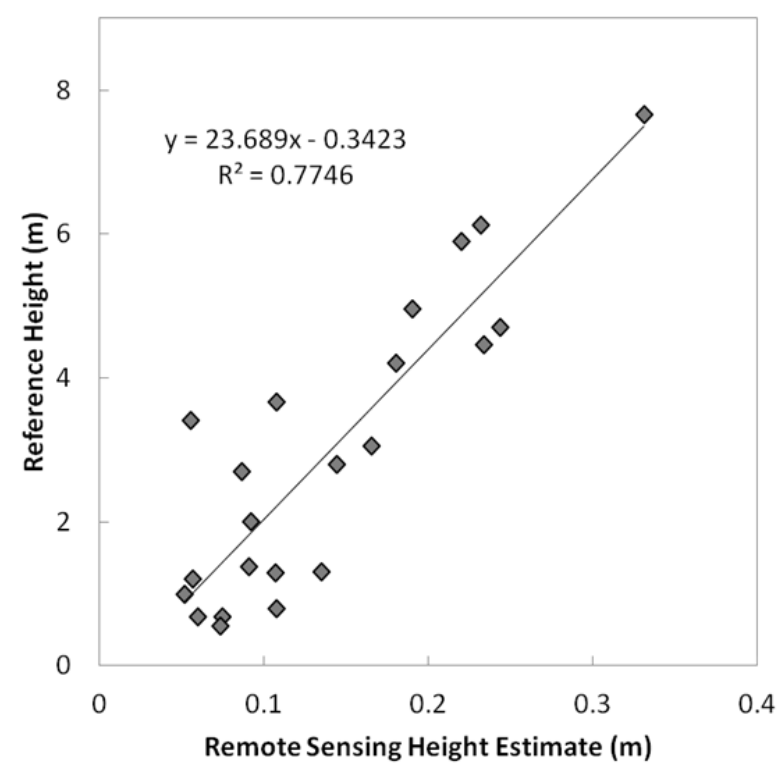

FIGURE 15 Correlation between Reference

Canopy Height and Canopy Height

Estimated Using Remote Sensing

TABLE 13 Accuracy of Canopy Height Maps before and after Refinement of Methodology

\begin{tabular}{lccccc}
\hline & $\boldsymbol{R}^{\boldsymbol{2}}$ & ME & MAE & RMSE & RMSE-MAE \\
\hline Previous & 0.71 & -2.83 & 2.83 & 2.86 & 0.03 \\
Refined & 0.77 & -2.68 & 2.68 & 3.45 & 0.77 \\
\hline
\end{tabular}

Abbreviations: $\mathrm{ME}=$ mean error; $\mathrm{MAE}=$ mean absolute error; $\mathrm{RMSE}=$ root mean squared error. 


\section{ANALYSIS OF VEGETATION ALLIANCES}

\subsection{BACKGROUND}

Using remote sensing, conditions of vegetation communities are often examined based on plant species abundance (Kilpatrick et al. 2015; Hamada et al. 2013) and richness (GodinezAlvarez et al. 2009; Hamada et al. 2013), plant life-form fractional cover (GodinezAlvarez et al. 2009; Ustin et al. 2009; Kilpatrick et al. 2015; Hamada et al. 2013; Frieswyk et al. 2007), the amount of exposed soil (Kilpatrick et al. 2015; Hamada et al. 2013) and aboveground biomass (Ustin et al. 2009), and/or presence of invasive plant species (Frieswyk et al. 2007). Because of the discontinuous nature of green vegetation in arid environments, SVIs calculated from remotely sensed images have been found to represent cover and canopy area more directly, which in turn may be related to biomass (Graetz 1990; Duncan et al. 1993). The discontinuous patterns of vegetation distribution are largely associated with distribution of accessible water across desert landscapes. In addition to overall distribution, spatial patterns of vegetation provide important information about conditions of vegetation communities (Phinn et al. 1996; Schlesinger et al. 1990; Roughgarden et al. 1991; Ustin et al. 1993). Using 15-cm multispectral aerial imagery, we characterized spatial patterns and abundance of vegetation for vegetation alliances within the study area and explored how the spatial patterns and abundance may be used to monitor changes in vegetation alliances in desert environments.

Three methods - visual interpretation of an SVI, summary statistics of surface cover fractions, and geostatistics (i.e., variogram) — were used for the analysis in conjunction with a VARI layer generated from the 2014 VHSR image. Visual interpretation of the VARI layer provides qualitative, yet detailed information about vegetation patterns such as overall canopy size, density, and spatial arrangement of plants that are characteristic of a specific vegetation alliance. Summary statistics provide overall information about vegetation and bare ground cover of alliances such as typical cover fractions and variability within an alliance. Geostatistics, specifically the variogram, help identify and quantify spatial patterns of plant canopies and patches by examining spatial autocorrelation.

In spatial data, correlation that is dependent on distance, known as spatial autocorrelation, is often observed such that data values that are close together are more similar than data values that are far apart. Tobler states "everything is related to everything else, but near things are more related than distant things (Tobler 1970)." This is known as Tobler's first law of geography. Geostatistics that consist of spatial statistical techniques evaluate the autocorrelation within spatial data. The variogram (or semivariogram) measures spatial continuity and quantitatively characterizes spatial autocorrelation in the data. To generate a variogram, one-half the average squared distance of data values for every pair of locations (semivaraince, $\gamma$ ) is first computed using the following equation:

$$
\gamma(h)=(1 / 2)(1 / N) \sum_{i=1}^{N}\left[Z\left(x_{i}\right)+Z\left(x_{i}+h\right)\right]^{2}
$$


where $x_{i}$ is a location of a data point, $Z\left(x_{i}\right)$ is the data value at location $x_{i}, h$ is a unit distance (or lag size), and $N$ is the number of data pairs that are $h$ distance apart. The semivariances are plotted against the distance between locations to visualize a variogram. An example of a variogram is shown in Figure 16. Using the variogram generated from actual data (experimental variogram), a modeled variogram was formulated by fitting an appropriate theoretical variogram model that is associated with known mathematical properties. Properties of the modeled variogram include form (or shape), range, sill, nugget, and difference between sill and nugget (sill - nugget). These properties are indicative of spatial patterns of features in space or landscapes under investigation (Wallace et al. 2000) (Table 14).

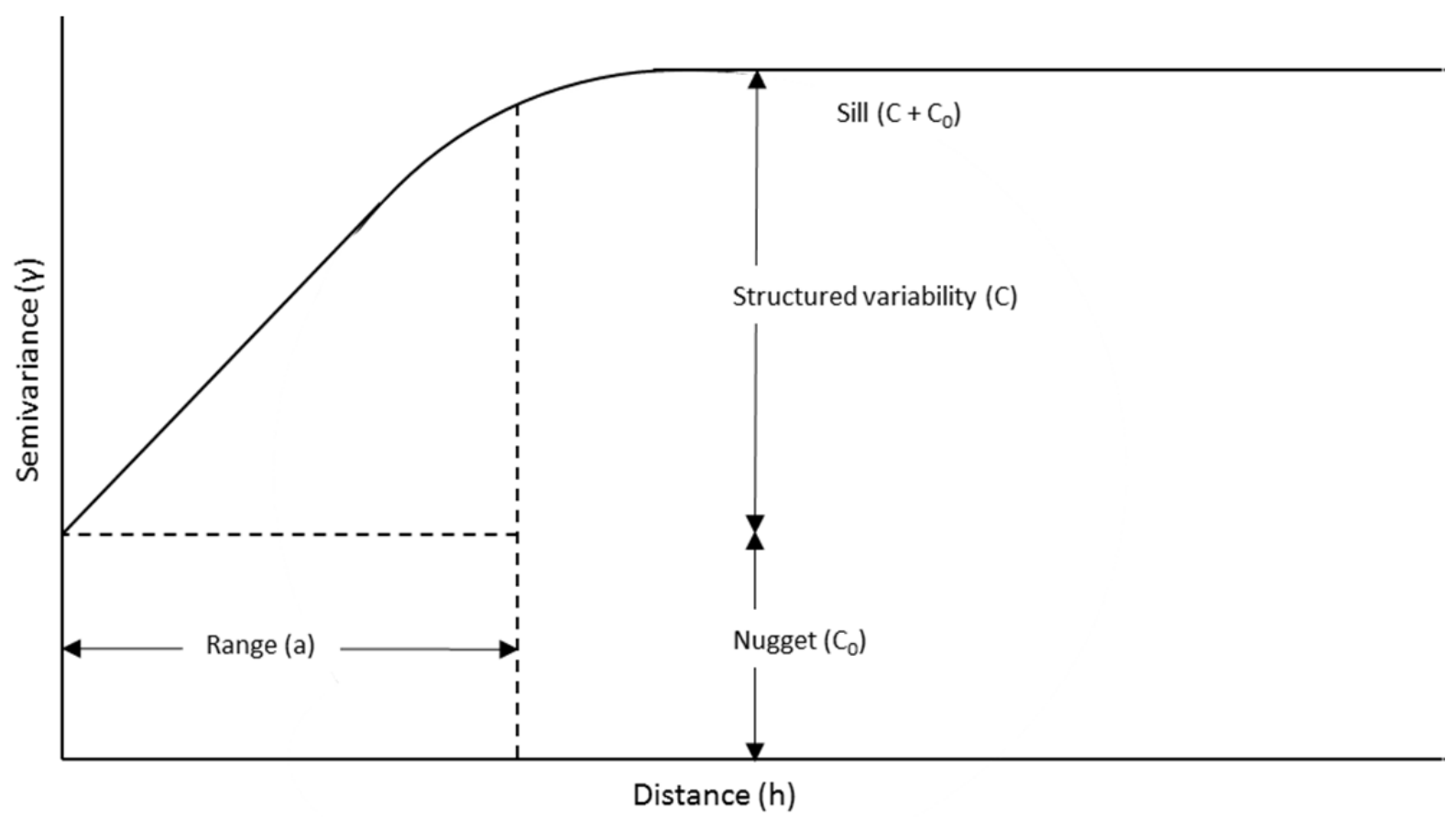

FIGURE 16 Example of Variogram

TABLE 14 Variogram Parameters

\begin{tabular}{|c|c|c|}
\hline Parameter & Definition & Indication \\
\hline Form & $\begin{array}{l}\text { Nature of spatial variability } \\
\text { within the data }\end{array}$ & $\begin{array}{l}\text { Pattern of features in the landscape and variance distribution } \\
\text { of landscape features. }\end{array}$ \\
\hline Range & $\begin{array}{l}\text { Distance over which data are } \\
\text { correlated }\end{array}$ & Size of dominant features in the landscape. \\
\hline Sill & Total variation & Density of features or background in the landscape. \\
\hline Nugget & $\begin{array}{l}\text { Level of random variation } \\
\text { within the data }\end{array}$ & Variation in the landscape NOT explained by distance. \\
\hline Sill-nugget & $\begin{array}{l}\text { Variation associated with } \\
\text { spatial structure }\end{array}$ & $\begin{array}{l}\text { Variation in the landscape explained by distance or } \\
\text { associated with spatial autocorrelation. }\end{array}$ \\
\hline
\end{tabular}


When using remotely sensed imagery, the variogram provides a graphical representation of the average variability within the data as a function of the distance between pixels (Curran 1988; Phinn et al. 1996). The dominant scale of spatial variability in an image typically corresponds to the size of features within the landscape (Woodcock et al. 1988a). Thus, when a variogram is generated using an SVI, its parameters are indicative of the spatial structure of vegetation (Table 14). For example, the range indicates the size of dominant features in the landscape such as plant canopies and patches, and the sill is correlated with vegetation density. The form (or shape) of the variogram is influenced by the vegetation pattern in the landscape and variance distribution of vegetation patches. For example, the variogram appears round when a range of canopy sizes are present in the landscape. Among these parameters, the range of the variogram generated from an image is found to correspond to "the distance of pixel separation beyond which image features are dissimilar and below which they are similar" (Phinn et al. 1996, p. 146); thus, it is particularly informative for vegetation community analysis, such as determining the size of dominant objects and patterns within the image, like canopies or vegetation stands (e.g., Woodcock and Strahler 1987; Woodcock et al. 1988a,b; Cohen et al. 1990; Atkinson 1993). When internal structures of vegetation communities change, the variogram properties - range, sill, and form - change accordingly; thus, they are useful indicators for monitoring status of vegetation alliances.

\subsection{DATA PREPARATION}

Four vegetation alliances were subject to examination for spatial patterns of the vegetation for this analysis-Chorizanthe rigida-Geraea canescens (CHRI-GECA), Larrea tridentata-Ambrosia dumosa (LATR-AMDU), Larrea tridentate-Encelia farinose (LATRENFA), and Parkinsonia florida-Olneya tesota (PAFL-OLTE). These four vegetation alliances were selected because they are dominant habitat types in the study area and present large contiguous aerial cover, which allowed us to exclude edge-effects or transitional zones from one habitat to another from the analysis.

We selected three 150-m plots for each alliance, which would provide sufficient aerial extent to capture spatial patterns in each alliance (Figure 17). A 150-m grid containing more than 2,700 plots was generated within the study area. Those plots falling completely within a single vegetation alliance were identified. Within those 12 plots ( 3 plots for each of the 4 alliances), 15-cm-resolution VARI pixels were converted to points. This analysis resulted in more than a million data points within each plot.

\subsection{QUALITATIVE OBSERVATION OF VEGETATION ALLIANCES}

Abundance and spatial distributions of vegetation in the four vegetation alliancesPAFL-OLTE, LATR-ENFA, LATR-AMDU, and CHRI-GECA-were qualitatively examined using the twelve 150-m to 150-m subsets of the VARI layer that consist of three plots for each of the four alliances (Figure 18). The only shared pattern across the alliances is discontinuous vegetation cover typical for arid environments. PAFL-OLTE, a major riparian habitat characterized by microphyll trees, exhibits larger canopy sizes compared with other alliances, but 


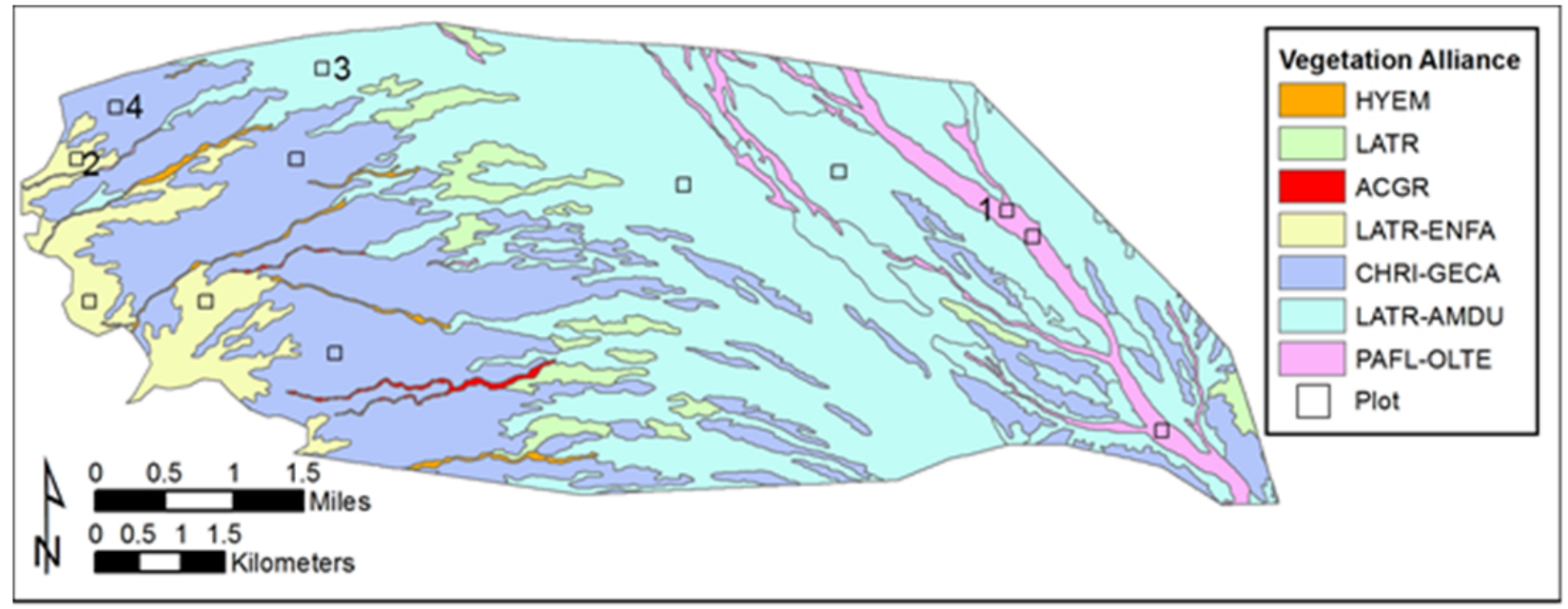

FIGURE 17 Plots Used for Characterizing Spatial Patterns of Vegetation Alliance (PAFL-OLTE = Parkinsonia florida-Olneya tesota, LATR-ENFA = Larrea tridentata-Encelia farinosa, LATRAMDU $=$ Larrea tridentata-Ambrosia Dumosa, CHRI-GECA = Chorizanthe rigida-Geraea canescens)

canopy size varies within the alliance due to intermixing of trees and shrubs (and dry herbs) (Figures 17 and 18). LATR-ENFA, a shrub-dominant habitat occurring in mountain-front, exhibits small yet dense vegetation having directional patterns associated with topography (Figures 17 and 18). LATR-AMDU, the most widespread shrub-dominant habitat in the study area, shows repetitive patterns of shrubs with relatively constant spacing (Figures 17 and 18). CHRI-GECA, herb-dominant habitat, shows linear vegetation distributions concentrated along ephemeral streams, which are likely shrubs (Figures 17 and 18).

Visual assessment of the VARI image subsets clearly indicated unique, recognizable differences in vegetation patterns among the four vegetation alliances. This suggests that the ability to quantify these patterns would be useful not only for differentiating vegetation alliances, but also for monitoring changes in the condition of alliances (e.g., type-conversion and changes in plant distribution and spatial patterns). In the following two sections, we explore methods for quantifying the intrinsic spatial structures and patterns of each vegetation alliance (Section 7.4) and for identifying appropriate image resolutions that capture those alliance-specific spatial characteristics that can be used for long-term monitoring (Section 7.5).

\subsection{FRACTIONAL COVER OF LAND COVER TYPE WITHIN VEGETATION ALLIANCES}

Before examining spatial patterns and structures of vegetation, we examined differences in fractional cover of land cover types across the PAFL-OLTE, LATR-ENFA, LATE-AMDU, and CHRI-GECA alliances to gain an overall understanding of vegetation abundance. 
Parkinsonia florida-Olneya tesota
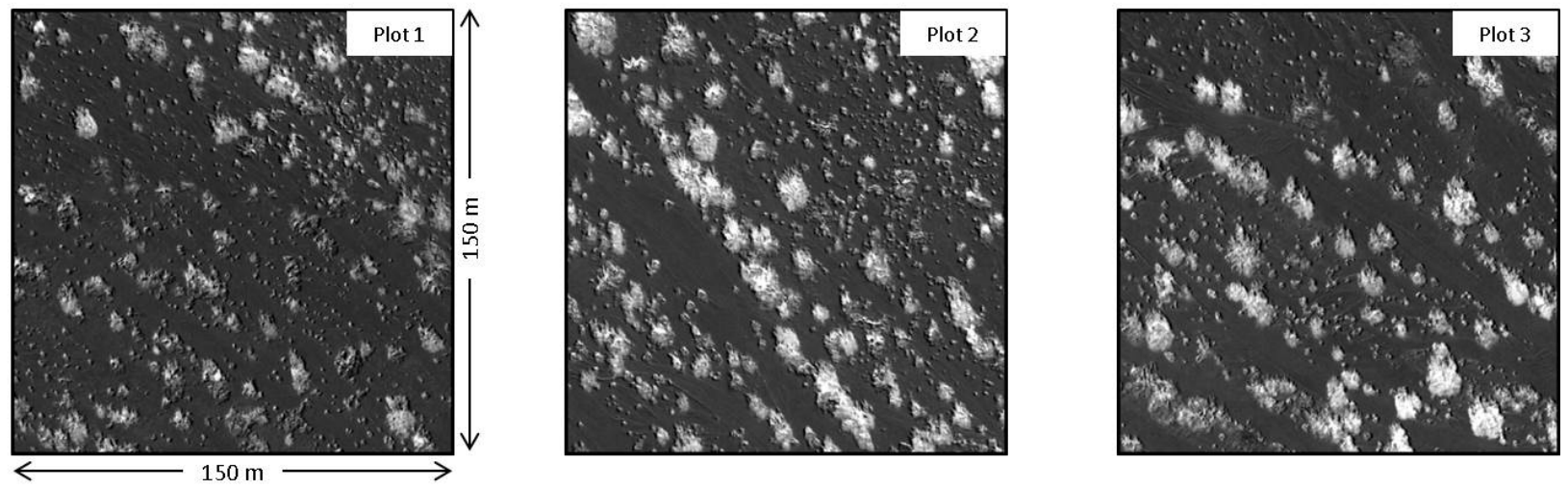

Larrea tridentata-Encelia farinosa
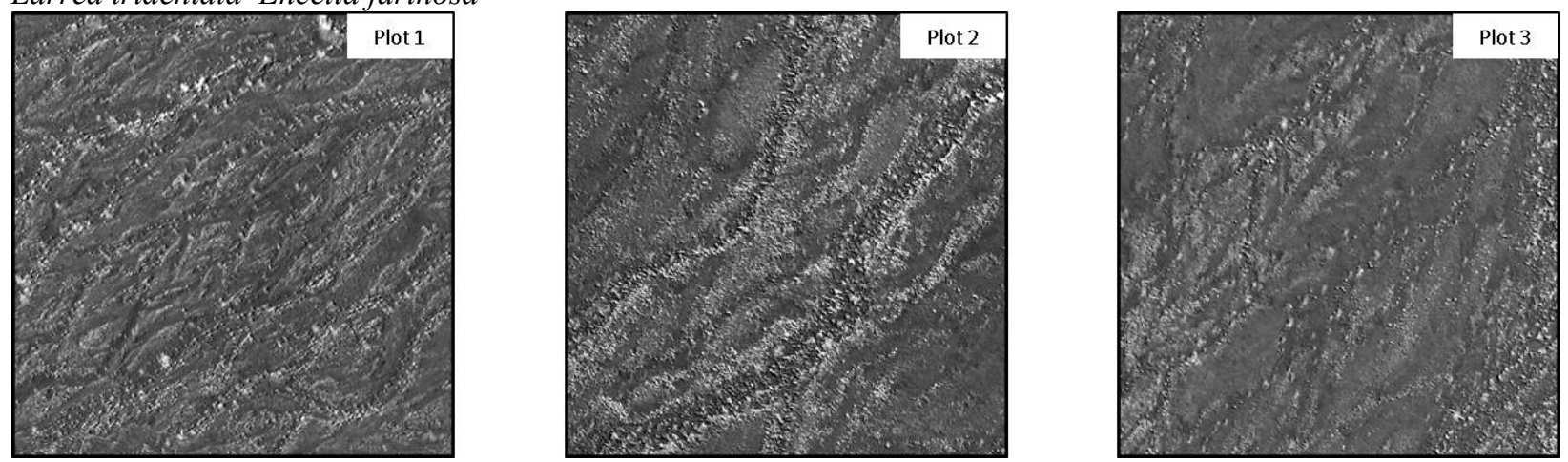

Larrea tridentata-Ambrosia Dumosa
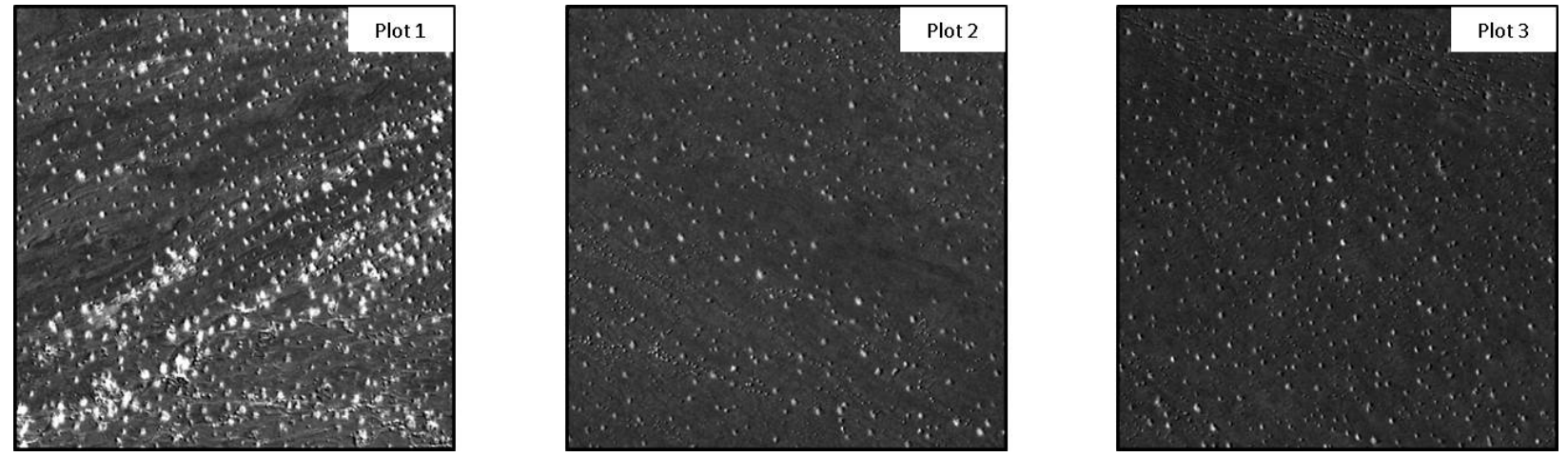

Chorizanthe rigida-Geraea canescens
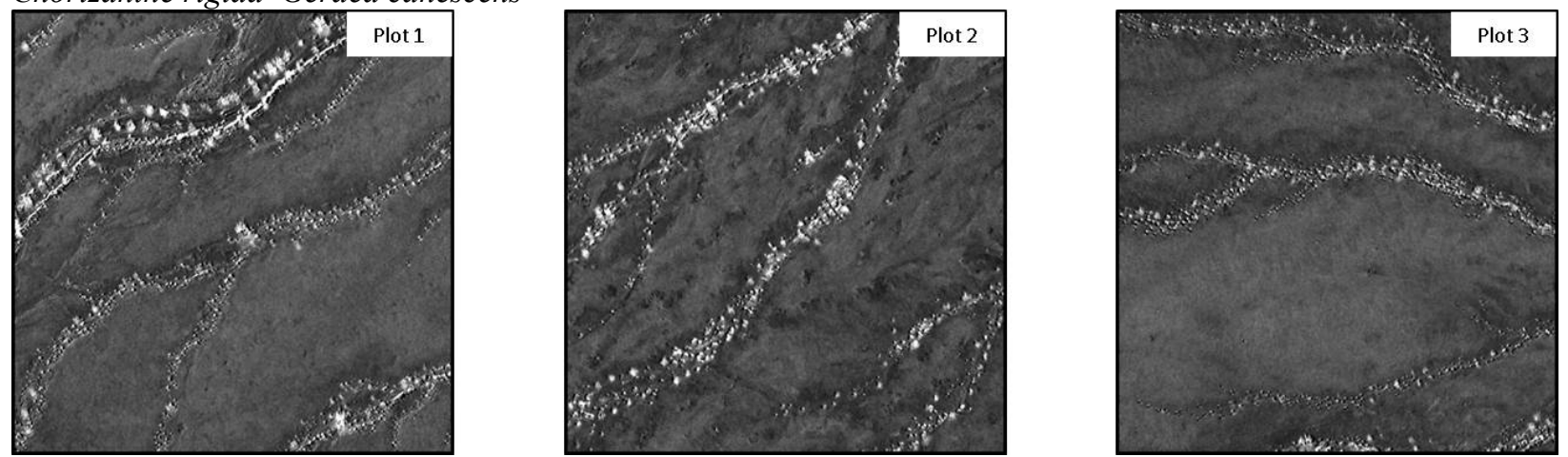

FIGURE 18 Subsets of Visible Atmospherically Resistant Index Used for Analysis 


\subsubsection{Method}

All 150-m × 150-m plots falling completely within a single vegetation alliance were identified (987 plots among the four alliances). The fractional cover of five land cover types (tree, shrub, desert varnish, pebble, and soil) was calculated within each plot based on the land cover classification map that was generated in our previous study (Hamada et al. 2014). To compare fractional cover among the vegetation alliances, summary statistics (mean, standard deviation, minimum, and maximum) were generated for land cover types within each vegetation alliance.

\subsubsection{Results}

Table 15 presents summary statistics of surface cover fractions of the PAFL-OLTE, LATR-ENFA, LATE-AMDU, and CHRI-GECA alliances. For all alliances, bare ground components - desert varnish, pebble, and soil — are the dominant surface covers and vegetation

TABLE 15 Summary Statistics of Surface Cover Fractions of Four Vegetation Alliances

\begin{tabular}{|c|c|c|c|c|c|}
\hline & & PAFL-OLTE & LATR-ENFA & LATR-AMDU & CHRI-GECA \\
\hline & Sample Size & 4 & 43 & 614 & 326 \\
\hline \multirow[t]{4}{*}{ Tree } & Mean & 0.14 & 0.08 & 0.01 & 0.02 \\
\hline & Std. & 0.04 & 0.04 & 0.01 & 0.02 \\
\hline & Min. & 0.08 & 0.00 & 0.00 & 0.00 \\
\hline & Max. & 0.17 & 0.16 & 0.07 & 0.11 \\
\hline \multirow{4}{*}{ Shrub } & Mean & 0.06 & 0.10 & 0.02 & 0.05 \\
\hline & Std. & 0.01 & 0.03 & 0.01 & 0.02 \\
\hline & Min. & 0.05 & 0.03 & 0.00 & 0.00 \\
\hline & Max. & 0.08 & 0.15 & 0.10 & 0.13 \\
\hline \multirow[t]{4}{*}{ Desert Varnish } & Mean & 0.03 & 0.43 & 0.04 & 0.61 \\
\hline & Std. & 0.02 & 0.12 & 0.05 & 0.15 \\
\hline & Min. & 0.01 & 0.13 & 0.00 & 0.00 \\
\hline & Max. & 0.05 & 0.58 & 0.41 & 0.94 \\
\hline \multirow[t]{4}{*}{ Pebble } & Mean & 0.35 & 0.27 & 0.78 & 0.24 \\
\hline & Std. & 0.06 & 0.07 & 0.14 & 0.13 \\
\hline & Min. & 0.29 & 0.18 & 0.31 & 0.04 \\
\hline & Max. & 0.40 & 0.48 & 0.95 & 0.99 \\
\hline \multirow[t]{4}{*}{ Soil } & Mean & 0.42 & 0.12 & 0.14 & 0.08 \\
\hline & Std. & 0.05 & 0.05 & 0.13 & 0.06 \\
\hline & Min. & 0.35 & 0.05 & 0.01 & 0.00 \\
\hline & Max. & 0.46 & 0.29 & 0.68 & 0.59 \\
\hline
\end{tabular}

Abbreviations: PAFL-OLTE $=$ Parkinsonia florida - Olneya tesot $a$ alliance; LATR-ENFA $=$ Larrea tridentata Encelia farinose alliance; LATR-AMDU = Larrea tridentata-Ambrosia dumosa alliance; CHRI-GECA = Chorizanthe rigida - Geraea canescens alliance; Std. = standard deviation; Min. = minimum; Max. = maximum . 
cover is very sparse. Among the sparsely vegetated alliances, PAFL-OLTE has the highest tree cover. Shrub cover is no greater than $10 \%$ for all alliances. LATR-AMDU has the lowest (2\%) shrub cover, while the other three alliances that are associated with ephemeral streams have a shrub cover $\geq 5 \%$. Desert varnish is significantly low for LATR-AMDU and PAFL-OLTE that commonly occur far from mountains, while it is high for LATE-ENFA and CHRI-GECA that often occur near foothills. Distinctively high pebble cover is seen for LATR-AMDU (78\%). When combining desert varnish and pebble cover, PAFL-OLTE $(3 \%+35 \%=38 \%)$ becomes noticeably different from other alliances $(>70 \%)$ (Table 15$)$. Greater cover of exposed soil is seen in PAFL-OLTE (42\%), the major tributary in the study area. Other alliances show $8 \%$ to $14 \%$ exposed soil cover, indicating that most of the bare ground in those alliances is dominated by rocks and pebbles. All cover types have consistently small variability for PAFL-ONTE $(\leq 5 \%)$ (Table 16). Tree and shrub cover have small variability across the alliances, which is likely influenced by their limited abundance in desert landscapes. Soil cover of PAFL-ONTE has a large mean and small standard deviation and minimum value, which suggests the consistently large exposed soil cover in the alliance.

\subsection{SPATIAL STRUCTURE OF VEGETATION ALLIANCES}

As described in Section 7.3, a qualitative analysis indicated that the individual vegetation alliances had unique spatial patterns. In this section we examine whether the spatial structures and patterns that are unique to a specific vegetation alliance can be quantified using a geostatistical tool, the variogram, which was discussed earlier.

TABLE 16 Lag Sizes Tested and Remotely Sensed Image Types Having Corresponding Spatial Resolutions

\begin{tabular}{c|ccc}
\hline $\begin{array}{c}\text { Lag Size and Spatial } \\
\text { Aggregation Scale }\end{array}$ & \multicolumn{3}{|c}{ Remotely Sensed Image Type $^{\mathbf{a}}$} \\
\hline $15 \mathrm{~cm}$ & Custom aerial & & \\
$30 \mathrm{~cm}$ & WorldView-3 & GeoEye-2 & \\
$50 \mathrm{~cm}$ & Pleiades & WorldView-2 & GeoEye-1 \\
$1 \mathrm{~m}$ & NAIP & IKONOS & \\
$1.5 \mathrm{~m}$ & SPOT-6 & SPOT-7 & \\
$2.5 \mathrm{~m}$ & SPOT-5 & & \\
$5 \mathrm{~m}$ & RapidEye & & \\
$10 \mathrm{~m}$ & Sentinel & \\
$15 \mathrm{~m}$ & Landsat 8 & \\
\hline
\end{tabular}

${ }^{a}$ Except for custom aerial and National Agricultural Imagery Program (NAIP) images, all image types were assumed to be pansharpened multispectral images using panchromatic images that were collected from the same platform types as corresponding multispectral images. 


\subsubsection{Method}

The point data having VARI values that share a common vegetation alliance were pooled to create a single alliance point dataset. Experimental variograms were calculated for each plot and the pooled data, by applying nine lag sizes $-0.15 \mathrm{~m}, 0.3 \mathrm{~m}, 0.5 \mathrm{~m}, 1 \mathrm{~m}, 1.5 \mathrm{~m}, 2.5 \mathrm{~m}, 5 \mathrm{~m}$, $10 \mathrm{~m}$, and $15 \mathrm{~m}$. These spatial scales were selected based on the approximate spatial resolutions of available high to moderate resolution remotely sensed imagery (Table 16). For each alliance, an appropriate model variogram was selected iteratively (Wallace et al. 2000) by fitting the experimental variogram. Variogram parameters such as nugget, range, and sill were analyzed to identify spatial patterns (e.g., average canopy sizes, spatial variability, and vegetation density) associated with each alliance.

\subsubsection{Results}

Variograms with six selected lag sizes (or sampling distances) are shown in Figures 19 through 22. In general, the variability decreased as the lag size increased. Nearly all alliances, except for LATR-ENFA, yielded robust variograms having nugget $=0$, when the $15-\mathrm{cm}$ lag size was applied. This suggests that total variability of greenness within each of the three vegetation alliances can be explained when using the 15-cm sampling distance along 15-m transects. When small lag sizes were applied (e.g., $<50 \mathrm{~cm}$ ), all variograms exhibited one of the transitional forms - spherical, exponential, and Gaussian models - with well-defined parameters (e.g., range and sill). This suggests that a relatively short sampling distance is required to capture meaningful spatial structure of vegetation for the alliances.

The PAFL-OLTE alliance exhibited unique patterns in variogram parameters, which appear to correspond to its characteristic vegetation patterns. Unlike those of shrub- or herbdominant alliances (LATR-ENFA, LATR-AMDU, and CHRI-GECA), variograms of PAFLOLTE exhibited an exponential model form. This pattern can be explained by the presence of features with varying shape and intra-canopy spacing (e.g., trees and shrubs), which is consistent with observations reported in classic studies using geostatistics by Phinn et al. (1996) and Woodcock et al. (1988a). While variograms of the shrub- and herb-dominant alliances became progressively obscured beyond $50 \mathrm{~cm}$ (e.g., large nuggets and small variance explained by distance with increased lag sizes), the variogram form of PAFL-OLTE remained robust up to an approximately 2-m lag size. More specifically, variograms appear to lose the robustness or form with the lag size of $50 \mathrm{~cm}$ for LATR-ENFA, $1 \mathrm{~m}$ for LATR-AMDU and CHRI-GECA, and $2.5 \mathrm{~m}$ for PAFL-OLTE. This suggests that it is unlikely that a single sampling distance (or spatial resolution of images) would be appropriate for all vegetation alliances.

Table 17 summarizes variogram parameters with relevant observations and field measurements. For both range and sill, there was a tenfold difference between the smallest and the largest values. They ranged from $90 \mathrm{~cm}$ for LATR-ENFA to $9 \mathrm{~m}$ for PAFL-OLTE. The sill ranged from 0.0009 for CHRI-GECA to 0.0090 for PAFL-OLTE. Variogram parameters provide explicit alliance-specific information about vegetation structure that complements information interpreted from the variograms. For PAFL-OLTE, the dominant range was $8.5 \mathrm{~m}$ and a corresponding lag size was less than or equal to $5 \mathrm{~m}$, which are the largest parameter 


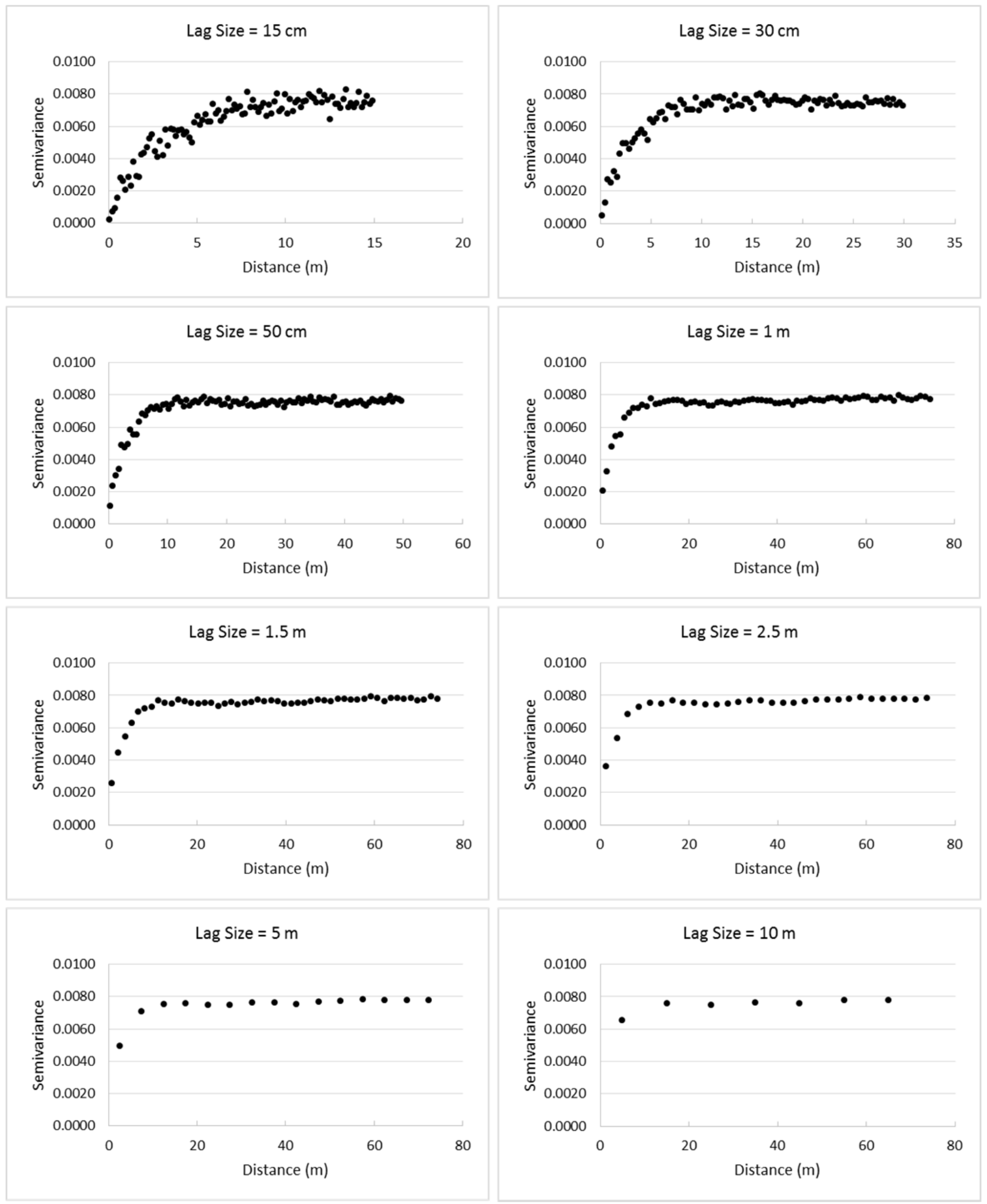

FIGURE 19 Semivariograms of the Parkinsonia florida-Olneya tesota Alliance with Lag Sizes of $15 \mathrm{~cm}, 30 \mathrm{~cm}, 50 \mathrm{~cm}, 1 \mathrm{~m}, 1.5 \mathrm{~m}, 5 \mathrm{~m}, 10 \mathrm{~m}$, and $15 \mathrm{~m}$ 


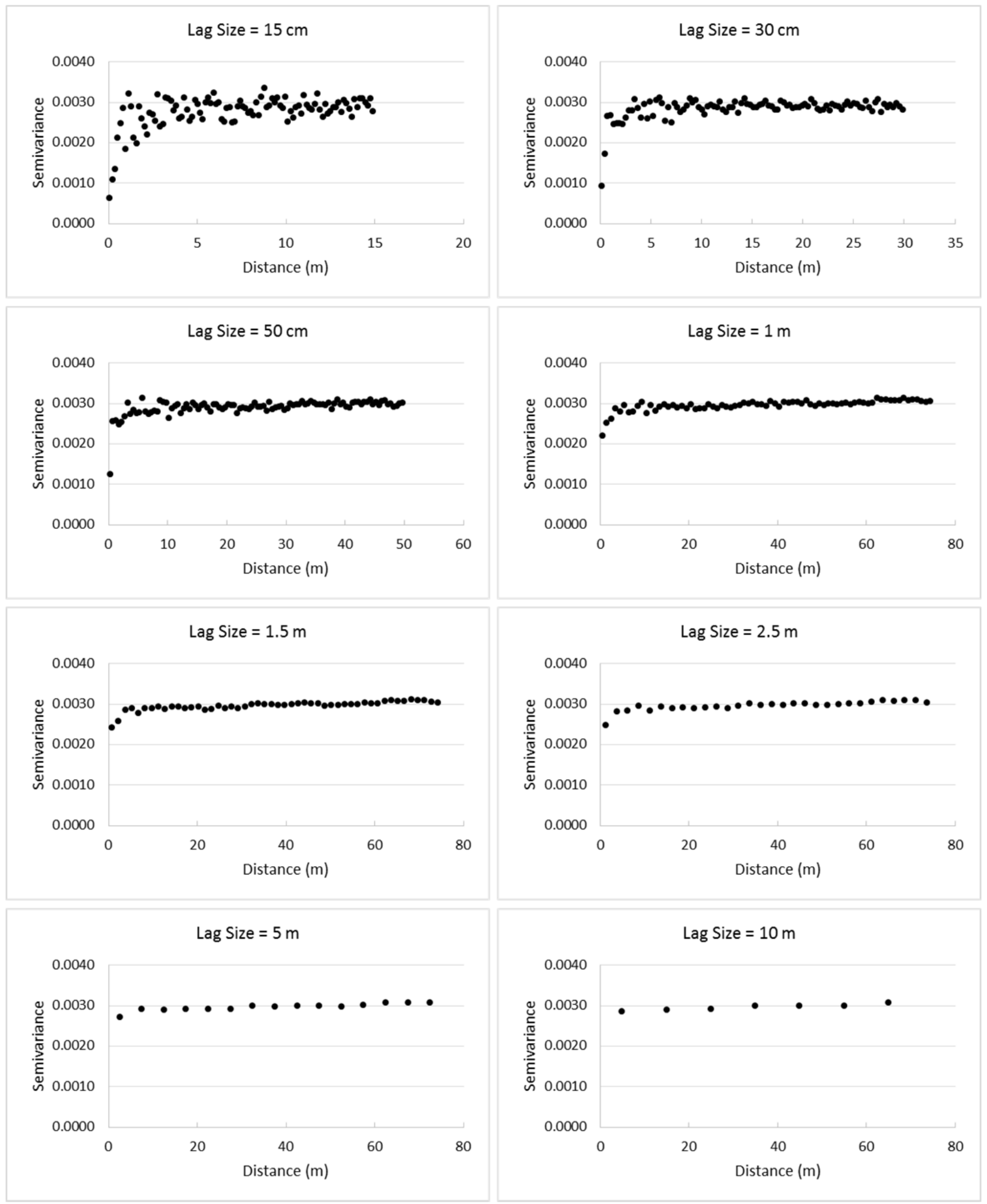

FIGURE 20 Semivariograms of the Larrea tridentata-Encelia farinosa Alliance with Lag Sizes of $15 \mathrm{~cm}, 30 \mathrm{~cm}, 50 \mathrm{~cm}, 1 \mathrm{~m}, 1.5 \mathrm{~m}, 5 \mathrm{~m}, 10 \mathrm{~m}$, and $15 \mathrm{~m}$ 


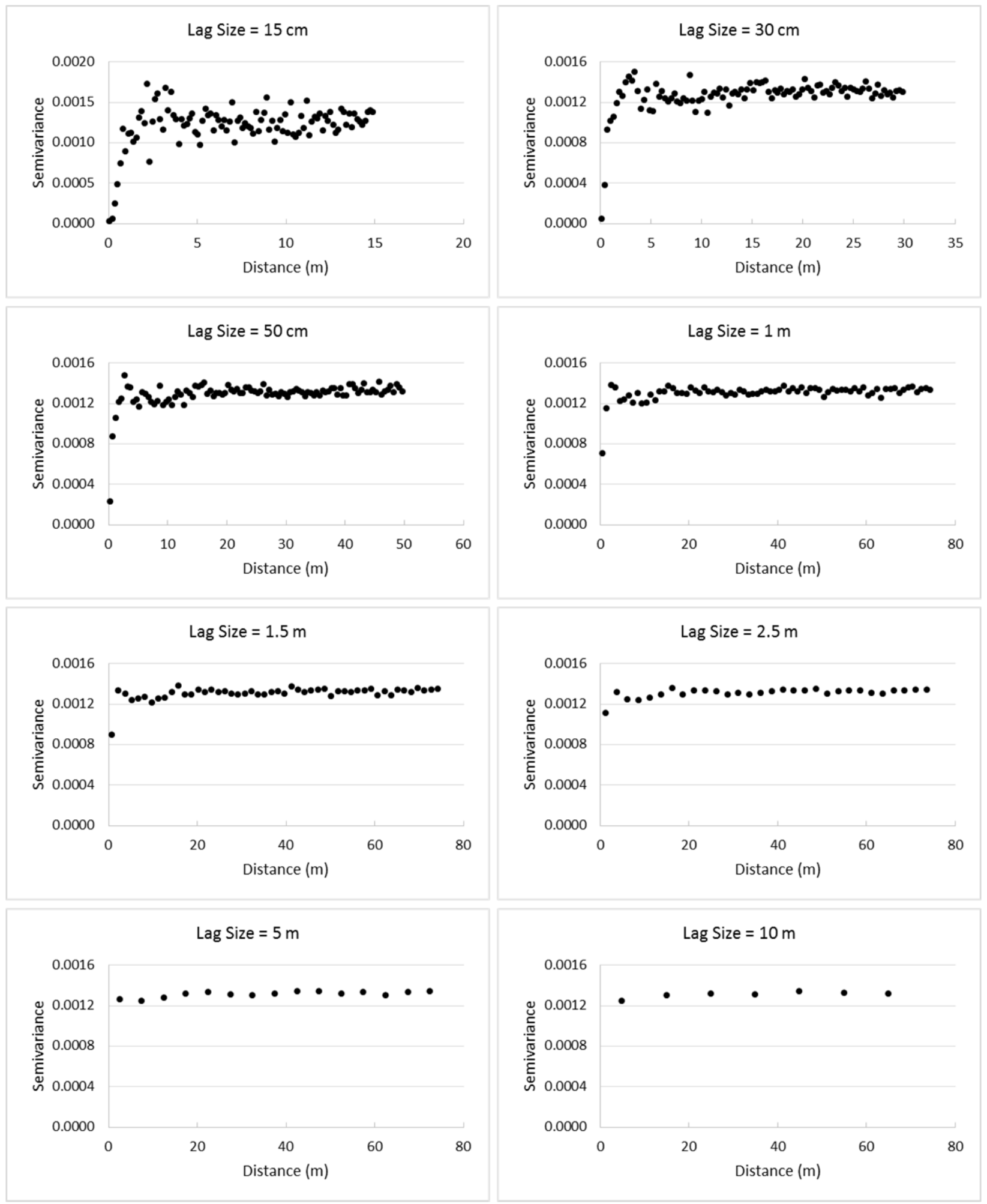

FIGURE 21 Semivariograms of the Larrea tridentata-Ambrosia Dumosa Alliance with Lag Sizes of $15 \mathrm{~cm}, 30 \mathrm{~cm}, 50 \mathrm{~cm}, 1 \mathrm{~m}, 1.5 \mathrm{~m}, 5 \mathrm{~m}, 10 \mathrm{~m}$, and $15 \mathrm{~m}$ 


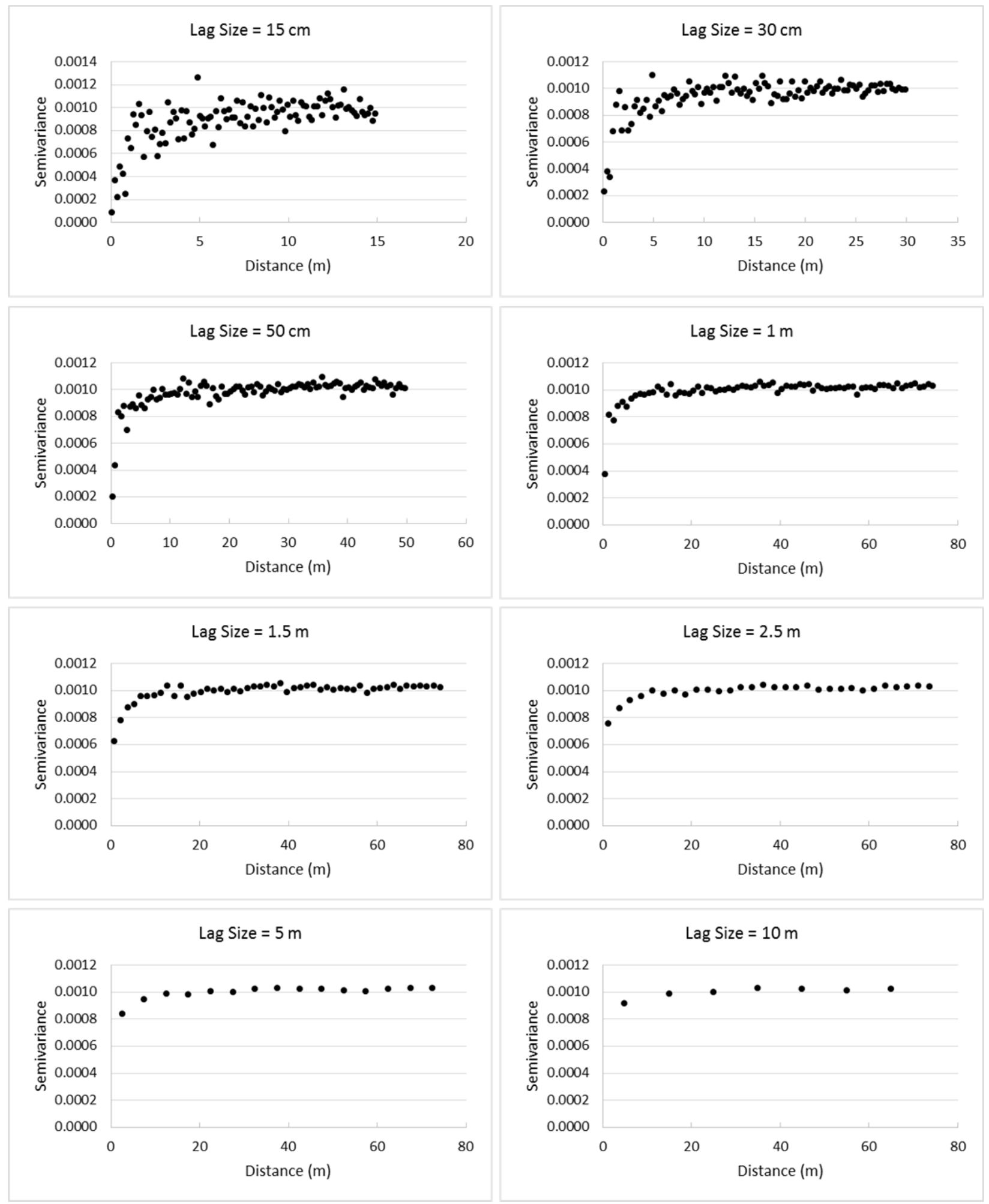

FIGURE 22 Semivariograms of the Chorizanthe rigida-Geraea canescens Alliance with Lag Sizes of $15 \mathrm{~cm}, 30 \mathrm{~cm}, 50 \mathrm{~cm}, 1 \mathrm{~m}, 1.5 \mathrm{~m}, 5 \mathrm{~m}, 10 \mathrm{~m}$, and $15 \mathrm{~m}$ 
TABLE 17 Summary of Semivariograms, Observations, and Field Measurements of Four Vegetation Alliances

\begin{tabular}{|c|c|c|c|c|}
\hline & PAFL-OLTE & LATR-ENFA & LATR-AMDU & CHRI-GECA \\
\hline \multicolumn{5}{|c|}{ Variogram parameter and scale } \\
\hline Form (dominant) & Exponential & Spherical & Spherical & Spherical \\
\hline Range (dominant) & $8.5 \mathrm{~m}$ & $90 \mathrm{~cm}$ & $1.9 \mathrm{~m}$ & $1.8 \mathrm{~m}$ \\
\hline Sill (dominant) & 0.0083 & 0.0028 & 0.0012 & 0.0009 \\
\hline Corresponding lag size & $\leq 5 \mathrm{~m}$ & $\leq 50 \mathrm{~cm}$ & $\leq 50 \mathrm{~cm}$ & $\leq 50 \mathrm{~cm}$ \\
\hline $\begin{array}{r}\text { Optimal resolution } \\
\text { (expected) }\end{array}$ & $2.5 \mathrm{~m}$ & $30 \mathrm{~cm}$ & $50 \mathrm{~cm}$ & $50 \mathrm{~cm}$ \\
\hline \multicolumn{5}{|l|}{ Observation } \\
\hline $\begin{array}{l}\text { Location in landscape } \\
\text { and spatial pattern }\end{array}$ & $\begin{array}{l}\text { Major riparian } \\
\text { habitat dominated } \\
\text { by microphyll } \\
\text { trees; co- } \\
\text { occurrence of } \\
\text { trees and shrubs; } \\
\text { varying canopy } \\
\text { sizes }\end{array}$ & $\begin{array}{l}\text { Shrub-dominant } \\
\text { habitat occurring } \\
\text { in mountain-front; } \\
\text { small yet dense } \\
\text { vegetation; } \\
\text { directional } \\
\text { patterns associated } \\
\text { with landform }\end{array}$ & $\begin{array}{l}\text { Most widespread } \\
\text { shrub-dominant } \\
\text { habitat; repetitive } \\
\text { patterns of shrubs } \\
\text { with uniform } \\
\text { canopy size; } \\
\text { relatively constant } \\
\text { spacing }\end{array}$ & $\begin{array}{l}\text { Herb-dominant } \\
\text { habitat; linear } \\
\text { plant distributions } \\
\text { along ephemeral } \\
\text { streams; } \\
\text { observable } \\
\text { vegetation likely } \\
\text { shrubs }\end{array}$ \\
\hline \multicolumn{5}{|l|}{ Field measurement } \\
\hline $\begin{array}{r}\text { Canopy diameter } \\
\text { (mean) }\end{array}$ & $\begin{array}{c}3.9 \mathrm{~m} \\
(5.4 \mathrm{~m} \text {; tree only) }\end{array}$ & $1.5 \mathrm{~m}$ & $2.3 \mathrm{~m}$ & $2.5 \mathrm{~m}$ \\
\hline $\begin{array}{r}\text { Canopy diameter } \\
\text { (standard deviation) }\end{array}$ & $2.7 \mathrm{~m}$ & $85 \mathrm{~cm}$ & $1.8 \mathrm{~m}$ & $2.2 \mathrm{~m}$ \\
\hline $\begin{array}{r}\text { Vegetation cover } \\
\text { (mean) }\end{array}$ & $20 \%$ & $18 \%$ & $3 \%$ & $7 \%$ \\
\hline
\end{tabular}

Abbreviations: PAFL-OLTE $=$ Parkinsonia florida-Olneya tesota LATR-ENFA $=$ Larrea tridentata - Encelia farinosa; LATR-AMDU = Larrea tridentata-Ambrosia Dumosa; CHRI-GECA = Chorizanthe rigida - Geraea canescens.

values of the alliances examined. For LATR-ENFA, the dominant range was $90 \mathrm{~cm}$ with a corresponding lag size less than and equal to $50 \mathrm{~cm}$, the smallest parameter values of the alliances examined. LATR-AMDU and CHRI-GECA had comparable parameter values. LATR-AMDU and CHRI-GECA had dominant ranges of $1.9 \mathrm{~m}$ and $1.8 \mathrm{~m}$, respectively. Both alliances have a corresponding lag size less than or equal to approximately $50 \mathrm{~cm}$.

Existing studies suggest that the range of the variogram corresponds to the average size of vegetation features in the landscape when applying an SVI (Table 17). In a relative sense, the range and the average canopy diameter exhibited this suggested pattern. The ranges were $8.5 \mathrm{~m}$ (PAFL-OLTE), $1.8 \mathrm{~m}$ to $1.9 \mathrm{~m}$ (LATR-AMDU and CHRI-GECA), and $90 \mathrm{~cm}$ (LATR-ENFA); the corresponding average canopy sizes were $3.9 \mathrm{~m}, 2.3 \mathrm{~m}$ to $2.5 \mathrm{~m}$, and $1.5 \mathrm{~m}$. However, absolute values were quite different between the range and the average canopy diameter (i.e., $4.6 \mathrm{~m}$ or $3.1 \mathrm{~m}$ difference for PAFL-OLTE, $40 \mathrm{~cm}-70 \mathrm{~cm}$ difference for LATR-AMDU and CHRI-GECA, and 60-cm difference for LATR-ENFA).

Existing studies suggest that the sill of the variogram correlates with the density of vegetation in the landscape when applying an SVI. In a relative sense, the sill and the vegetation cover show the suggested correlation (Table 17). The sills are 0.0083 (PAFL-OLTE), 0.0028 
(LATR-ENFA), and 0.0009-0.0012 (CHRI-GECA and LATR-AMDU); vegetation cover fractions were $20 \%, 18 \%$, and $3 \%$ to $7 \%$.

The relationships between the variogram parameters and vegetation patterns observed in the field can be observed within a confined range of scale. Those scales are expressed with lag sizes (Table 17). For PAFL-OLTE, the relationship was observed when values were collected at intervals of $5 \mathrm{~m}$ or smaller. For other alliances, the observed relationships were only associated with data collected at 50-cm intervals or smaller. In conjunction with the range, which indicates the size of dominant vegetation features in a landscape, examining multiple sampling intervals can provide insights into understanding the maximum spatial resolution of images that indicates the intrinsic spatial patterns of vegetation alliances.

It should be noted that there are clear differences in the data used for the variogram analysis and those collected in the field, including data collection year, vegetation phenology, plot design and location, and definition of a canopy. When the VHSR image was collected in January 2014 , herbaceous vegetation was completely senesced. Herbaceous vegetation appears as non-vegetation in the VARI layer. Therefore, it is unlikely that the variogram analysis depicted characteristics of herbaceous plants. Instead, the analysis likely corresponded to shrubs. In contrast, the herbaceous plants were predominantly senesced but still recognizable during the field survey in March 2015. These individuals were recorded as vegetation in the field; thus, the density calculation accounted for this senesced vegetation.

Upon selecting survey plots (35-m radius circles), we selected relatively homogeneous, representative areas by avoiding sharp boundaries of multiple habitats (e.g., riparian vs. nonriparian habitats) in order to mitigate positional uncertainty between the field data and image. For the variogram analysis, plots $(150-\mathrm{m} \times 150-\mathrm{m}$ rectangles $)$ were selected based on the vegetation alliance layer that the BLM provided. Because of the intrinsic minimum mapping unit of the vegetation alliance map, the plots contained considerable heterogeneity, particularly for the CHRI-GECA alliance (e.g., desert pavement and narrow ephemeral channels; Figure 18).

The effects of vegetation phenology and composition heterogeneity within a plot are expected to be greatest for herb-dominant habitats with mosaics of fragmented land surface types (e.g., narrow channels, sizable bare ground, and vegetation clusters). In this study, those characteristics fit the CHRI-GECA alliance perfectly, which can explain the inconsistency of our findings with existing studies.

\subsubsection{Application for Monitoring Vegetation Alliances}

Variograms generated using relatively high-resolution images would indicate several types of vegetation changes in the vegetation alliances over time, including changes in (1) diversity and geometry of vegetation types; (2) canopy and vegetation patch size; and (3) vegetation density, including loss or new growth of individual plants. Specific examples are provided below in the context of the Riverside East SEZ: 
1. Changes in diversity and geometry of vegetation types (or plant life-form types) would influence the form or shape of the variogram. For example, when a change in surface water flow results in reduction in tree abundance and size and promotes shrub dominance in a part of the McCoy Wash, the variogram form is expected to shift from an exponential form to a spherical form.

2. Changes in canopy and vegetation patch size are expected to influence the range of the variogram. For example, when overall canopy size of microphyll trees reduces in the McCoy Wash due to drought, the range of the variogram is expected to decrease. When tree canopies expand during wet years, the range of the variogram is expected to increase.

3. Changes in vegetation density associated with both loss and emergence of individual plants, as well as contraction and expansion of canopies and patches, would influence the sill of the variogram. For example, when shrub canopy expands and new shrub growth occurs in creosote-dominant habitats such as the LATR-AMDU and LATR-ENFA alliances during wet years, the sill of the variogram is expected to increase. On the other hand, when shrub density decreases during drought, the sill of the variogram is expected to decrease.

The relationships between vegetation patterns and variogram parameters appear scale dependent. The range, which is indicative of the size of vegetation features, and the corresponding lag size, which retains intrinsic spatial patterns of vegetation in landscapes, would provide useful insights into estimating an appropriate resolution for remotely sensed imagery. Although a $15-\mathrm{cm}$ resolution may not be required to observe the intrinsic patterns of vegetation alliances, using remotely sensed images having an appropriate spatial resolution is crucial, because the intrinsic vegetation patterns would be lost if the resolution of images does not resolve features or elements of interest. Based on the results, we can hypothesize appropriate spatial resolutions as follows:

- The range and corresponding lag size of PAFL-OLTE were $8.5 \mathrm{~m}$ and $2.5 \mathrm{~m}$, respectively. The measured average canopy size was $3.9 \mathrm{~m}$. An image having a spatial resolution of $1.5-\mathrm{m}$ or finer would resolve the majority of canopies within the alliance and would be expected to portray its intrinsic vegetation patterns.

- The range and corresponding lag size of LATR-ENFA were $90 \mathrm{~cm}$ and $50 \mathrm{~cm}$, respectively. The measured average canopy size was $1.5 \mathrm{~m}$. An image having a spatial resolution of $50 \mathrm{~cm}$ or finer would resolve the majority of canopies within the alliance and would be expected to portray its intrinsic vegetation patterns.

- The range and corresponding lag size of LATR-AMDU were $1.9 \mathrm{~m}$ and $50 \mathrm{~cm}$, respectively. The measured average canopy size was $2.3 \mathrm{~m}$. An image 
having a spatial resolution of $50 \mathrm{~cm}$ or finer would resolve the majority of canopies within the alliance and would be expected to portray its intrinsic vegetation patterns.

- The range and corresponding lag size of CHRI-GECA were $1.8 \mathrm{~m}$ and $50 \mathrm{~cm}$, respectively. The measured average canopy size was $2.5 \mathrm{~m}$. An image having a spatial resolution of $50 \mathrm{~cm}$ or finer would resolve the majority of canopies within the alliance and would be expected to portray its intrinsic vegetation patterns.

Based on the estimates, we could hypothesize that remotely sensed images having $50-\mathrm{cm}$ spatial resolution that are comparable to WorldView-2, GeoEye-1, and Pleiades images would be expected to provide spatial structures and patterns of vegetation that can be used to monitor changes in vegetation alliances in desert environments over time. To test this hypothesis, we examined the impacts of image resolutions on spatial structures of vegetation; our evaluation is presented in the following sections.

\subsection{IMAGE RESOLUTION AND VEGETATION PATTERNS}

Based on the findings from Section 7.5.2, we hypothesized that 50-cm resolution images would provide the intrinsic spatial characteristics associated with each vegetation alliance. This section discusses the method and results of hypothesis testing. The findings from the analysis would help us understand an appropriate spatial resolution for long-term monitoring of the spatial structures and patterns of desert vegetation.

\subsubsection{Method}

To determine whether the intrinsic spatial structure identified at the $15-\mathrm{cm}$ scale can be observed at coarser scales, we generated VARI layers having four spatial scales that correspond to existing satellite image types and one aerial image type- $30 \mathrm{~cm}$ (WorldView-3, GeoEye-2), $50 \mathrm{~cm}$ (Pleiades, WorldView-2, and GeoEye-1), $1 \mathrm{~m}$ (National Agricultural Imagery Program [NAIP], IKONOS), and $1.5 \mathrm{~m}$ (SPOT-6 and -7). This examination would help determine the optimal spatial resolution for characterizing vegetation alliances and monitor its changes over time. These VARI layers with varying spatial resolutions were generated by spatially aggregating the original $15-\mathrm{cm}$ image into the target resolutions and then computing the index. To analyze the spatial patterns of vegetation at the three coarse spatial scales, we used the same plots as those for the previous analysis. We first reviewed the VARI subset for each plot to examine the interpretability of vegetation feature changes across spatial resolutions.

To perform a quantitative analysis, we prepared the data in a comparable manner to the previous analysis, which resulted in 90,000, 22,500, and 10,000 points for the $0.5-\mathrm{m}, 1-\mathrm{m}$, and $1.5-\mathrm{m}$ resolution VARI layers, respectively. Using the point data, we calculated an experimental variogram, selected the best fit variogram model, and extracted variogram parameters (e.g., range, nugget, and sill) for each vegetation alliance. We examined how well the patterns 
that were observed at the original resolution were preserved and determined appropriate spatial resolutions for monitoring changes in the vegetation alliances.

\subsubsection{Results}

Figures 23 through 26 show subsets of VARI layers with $15-\mathrm{cm}, 30-\mathrm{cm}, 50-\mathrm{cm}, 1-\mathrm{m}$, and $1.5-\mathrm{m}$ resolutions. In general, vegetation features are progressively obscured as spatial resolution increases across the vegetation alliances. The majority of trees and shrubs are recognizable for PAFL-OLTE across the spatial resolutions (Figure 23). For LATR-AMDU, LATR-ENFA, and CHRI-GECA, the majority of shrubs became uninterpretable at resolutions of $50 \mathrm{~cm}$ or coarser (Figures 24 through 26). At 1-m resolution, only large shrubs are recognizable within LATR-AMDU, and relatively large shrubs with sparse foliage have obscured canopy boundaries. For LATR-ENFA and CHRI-GECA at 1-m resolution, individual shrubs are unrecognizable, and those growing close together along ephemeral streams became less-defined vegetation clusters. These observations suggest that LATR-AMDU, LATR-ENFA, and CHRI-GECA would likely require a $50-\mathrm{cm}$ resolution to identify large vegetation canopies and a resolution $<50 \mathrm{~cm}$ to resolve variation of shrub canopies in order to characterize spatial patterns. These observations agree with our estimation of appropriate resolutions based on the previous analysis (Section 7.4).

Figures 27 and 28 show variograms with $30-\mathrm{cm}, 50-\mathrm{cm}, 1-\mathrm{m}$, and $1.5-\mathrm{m}$ resolutions for the PAFL-OLTE, LATR-ENFA, LATR-AMDU, and CHRI-GECA alliances. As the spatial resolution increases, the variability in semivariance reduces and the robustness progressively decreases (e.g., increased nugget and obscure shape) regardless of the vegetation alliances. The sill was fairly constant across resolutions and did not show substantial decline, which suggests that total variability in vegetation patterns in the original resolution were preserved in coarse images. This observation is inconsistent with existing studies (Phinn et al. 1996; Woodcock et al. 1988a), perhaps because the range of resolutions tested in this study (30 cm-1.5 m) was not sufficient to observe a noticeable decline in sill with increasing resolutions. The variogram shape for PAFL-OLTE was more round than that for other alliances, indicating that its distinct characteristics - great variability in canopy size - is maintained in coarse resolution images. PAFL-OLTE retained its variogram form well up to $1.5-\mathrm{m}$ resolution, suggesting that we could examine the diverse canopy size in the alliance using a $1.5-\mathrm{m}$ resolution image. In contrast, the rest of the alliances lost the robustness of variograms at relatively fine resolutions. The variogram form became nearly flat at $50-\mathrm{cm}$ and $1-\mathrm{m}$ resolution for LATR-ENFA and LATR-AMUD, respectively. This indicates the limit of spatial resolution at which vegetation patterns can be examined for the shrub-dominated alliances.

Table 18 summarizes the variogram parameters with $15-\mathrm{cm}, 30-\mathrm{cm}, 50-\mathrm{cm}, 1-\mathrm{m}$, and 1.5-m resolution for the PAFL-OLTE, LATR-ENFA, LATR-AMDU, and CHRI-GECA alliances. When comparing variogram parameters, the sill showed an initial decline from a 15-cm resolution to a 30-cm resolution, except for CHRI-GECA. For PAFL-OLTE, the sill was generally consistent (approximately 0.0073 ) across the spatial resolutions. The shrub-dominant alliances-LATR-ENFA and LATR-AMDU—showed subtle increases in sill at 50-cm 

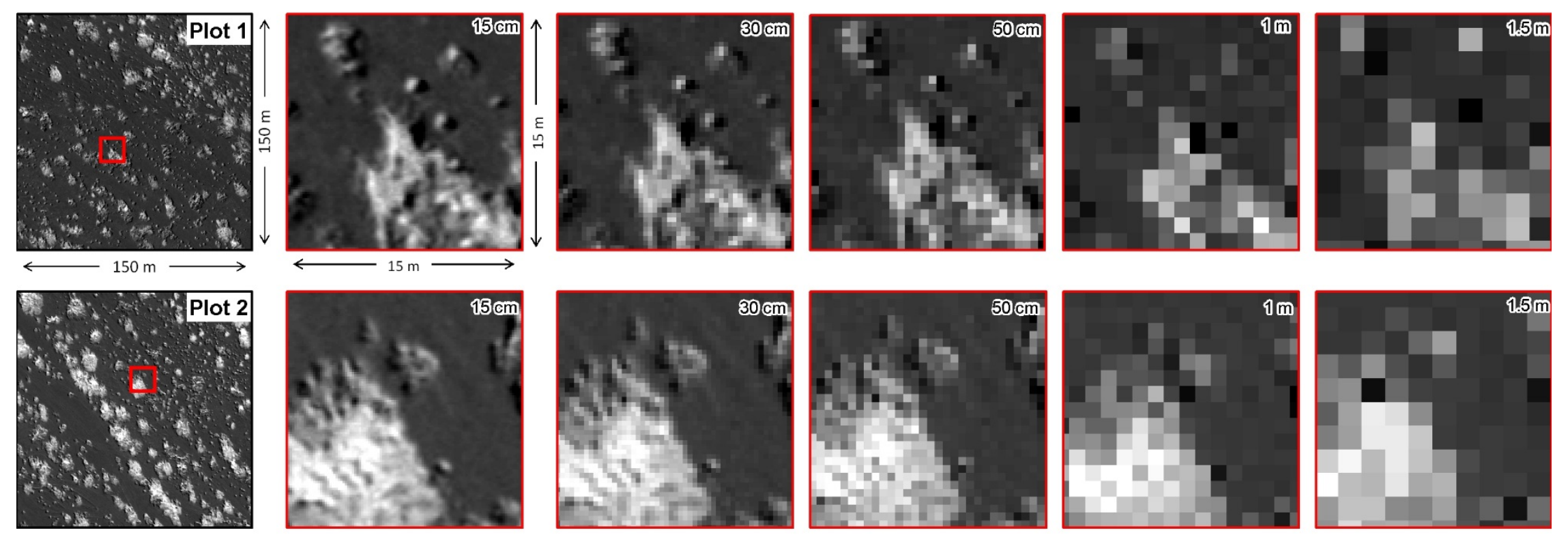

崩
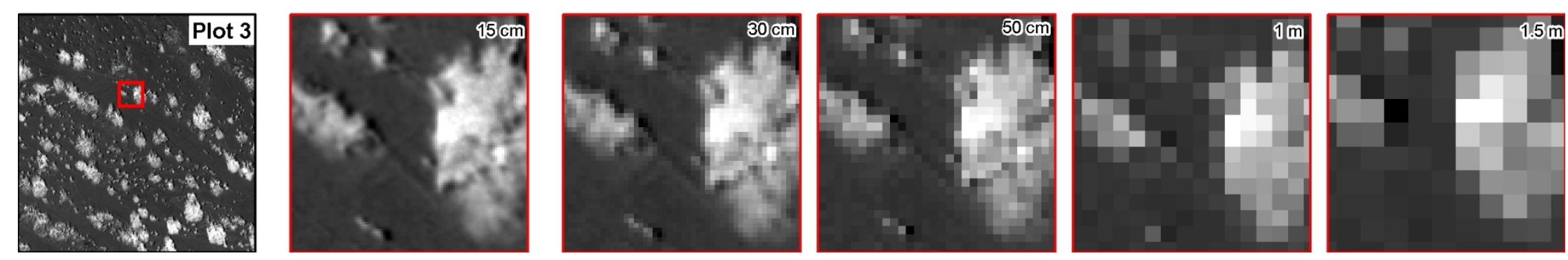

FIGURE 23 Subsets of Visible Atmospherically Resistant Index for the Parkinsonia florida-Olneya tesota Alliance with 15-cm, 30-cm, 50-cm, 1-m, and 1.5-m Spatial Resolutions 

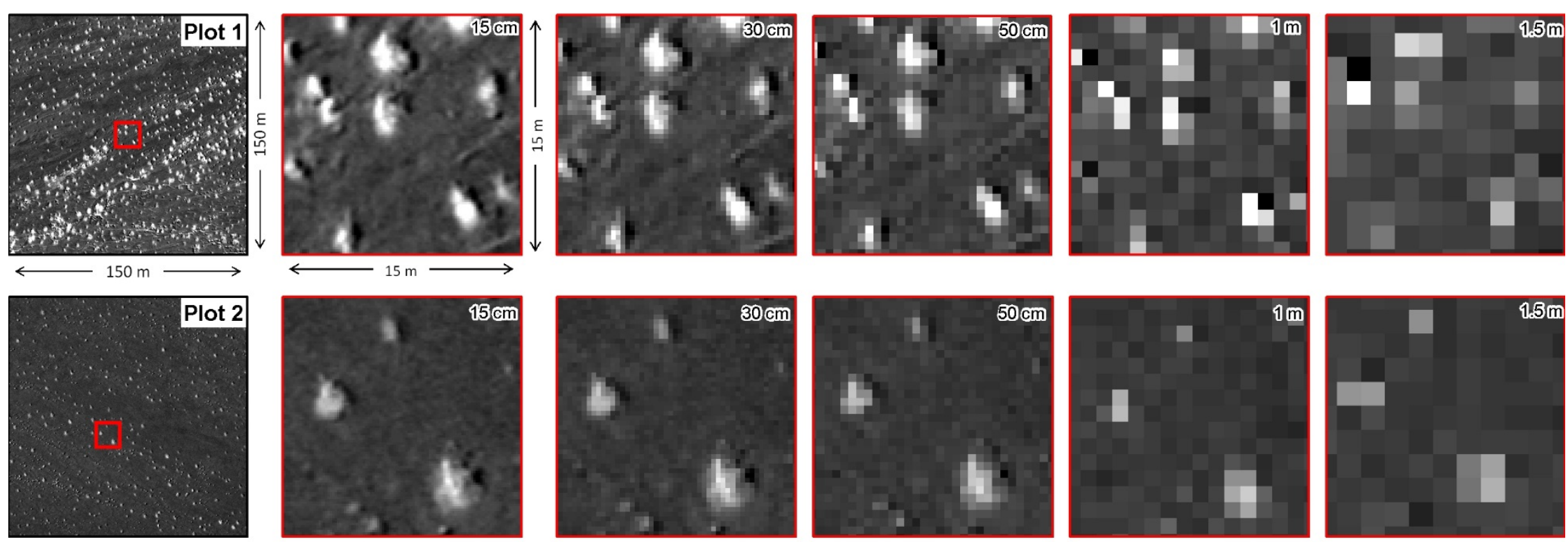

Чै่
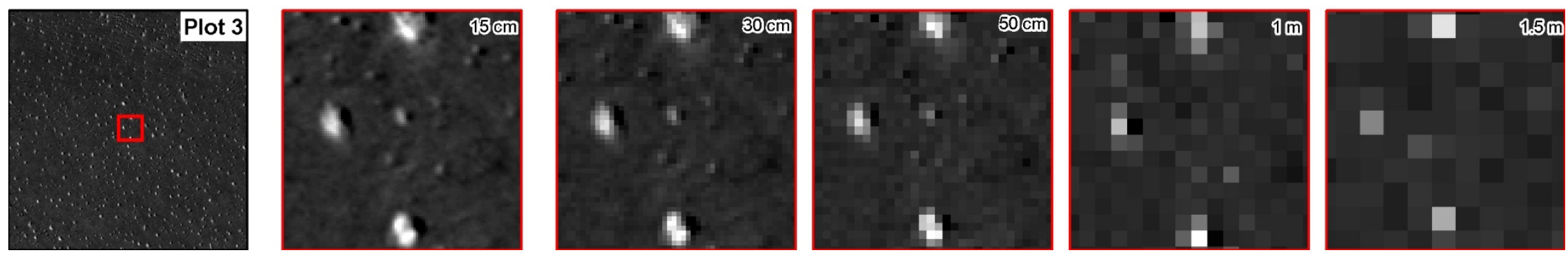

FIGURE 24 Subsets of Visible Atmospherically Resistant Index for the Larrea tridentata-Ambrosia Dumosa Alliance with 15-cm, 30-cm, 50-cm, 1-m, and 1.5-m Spatial Resolutions 

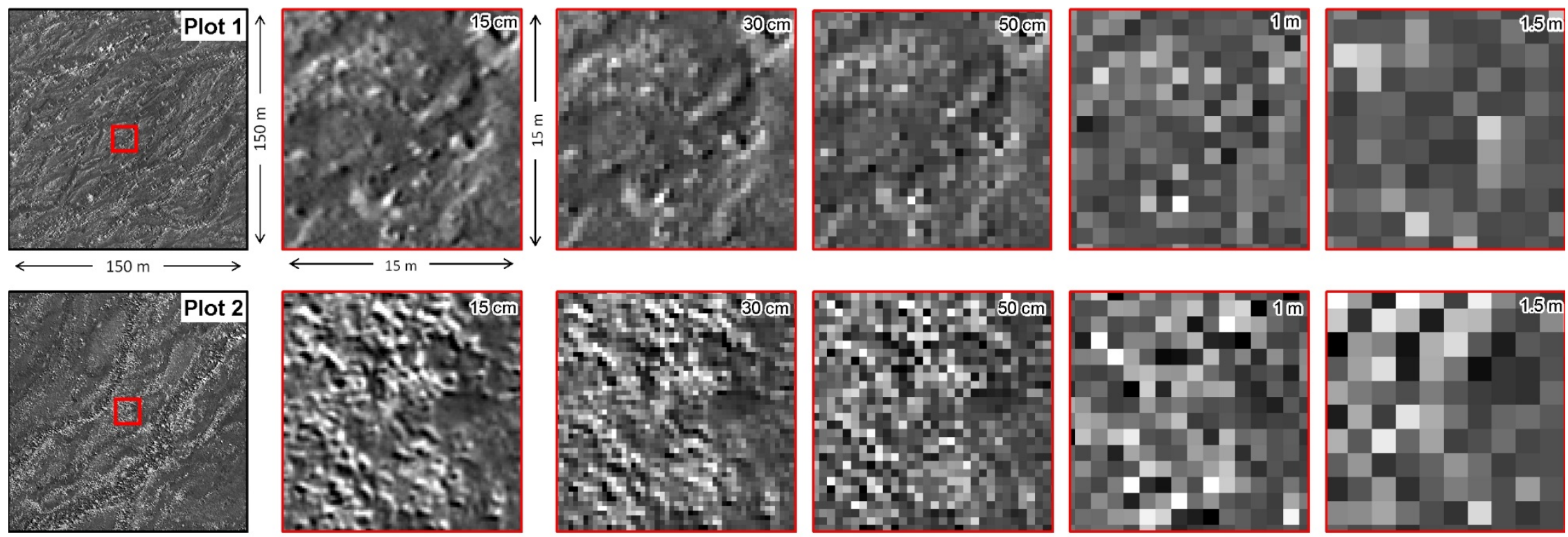

8
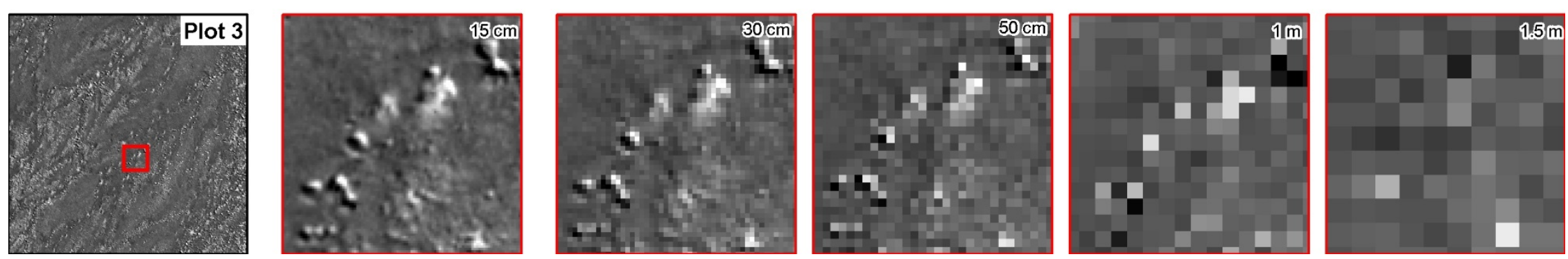

FIGURE 25 Subsets of Visible Atmospherically Resistant Index for the Larrea tridentata-Encelia farinosa Alliance with 15-cm, 30-cm, 50-cm, 1-m, and 1.5-m Spatial Resolutions 

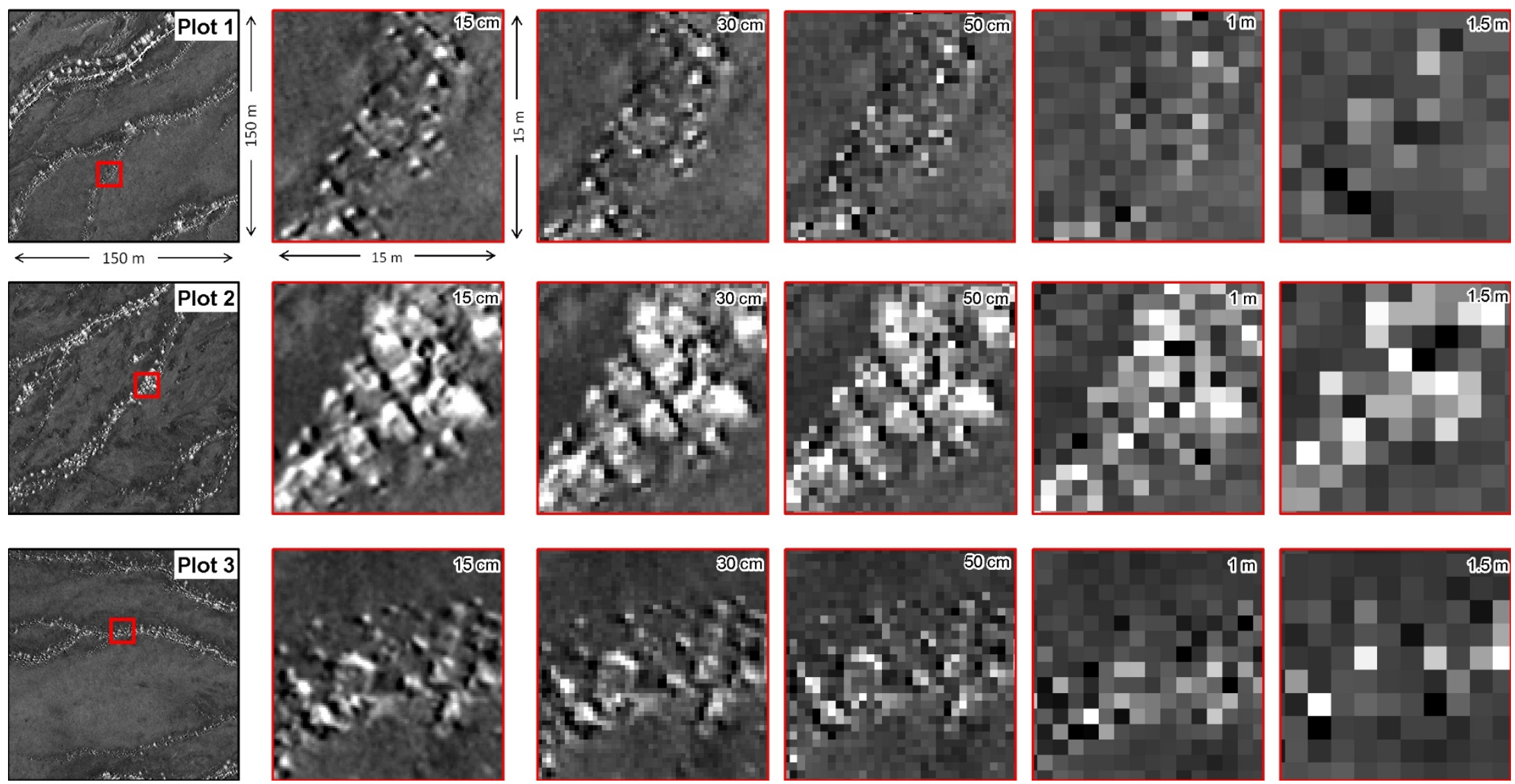

FIGURE 26 Subsets of Visible Atmospherically Resistant Index for the Chorizanthe rigida-Geraea canescens Alliance with 15-cm, 30-cm, 50-cm, 1-m, and 1.5-m Spatial Resolutions 
PAFL-OLTE
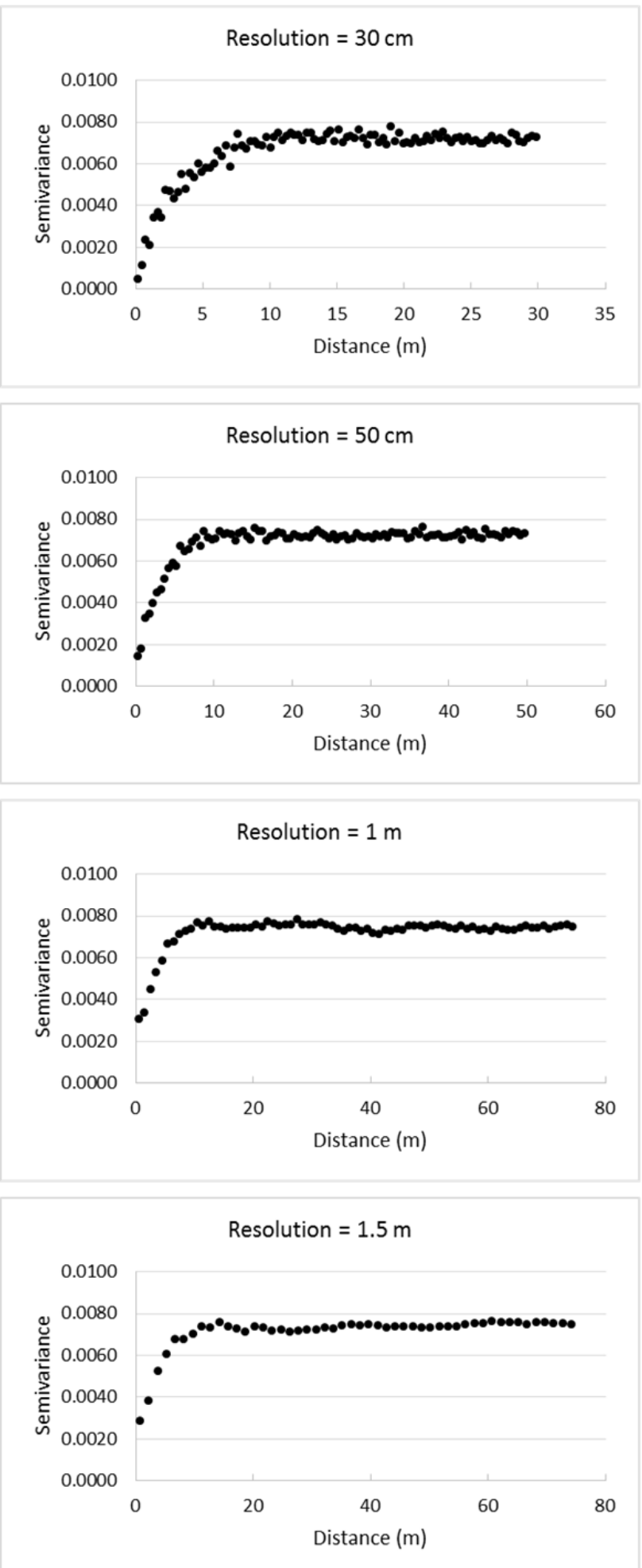

LATR-ENFA
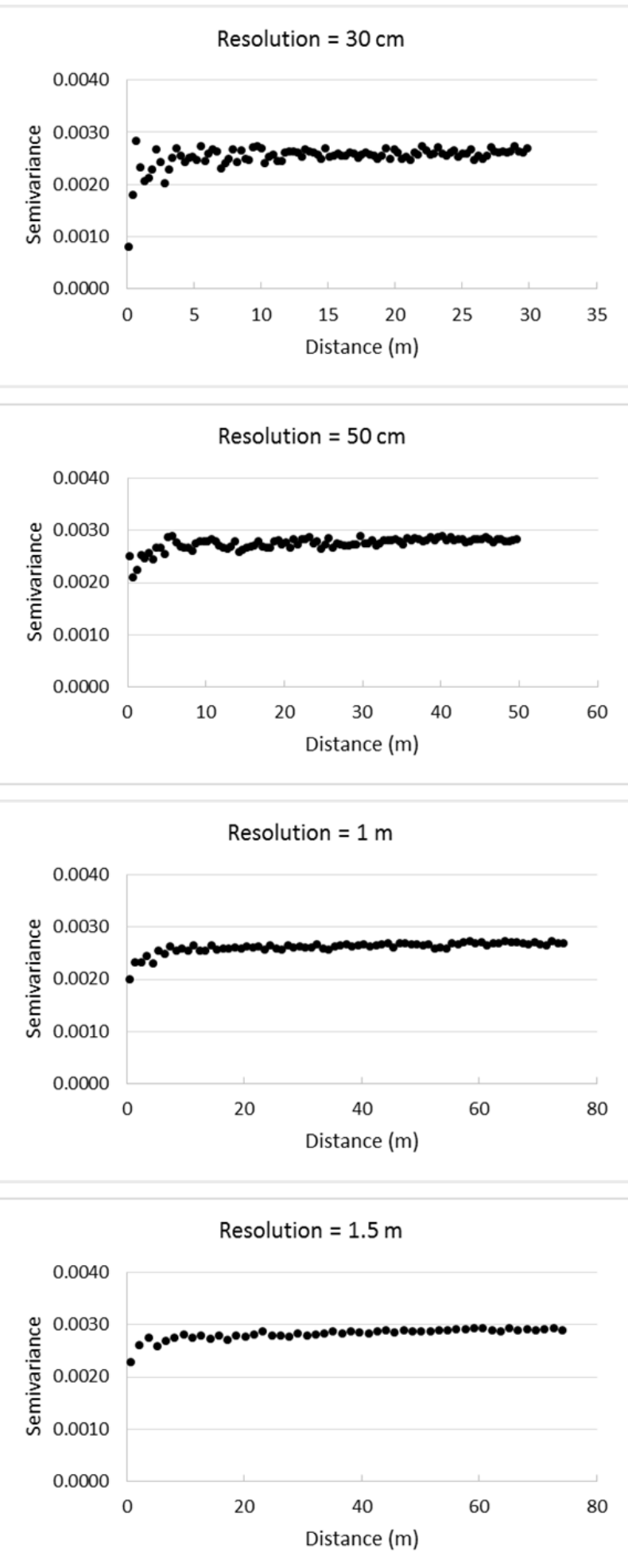

FIGURE 27 Semivariograms of the Parkinsonia florida-Olneya tesota (PAFL-OLTE) and Larrea tridentata-Encelia farinosa (LATR-ENFA) Alliances with 30-cm, 50-cm, 1-m, and 1.5-m Resolutions 


\section{LATR-AMDU}
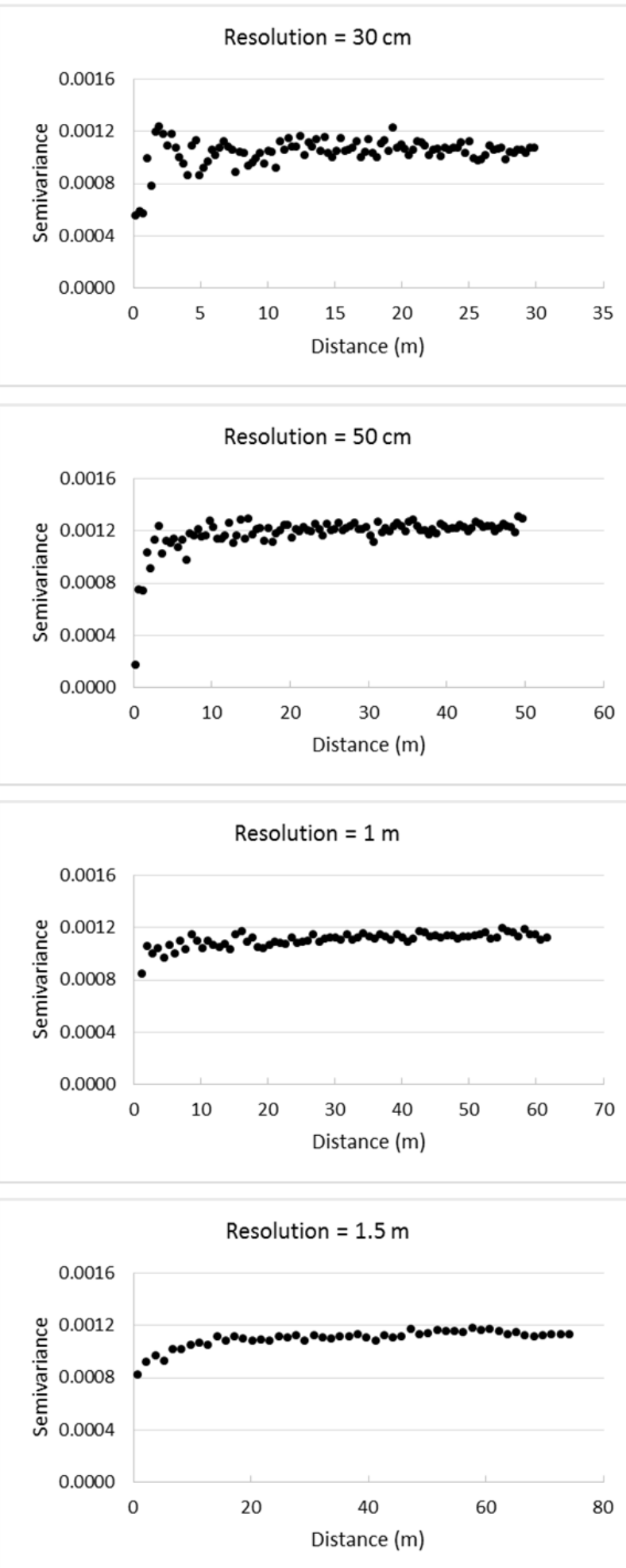

\section{CHRI-GECA}
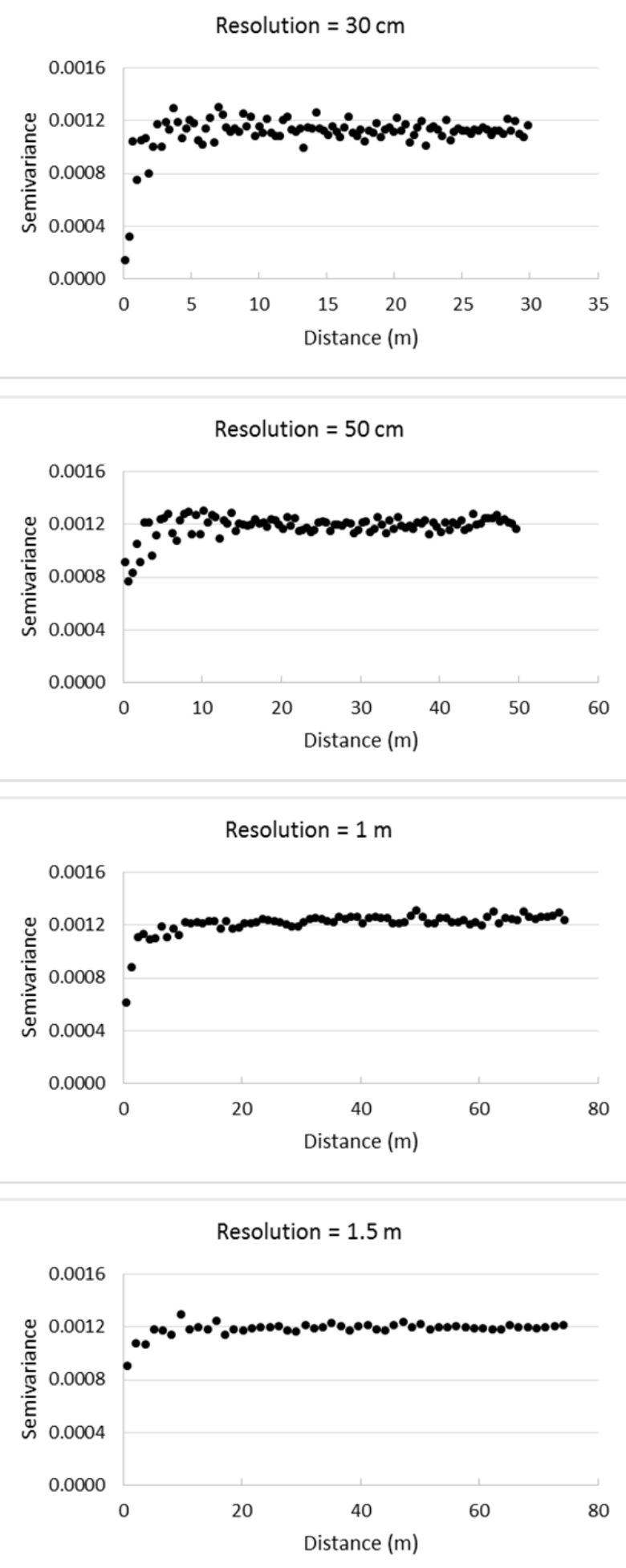

FIGURE 28 Semivariograms of the Larrea tridentata-Ambrosia Dumosa (LATR-AMDU) and Chorizanthe rigida-Geraea canescens (CHRI-GECA) Alliances with 30-cm, 50-cm, 1-m, and 1.5-m Resolutions 
TABLE 18 Variogram Parameters for Four Vegetation Alliances across Resolutions

\begin{tabular}{cccccc}
\hline $\begin{array}{c}\text { Spatial } \\
\text { Resolution }\end{array}$ & $\begin{array}{c}\text { Variogram } \\
\text { Parameter }\end{array}$ & PAFL-OLTE & LATR-ENFA & LATR-AMDU & CHRI-GECA \\
\hline \multirow{2}{15}{$\mathrm{cm}$} & Model & Exponential & Spherical & Gaussian & Spherical \\
& Nugget & 0.00044 & 0.00000 & 0.00000 & 0.00000 \\
& Range & 8.96456 & 0.90242 & 1.29848 & 1.71518 \\
& Sill & 0.00764 & 0.00273 & 0.00128 & 0.00084 \\
\hline \multirow{2}{*}{$30 \mathrm{~cm}$} & Model & Exponential & Spherical & Spherical & Exponential \\
& Nugget & 0.00024 & 0.00000 & 0.00007 & 0.00031 \\
& Range & 8.34347 & 0.72044 & 1.61551 & 2.19855 \\
& Sill & 0.00722 & 0.00243 & 0.00103 & 0.00144 \\
\hline $50 \mathrm{~cm}$ & Model & Spherical & Spherical & Spherical & Spherical \\
& Nugget & 0.00189 & 0.00210 & 0.00045 & 0.00074 \\
& Range & 8.74060 & 6.05770 & 3.27346 & 5.55462 \\
& Sill & 0.00723 & 0.00275 & 0.00115 & 0.00121 \\
\hline $1 \mathrm{~m}$ & Model & Spherical & Exponential & Spherical & Exponential \\
& Nugget & 0.00239 & 0.00205 & 0.00035 & 0.00053 \\
& Range & 8.76090 & 9.73935 & 2.54976 & 4.06671 \\
& Sill & 0.00745 & 0.00260 & 0.00109 & 0.00114 \\
\hline \multirow{2}{*}{$1.5 \mathrm{~m}$} & Model & Exponential & Flat & Spherical & Spherical \\
& Nugget & 0.00080 & $-{ }^{\mathrm{a}}$ & 0.00087 & 0.00090 \\
& Range & 9.51192 & - & 17.69832 & 7.02698 \\
& Sill & 0.00742 & - & 0.00110 & 0.00119 \\
\hline
\end{tabular}

Abbreviations: PAFL-OLTE $=$ Parkinsonia florida-Olney a tesota , LATR-ENFA $=$ Larrea tridentata-Encelia farinosa; LATR-AMDU $=$ Larrea tridentata-Ambrosia Dumosa $;$ CHRI-GECA $=$ Chorizanthe rigida - Geraea canescens.

${ }^{\mathrm{a}}-=$ no value.

resolution. Ranges were consistently greater for the aggregated spatial resolutions than those for the original resolution for LATR-AMDU and CHRI-GECA, while the opposite pattern was observed for PAFL-OLTE and LATR-ENFA. Shrub- and herb-dominant alliances had varying ranges across the spatial resolutions tested. Although shrub-dominant alliances retain somewhat recognizable variogram forms at $50-\mathrm{cm}$ or $1-\mathrm{m}$ resolutions, the parameters at the resolutions no longer correspond to vegetation canopies, which are very small and sparse. Therefore, the exploratory analysis suggests that a $30-\mathrm{cm}$ resolution is required to monitor shrub-dominant alliances based on the spatial structures and patterns of vegetation.

\subsubsection{Application for Monitoring Vegetation Alliances}

Based on our analyses described above, a combination of fractional cover of surface types and spatial structure of landscapes using high-resolution remotely sensed imagery would provide valuable information about changes in vegetation alliances of desert environments. 
Changes in fractional cover of surface types could indicate the early stage of habitat transition from one vegetation alliance to another due to changes in surface water flow and/or surface erosion. Variograms would provide structural information within the alliance such as average canopy size, variability of canopy size, and typical canopy spacing. When the variogram parameters (e.g., sill, range, and shape) change, managers can suspect recognizable changes in the habitat.

The variogram analysis indicated that a tree-dominant alliance (i.e., PAFL-OLTE) can be monitored using imagery as coarse as 1-m resolution, which makes NAIP imagery a viable data source. Shrub- and herb-dominant alliances (i.e., LATR-ENFA, LATR-AMDU, and CHRIGECA), on the other hand, require a finer spatial resolution than $1 \mathrm{~m}$. Images having $50-\mathrm{cm}$ and $30-\mathrm{cm}$ resolutions are likely required to monitor overall vegetation cover and spatial structure of vegetation, respectively. However, images captured at the end of the growing season (or wet season) may allow slightly coarser images to produce similar results, because the size of vegetation canopies and patches are expected to be larger, denser, and greener than those in the imagery used in this study.

Sub-meter resolution imagery having a greater number of spectral bands has become increasingly available in recent years. WorldView-2 $(50 \mathrm{~cm})$ and $-3(30 \mathrm{~cm})$ are currently available at $\$ 25$ per $\mathrm{km}^{2}$, which makes commercial satellite images dependable data sources for cost-effective long-term land resource monitoring. The high frequency of image collection and image archives provide flexibility for selecting data collected at the appropriate timing for desert environment monitoring, which would be challenging for aerial and field survey methods. 
This page intentionally left blank. 


\section{SUMMARY}

\subsection{SYNTHESIS}

We developed and tested remote sensing methodologies using VHSR $(15 \mathrm{~cm})$, visibleNIR multispectral aerial image mosaics derived from highly overlapping frames $(65 \%-80 \%)$ and the DSM and DTM that were derived from those image frames in order to characterize desert landscapes for monitoring vegetation, surface hydrology, and land surface. The findings of our studies conducted from 2012 to 2015 are summarized below.

\subsubsection{Vegetation}

For mapping vegetation distribution, adjustment of the threshold index value applied for the VARI (the optimal SVI in our earlier study), in conjunction with additional masking, did not improve vegetation detection accuracy. Thus, $77 \%$ may be the highest achievable accuracy for mapping vegetation distribution using this type of imagery collected in winter time. One of the major reasons for the limited accuracy is increased spectral heterogeneity within vegetation, which is a common problem for VHSR remote sensing. When the spatial resolution of the image is comparable to vegetation canopy or patch size, a pixel would contain shaded and sunlit leaves, stems and branches, and canopy gaps, which create an average spectral signature of vegetation (Figure 29, left). When the spatial resolution of the image is finer than the canopy or patch size, multiple pixels would capture different parts of the vegetation, which create highly heterogeneous spectral signatures for representing vegetation (Figure 29, right).

The limited vegetation detection accuracy also stemmed from the quality of the VHSR images. Because such a fine-resolution aerial imagery has never been collected in the study area, educated decisions and trials-and-errors were inevitable. Mosaicking 1,000+ frames was
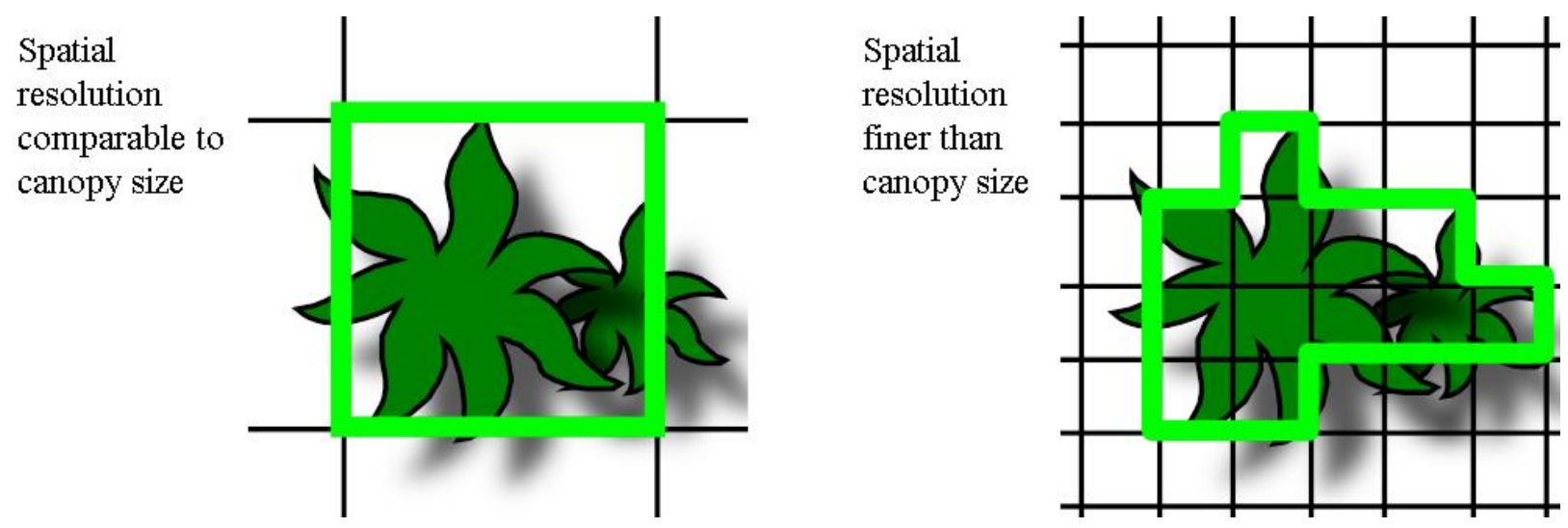

FIGURE 29 Schematic Representation of Relationship between Spatial Resolution of Image and Vegetation Canopies (Vegetation pixels are delineated in green.) 
extremely complex due to vignetting, ${ }^{1}$ sun-viewing angle variability, and atmospheric variation. To standardize pixel values between the 2012 and 2014 images, an empirical approach was used rather than a physically based radiative transfer model, because the required parameters at the time of image collection were not available. All of these factors likely introduced spectral inconsistency that could have impacted the accuracy of vegetation detection.

Other factors likely contributed to the limited vegetation detection accuracy, including the timing of image collection and time lag between image collection and field data collection. We collected images in November 2012 and January 2014, both of which may not provide stable vegetation conditions each year due to rainfall patterns in desert regions. Because desert vegetation is very sensitive to precipitation, it may be challenging to determine the best time of image collection if image collection is restricted to once a year. The time lag between image collection and field data collection was particularly problematic for the 2012 image analysis, which had a 7-week time lag. In addition, the spectral bands available with typical aerial images (i.e., blue, green, red, and NIR) may be insufficient for capturing dryland vegetation. The shortwave infrared (SWIR) spectral band is known for its sensitivity to moisture content and abundance of cellulose and lignin in plants and would provide useful spectral information for studying desert vegetation (Fensholt and Sandholt 2003). However, the SWIR band is not readily available in aerial images.

For estimating canopy height, our previous approach, which was a simple subtraction technique (i.e., DSM - DTM), considerably overestimated the actual height of plants (RMSE $=2.86 \mathrm{~m}$ ) but had fairly reasonable correlation with the reference height $\left(R^{2}=0.72\right)$. The refined methodology that integrates modeling of elevation under vegetation canopies based on the technique described in Gillan et al. (2014) showed slight improvement in correlation $\left(R^{2}=0.77\right)$ and MAE $(2.68 \mathrm{~m})$. However, the refined methodology underestimated absolute height by a factor of 20, and RMSE increased by $0.59 \mathrm{~m}$ from the previous method. These results suggest that accurate and precise estimation of canopy height would require a separate image collection strategy from that for other indicators (e.g., vegetation and desert pavement distributions). For example, high-resolution satellite images (e.g., 50-cm WorldView-2) would be used for estimating vegetation and desert pavement cover and surface stability would be adequate, while highly overlapped VHSR aerial images $<15$-cm resolution (e.g., Gillan et al. 2014) or LiDAR data would be needed for estimating canopy height.

Having two separate remote sensing approaches - one for land cover characterization (e.g., vegetation, desert pavement, and surface stability) and the other for canopy height estimation - would have advantages and disadvantages for long-term monitoring. One of the greatest advantages of using two separate methods would be the possibility of using satellite images for land cover characterization and change quantification, which would permit larger areal coverage, more frequent data collection, availability of a wide range of spectral bands, and access to standardized image preparation tools (atmospheric, geometric, and radiometric corrections). This would be a great advantage in establishing a standardized remote sensing methodology for long-term monitoring for large areas without managing the many issues associated with the ad hoc aerial image collection outlined earlier. With commercial and publicly

1 An illustration effect that gradually decreases brightness in the image from its center to the edge. 
available platforms combined, satellite remote sensing provides images with a range of spatial scales from 30-cm WorldView-3 and 5-m IKONOS images at high resolutions, to 30-m Landsat Enhanced Thematic Mapper Plus (ETM+) and 250-m Moderate Resolution Imaging Spectroradiometer (MODIS) images at moderate-coarse resolutions. Use of combinations of these remotely sensed image types would permit multi-scale monitoring, such as anomaly detection at a coarse or moderate scale to give alert to potential environmental changes in general areas, and allow investigation through change identification at a fine resolution, for example, loss and degradation of riparian habitat or desert pavement.

One of the disadvantages of using satellite imagery for land resource monitoring is that canopy height could not readily be estimated because of the lack of overlaps in image frames. Thus, separate aerial data collection would be required for accurately mapping canopy height across the landscape. When using aerial imagery or LiDAR data, the extent for monitoring canopy height would be substantially smaller than that for other monitoring indicators because the inherent cost, data size, and data processing effort for the approach are expected to be high for large areas. Another shortcoming is that canopy height information would not be available for differentiating between tree and shrub in the current land cover classification routine when using satellite imagery. Thus, how well these life-form types can be distinguished without height information should be investigated.

\subsubsection{Fractional Cover of Surface Type}

Fractional cover of vegetation and surface types can be estimated relatively reliably. The accuracy of fractional cover varied depending on the cover type (e.g., tree, shrub, NPV, and bare ground) and how surface materials such as physical crust, embedded litter, and rock are classified (e.g., shrub, NPV, or bare ground). Because the AIM core indicators include vegetation, particularly trees and shrubs, classifying the surface materials into three classes (i.e., tree, shrub, and bare ground [or other]) seems appropriate. When applying the 3-class scheme, fractional cover estimates of all three classes were fairly accurate. Correlations $\left(R^{2}\right)$ of tree, shrub, and bare ground cover were $0.60,0.61$, and 0.78 , respectively. Absolute error in fractional cover was minimal across the classes (RMSE $<7.2 \%$ absolute cover). This suggests that the minimum detectable change in fractional cover would be $7.2 \%$. By using Argonne's current method, managers will be able to confidently detect land cover change in a given area when the tree, shrub, or bare ground cover changes $10 \%$ or more over time. The ability to determine minimum detectable change is critical to establishing specific, measurable, achievable, relevant, and time sensitive (SMART) monitoring objectives, which define the acceptable level of resource change that needs to be detected and the number of samples required to detect such a change.

The 3-class classification scheme permits the use of a ternary plot to visualize the surface cover type fractions. This visualization provides fractional cover structure of various habitats in the desert landscape. The example shown in Figure 7 suggests that $18 \%$ shrub cover could be a critical threshold separating riparian and non-riparian habitats. Delineation of riparian habitat could be useful for land management decision making. 
Although the AIM protocols suggest that NPV, which is dry vegetation materials, should be aggregated into a single bare ground category, independently quantifying NPV cover could provide valuable information for understanding dieback in desert vegetation that was caused by prolonged drought, severe heat stress, or disease. Although differentiating big galleta from shrubs was challenging, even with using $15-\mathrm{cm}$ resolution images, it was one of the most widespread species in the study area and appears to serve as a stabilizer of sandy surface in desert landscape. Thus, the species distribution or cover could serve as a beneficial indicator for surface stability, especially if future solar projects adopt big galleta as a biological means of mitigating surface disturbance and erosion.

\subsubsection{Desert Pavement, Biological Soil Crust, Surface Stability, and Ephemeral Channels}

Desert pavement is one of the most amenable desert surface features to map using remote sensing. The current methodology embedded in the land cover classification algorithm yielded very high detection accuracy for desert pavement (i.e., $K$ and overall accuracy of 0.79 and $89 \%$, respectively). We concluded that desert pavement can be accurately mapped using the current remote sensing methodology for long-term monitoring of desert landscapes. Because of the large patch size and relatively homogeneous spectral signatures of desert pavement, we expect that imagery with coarser spatial resolution (e.g., $\sim 1 \mathrm{~m}$ ) could achieve comparable accuracy.

Distribution of biological soil crust was very scarce in the study area compared with other surface types (e.g., exposed soil, rock fragment, shrub, and tree). In addition, the BSCI (Chen et al. 2005) that was developed for lichen-dominant soil crust less likely reflects the composition of biological soil crusts in the Riverside East SEZ, where cyanobacterial crusts predominate overall with intermittent local patches of lichen-dominant crusts. For these reasons, neither the BSCI nor CI yielded satisfactory accuracy for mapping biological soil crust potential. Ongoing work conducted by Nicole Pietrasiak at New Mexico State University is focused on characterizing biological soil crusts in wilderness areas, including the Palen McCoy Wilderness adjacent to the Riverside East SEZ. Project results could provide helpful insight into a remote sensing approach for classifying biological soil crust communities in southern California deserts.

ERI provides useful insights into erosion risks. Vegetation was positively correlated with ERI, indicating increased surface stability, while exposed soil and small rocks were negatively correlated with ERI suggesting an increased risk of erosion. Despite these correlations, only 55\% of the variability of ERI could be explained by materials composing desert surface (e.g., vegetation, soil, and rock $<1 \mathrm{~cm}$ ). In addition to surface materials, mineral composition and surface roughness likely influence surface color and surface interaction with light in dryland environments. Although additional understanding of these factors would provide a scientific basis for data interpretation, applying knowledge about desert landscapes and their spectral characteristics (e.g., highly stable surface such as rock and pebble dominant surfaces often appear dark while exposed soil such as streambeds and disturbed surfaces appear bright) can be equally informative or even more operationally beneficial for monitoring surface stability. ERI is a useful indicator of erosion risks because there is a consistent relationship between spectral responses and physical environments, such as materials and their properties, which are associated with surface stability or surface conditions. 
The ephemeral stream extraction algorithm used for this study has its strengths and weaknesses. The algorithm accurately extracted narrow streams (many of which were not mapped in the NHD) with good contrast from surrounding areas, but performed poorly for wide streams with heterogeneous channel forms, width, and vegetation patterns (these wide streams were well represented in the NHD). This trend indicates that a multi-scale consensus approach, particularly one using multi-resolution remotely sensed data collected on close dates, would yield the optimal result. Although detailed status of ephemeral streams is important for hydrological modeling to understand water cycles, signals alerting undesired soil erosion resulting from hydrological alteration are important for land resource management because they may indicate a threat to habitat or infrastructure. In conjunction with ERI, the detailed ephemeral stream maps may be transformed into spatially explicit information that signals surface erosion from the $15-\mathrm{cm}$ resolution to a coarse spatial scale that would be useful for managers to detect early occurrence of erosion, as well as to provide insights into the causes of erosion (e.g., whether due to storm severity related to climate change or to unanticipated synergy with a solar energy installation).

\subsubsection{Vegetation Alliance Analysis}

Many vegetation alliances in arid environments are characterized by sparsely distributed short-statured shrubs and forbs. This seemingly generalizable landscape is actually extremely heterogeneous and dynamic and supports varying functions in ecosystems of the region. We examined vegetation abundance and patterns that are specific to the four vegetation alliancesPAFL-OLTE, LATR-ENFA, LATR-AMDU, and CHRI-GECA — in the study area using 15-cm multispectral aerial imagery. We explored how the changes in spatial patterns and structures may be quantified and monitored using remote sensing based on interpretation of an SVI (VARI), fractional vegetation cover, and variograms. Our exploration focused on gaining insight into types of detectable changes, appropriate spatial resolution of imagery, and alliance-specific requirements. Our findings can be summarized as follows:

1. The early stages of possible habitat transition from one vegetation alliance to another resulting from anthropogenic disturbance may be observed as changes in fractional cover of surface type.

2. Expansion and contraction of plant canopy and patch size would result in increased and decreased ranges in variograms, respectively.

3. Improvement and decline of vegetation type diversity, which influence variability of canopy size, would result in a shift of the variogram form from spherical to exponential and exponential to spherical, respectively.

4. An increase in and a reduction of vegetation density due to loss and new growth of individual plants, as well as expansion and contraction of canopies and patches, would result in an increased and decreased sill in variograms, respectively. 
5. A tree-dominant alliance can be monitored using imagery as coarse as $1-\mathrm{m}$ resolution, while shrub- and herb-dominant alliances would require $50-\mathrm{cm}$ and $30-\mathrm{cm}$ resolutions to monitor overall vegetation cover and spatial structure of vegetation, respectively.

6. Images at 1- to $1.5-\mathrm{m}$ resolution may provide similar results when they are captured at the end of the growing season (or wet season) because of the larger, denser, and greener vegetation canopies.

7. The use of commercial high-resolution images could be a viable option for cost-effective long-term land resource monitoring. These images are collected daily and archived continuously, providing considerable flexibility for selecting images collected at the appropriate timing for desert environment monitoring.

\subsection{RECOMMENDATIONS}

Based on our previous and current studies, we recommend the following activities for further facilitating applications of remote sensing methodologies for long-term monitoring of desert regions:

1. Estimate the distribution and fractional cover of vegetation type using a single-date image without canopy height information will likely be challenging. The use of multi-temporal images or seasonal image time series could mitigate for the lack of height information. Plant life-form types respond to temperature and moisture differently based on their functional traits and adaptive strategies. Characterizing the rate of green-up, peak greenness, and/or timing of senescence of vegetation could inform differentiation between those plant types. This multi-temporal approach could be efficient and cost-effective for characterization and monitoring of microphyll woodlands in desert landscapes by either using commercial high resolution multispectral satellite imagery or publicly available coarse resolution satellite imagery such as Landsat ETM+.

2. Test methodologies for high-resolution satellite images that are highly standardized and have the SWIR spectral bands in addition to conventional visible and NIR spectral bands. This task would aim to transfer application of current remote sensing methodologies using custom, non-standardized VHSR aerial images to standardized, quality controlled, widely available highresolution satellite images, so that spatially comprehensive monitoring can be seamless and standardized across BLM-administered lands over time. Continuously collected and archived satellite images would provide the flexibility of selecting images collected from a desirable time of year and provide access to baseline conditions via retrospective analysis of archived images. The methodologies using high-resolution satellite images would 
include all vegetation and land surface variables and parameters that were examined in our previous and current studies. These year-round, highresolution multispectral images may be available at low cost.

3. Investigate the utilization of coarse-scale, high-temporal-frequency satellite images for early detection of potential land surface changes in desert environments. This task would aim to improve the effectiveness and efficiency of monitoring by continuously scanning large areas at a coarse scale to cost-effectively detect general areas of potential environmental change in order to narrow monitoring to areas that appear to be changing. Detailed assessment or change identification monitoring would require highresolution images (e.g., unmanned aerial systems) in conjunction with a free, easy-to-use image processing tool such as the Image Interpreter available at the Landscape Toolbox (http://www.landscapetoolbox.org/tools/imageinterpreter).

4. Develop a standardized, spatially comprehensive long-term strategy for using multi-scale remote sensing. This would be an important task for implementing remote sensing applications into financially sustainable long-term monitoring of public land. Selected indicators could be monitored using standardized high-resolution satellite images in accordance with BLM's monitoring protocols currently being finalized (Recommendation 2). Unforeseen landscape anomalies could be detected from images obtained in near-real time (e.g., within 5-7 days) using continuously collected moderate to coarse resolution satellite images (Recommendation 3). Subsequent landscape change assessment using VHSR images or field surveys would facilitate timely mitigation actions. Location, type, and magnitude of changes are often difficult to anticipate. Thus, it is important to develop a multi-scale monitoring strategy that integrates low-temporal-frequency yet systematic field surveys using the AIM protocols to monitor detailed changes, with coarse-scale yet frequent data collection that uses satellite remote sensing to monitor unforeseen changes.

5. Investigate the indicative power of ERI for desert pavement integrity. Protecting the integrity of desert pavement is one of BLM's conservation objectives (BLM 2016). Our study indicated a correlation between ERI and land surface conditions (Hamada and Grippo 2015b). A strong correlation between a range of ERI values and a gradient of disturbance in desert pavement was particularly apparent. Determining detectable types, extent, and magnitude of desert pavement degradation would be beneficial for monitoring and detecting desert pavement disturbance. 
This page intentionally left blank. 


\section{REFERENCES}

Atkinson, P.M., 1993, "The Effect of Spatial Resolution on the Experimental Variogram of Airborne MSS Imagery,” International Journal of Remote Sensing 14(5):1005-1011.

BLM (Bureau of Land Management), 2012, Approved Resource Management Plan Amendments/Record of Decision (ROD) for Solar Energy Development in Six Southwestern States, U.S. Department of the Interior, Bureau of Land Management, Oct.

BLM, 2016, Riverside East Solar Energy Zone Long Term Monitoring Strategy, U.S. Department of the Interior, Bureau of Land Management, Mar.

Chen, J., Zhang, M.Y., Wang, L., Shimazaki, H., and Tamura, M., 2005, “A New Index for Mapping Lichen-Dominated Biological Soil Crusts in Desert Areas," Remote Sensing of Environment 96(2):165-175.

Cohen, W.B., Spies, T.A., and Bradshaw, G.A., 1990, "Semivariograms of Digital Imagery for Analysis of Conifer Canopy Structure," Remote Sensing of Environment 34(3):167-178.

Curran, P.J., 1988, “The Semivariogram in Remote Sensing: An Introduction,” Remote Sensing of Environment 24(3):493-507.

Dube, P.O., 1994, "Monitoring Land Degradation in Semi-arid Regions Using High-resolution Satellite Data," pp. 125-135 in Natural Vegetation as a Resource: A Remote Sensing Workbook for East \& Southern Africa, Scurlock, J.M.O., M.J. Wooster, and G.D. Souza (eds.).

Duncan, J., Stow, D., Franklin, J., and Hope, A., 1993, “Assessing the Relationship between Spectral Vegetation Indices and Shrub Cover in the Jornada Basin, New Mexico," International Journal of Remote Sensing 14(18):3395-3416.

Fensholt, R., and Sandholt, I., 2003, "Derivation of a Shortwave Infrared Water Stress Index from MODIS Near- and Shortwave Infrared Data in a Semiarid Environment," Remote Sensing of Environment 87(1):111-121.

Frieswyk, C.B., Johnston, C.A., and Zedler, J.B., 2007, "Identifying and Characterizing Dominant Plants as an Indicator of Community Condition," Journal of Great Lakes Research 33(sp3):125-135.

Gillan, J.K., Karl, J.W., Duniway, M., and Elaksher, A., 2014, "Modeling Vegetation Heights from High Resolution Stereo Aerial Photography: An Application for Broad-Scale Rangeland Monitoring," Journal of Environmental Management 144:226-235.

Gitelson, A.A., et al., 2002, "Novel Algorithms for Remote Estimation of Vegetation Fraction," Remote Sensing of Environment 80(1):76-78. 
Godinez-Alvarez, H., Herrick, J.E., Mattocks, M., Toledo, D., and Van Zee, J., 2009, "Comparison of Three Vegetation Monitoring Methods: Their Relative Utility for Ecological Assessment and Monitoring,” Ecological Indicators 9(5):1001-1008.

Graetz, R.D., 1990, "Remote Sensing of Terrestrial Ecosystem Structure: An Ecologist's Pragmatic View," in Remote Sensing of Biosphere Functioning, Hobbs, R.J. and H.A. Mooney (eds.), Springer-Verlag, New York.

Hamada, Y., and Grippo, M.A., 2015a, "Remote-Sensing Application for Facilitating Land Resource Assessment and Monitoring for Utility-Scale Solar Energy Development," Journal of Applied Remote Sensing 9(1):097694-097694.

Hamada, Y., and Grippo, M.A., 2015b, "Erosion Resistance Index (ERI) to Assess Surface Stability in Desert Environments," IEEE Geoscience and Remote Sensing Letters 12(11):21932197.

Hamada, Y., Grippo, M.A., and Smith, K.P., 2014, Long-Term Monitoring of Utility-Scale Solar Energy Development and Application of Remote Sensing Technologies: Summary Report, ANL/EVS-14/12, Argonne National Laboratory, Argonne, Ill.

Hamada, Y., Stow, D.A., Roberts, D.A., Franklin, J., and Kyriakidis, P.C., 2013, "Assessing and Monitoring Semi-arid Shrublands Using Object-Based Image Analysis and Multiple Endmember Spectral Mixture Analysis," Environmental Monitoring and Assessment 185(4):3173-3190.

Herrick, J.E., Van Zee, J.W., Havstad, K.M., Burkett, L.M., and Whitford, W.G., 2005a, Monitoring Manual for Grassland, Shrubland and Savanna Ecosystems, Volume I: Quick Start, USDA-ARS Jornada Experimental Range, Las Cruces, N.Mex.

Herrick, J.E., Van Zee, J.W., Havstad, K.M., Burkett, L.M., and Whitford, W.G., 2005b, Monitoring Manual for Grassland, Shrubland and Savanna Ecosystems, Volume II: Design, Supplementary Methods and Interpretation, USDA-ARS Jornada Experimental Range, Las Cruces, N.Mex.

Herrick, J.E., Van Zee, J.W., McCord, S.E., Courtright, E.M., Karl, J.W., and Burkett, L.M., 2015, Monitoring Manual for Grassland, Shrubland and Savanna Ecosystems, 2nd Ed.,Vol. I: Core Methods. Available at www.landscapetoolbox.org/manuals/monitoring-manual.

Huete, A.R., 1988, “A Soil-adjusted Vegetation Index (SAVI)," Remote Sensing of Environment 25:295-309.

Karnieli, A., Kidron, G.J., Glaesser, C., and Ben-Dor, E., 1999, "Spectral Characteristics of Cyanobacteria Soil Crust in Semiarid Environments," Remote Sensing of Environment 69(1): 67-75. 
Kilpatrick, A.D., Lewis, M.M., and Ostendorf, B., 2015, "Rangeland Condition Monitoring: A New Approach Using Cross-Fence Comparisons of Remotely Sensed Vegetation," PloS ONE 10(11):e0142742.

Pellant, M., Shaver, P., Pyke, D.A., and Herrick, J.E., 2005, Interpreting Indicators of Rangeland Health, Version 4, Tech Ref 1734-6, U.S. Department of the Interior, Bureau of Land Management, National Science and Technology Center, Denver, Colo. Available at www.blm.gov/nstc/library/techref.htm.

Phinn, S., Franklin, J., Hope, A., Stow, D., and Huenneke, L., 1996, "Biomass Distribution Mapping Using Airborne Digital Video Imagery and Spatial Statistics in a Semi-Arid Environment," Journal of Environmental Management 47(2):139-164.

Pickup, G., and Nelson, D.J., 1984, "Use of Landsat Radiance Parameters to Distinguish Soil Erosion, Stability, and Deposition in Arid Central Australia," Remote Sensing of Environment 16(3):195-209.

Qi, J., Chehbouni, A., Huete, A.R., Kerr, Y.H., and Sorooshian, S., 1994, “A Modified Soil Adjusted Vegetation Index," Remote Sensing of Environment 48(2):119-126.

Roughgarden, J., Running, S.W., and Matson, P.A., 1991, "What Does Remote Sensing Do for Ecology?” Ecology 72(6):1918-1922.

Schlesinger, W.H., Reynolds, J.F., Cunningham, G.L., Huenneke, L.F., Jarrell, W.M., Virginia, R.A., and Whitford, W.G., 1990, "Biological Feedbacks in Global Desertification," Science 247(4946):1043-1048.

Tobler, W.R., 1970, “A Computer Movie Simulating Urban Growth in the Detroit Region," Economic Geography 46 (Suppl.):234-240.

Toevs, G.R., Taylor, J.T., Spurrier, C.S., MacKinnon, W.C., and Bobo, M.R., 2011, Assessment, Inventory, and Monitoring Strategy: For Integrated Renewable Resources Management, Bureau of Land Management, National Operations Center, Denver, Colo.

Tucker, C.J., 1979, "Red and Photographic Infrared Linear Combinations for Monitoring Vegetation," Remote Sensing of Environment 8:127-150.

USGS (U.S. Geological Survey), 2008, National Hydrography Dataset. Available at http://nhd.usgs.gov.

Ustin, S.L., Jacquemoud, S., Palacios-Orueta, A., Li, L., and Whiting, M.L., 2009, "Remote Sensing Based Assessment of Biophysical Indicators for Land Degradation and Desertification," pp. 15-44 in Recent Advances in Remote Sensing and Geoinformation, Processing for Land Degradation Assessment, Roeder, A. and J. Hill (eds.), ISPRS Series, London. 
Ustin, S.L., Smith, M.O., and Adams, J.B., 1993, "Remote Sensing of Ecological Processes: A Strategy for Developing and Testing Ecological Models Using Spectral Mixture Analysis, pp. 339-357 in Scaling Physiological Processes: Leaf to Globe, Ehleringer, J.R., and C.B. Field (eds.), Academic Press, San Diego, Calif.

Wallace, C.S., Watts, J.M., and Yool, S.R., 2000, "Characterizing the Spatial Structure of Vegetation Communities in the Mojave Desert Using Geostatistical Techniques," Computers \& Geosciences 26(4):397-410.

Washington-Allen, R.A., West, N.E., Ramsey, R.D., Phillips, D.H., and Shugart, H.H., 2010, "Retrospective Assessment of Dryland Soil Stability in Relation to Grazing and Climate Change," Environmental Monitoring and Assessment 160(1-4):101-121.

Watson, D.F., and Philip, G.M., 1985, “A Refinement of Inverse Distance Weighted Interpolation," Geo-processing 2(4):315-327.

Woodcock, C., Strahler, A.H., and Jupp, D.L.B., 1988a, "The Use of Variograms in Remote Sensing: I. Scene Models and Simulated Images," Remote Sensing of Environment 25:328-348.

Woodcock, C., Strahler, A.H., and Jupp, D.L.B., 1988b, “The Use of Variograms in Remote Sensing: II. Real Digital Images," Remote Sensing of Environment 25:349-379.

Woodcock, C.E., and Strahler, A.H., 1987, "The Factor of Scale in Remote Sensing," Remote Sensing of Environment 21(3):311-332. 



\section{Argonne}

\section{Environmental Science Division}

Argonne National Laboratory

9700 South Cass Avenue, BIdg. 240

Argonne, IL 60439-4854

www.anl.gov 